Global Fabrications: Fashioning Modernity in Text and Textile

\author{
Rebecca Strauss \\ New York, New York
}

B.A., Barnard College, Columbia University, 2006

A Dissertation presented to the Graduate Faculty of the University of Virginia in Candidacy for the Degree of Doctor of Philosophy

Department of English

University of Virginia

August 2014 
(C) Copyright by

Rebecca Strauss

All Rights Reserved

August 2014 


\section{Abstract \\ Global Fabrications: Fashioning Modernity in Text and Textile}

Across the arc of what Giovanni Arrighi calls the long twentieth century, the vast reaches of empire, colonialism, and neoimperial globalization came increasingly to pose representational problems for fiction. Because novels fashion aesthetic worlds that respond and correspond to the lived world, these global economic processes restructure the relation between the world inside a novel and the world outside it. "Global Fabrications" connects the rise of the global novel to the global fashion industry, which underpins industrialization, economic modernization, and the rise, expansion, and development of globalization. Because practices of fashion-from textile manufacture to branding, and from cross-dressing to street style - relate the representational to the phenomenological, the imagined to the material, the literary to the non-literary, "Global Fabrications" centers on key ways in which dress threads through narrative fabrications of a densely interconnected global modernity.

To demonstrate how fashion comes to speak to and for the contradictory experience of global modernity, the project traces material and social practices of dress as they inflect novels from the fin de siècle through the present day. Yoking literature to overlaps between individual self-fashioning and global inequality, the introduction recasts Oscar Wilde's fashion statements - whether his iconic green-for-Irish Home Rule fur coat, the fashion plate Dorian Gray, or the prison uniform in De Profundis-revealing how they work to eradicate the invisibility of colonial, queer, and incarcerated subjects. By connecting the unfashionable muslin frock worn by the long-suffering eponymous 
heroine of Thomas Hardy's Tess of the D'Urbervilles to Dacca muslin, the first chapter shows how Tess's rural marginality is of a piece with the colonial subjugation of female textile workers in British India. The second chapter examines The Princess Casamassima, Henry James's anomalous novel of working-class London, in which hats, buttons, and cloth-bound books refashion James's "international theme"; the anarchism practiced by the novel's male protagonists gives way to an affective materialist feminism figured in the novel's transnational female fashion industry workers - an American princess turned class transvestite, a humble Victorian seamstress, a cockney shop-girl, and an imprisoned French milliner-murderess. The third chapter canvasses Virginia Woolf's oeuvre, where what Woolf calls "frock consciousness" is a form of global consciousness that provides new vistas for imagining citizenship in the face of British imperialism, mass violence, and world war. In the final chapter on Zadie Smith's On Beauty, countercultural brand names like Levi Strauss \& Co., Jimmy Choo, and even Smith's own cosmopolitan brand name paradoxically signal opposition to the stark global conditions of labor, circulation, and exchange that fashioned them.

"Global Fabrications" situates fiction within the broader history of global modernity, drawing upon an archive that includes fabrics, advertisements, photography, and brand images and using an interdisciplinary framework that combines narrative and aesthetic theory with political philosophy, studies of empire, and economic theories of globalization. Between its literary concerns and its investments in cultural and economic history, the project offers a new strategy for reading literary texts, anchoring the aesthetic in critical conversations about the global. Taken together, these investigations stitch the materiality of dress into the narrative fabrication of global modernity. 


\section{Table of Contents}

Acknowledgments

$\mathrm{i}-\mathrm{iii}$

Introduction

$1-38$

Chapter One: Muslin and the Worlding

$39-80$

of Thomas Hardy's Tess of the D'Urbervilles

Chapter Two: Henry James's Social Fabric

$81-133$

in The Princess Casamassima's Atelier

Chapter Three: Across Dressing:

$134-183$

Virginia Woolf's Global Modernism

Chapter Four: The Empire's New Clothes:

$184-227$

Global Branding in Zadie Smith's On Beauty

Works Cited

$228-269$ 


\section{Acknowledgments}

I consider myself immensely lucky to have so many people to thank. Above all is Jennifer Wicke, whose generosity of spirit has humbled and inspired me since our very first meeting. I am grateful beyond words for the extraordinary gifts of her mentorship, her insight, her humor, her kindness, her patience, and perhaps most of all, her friendship. I am honored to have been the recipient of Stephen Arata's boundless wisdom, dry wit, and almost inconceivably zen-like calm in the face of chaos, and to have learned so much from the discerning and ever-astute advice of Rita Felski, whose intellectual rigor, precision, and unflappability I can only hope one day to emulate. I am grateful to Ari Blatt, who was generous enough to read this project in its entirety even as he was embarking on new fatherhood, and whose feedback on it has been invaluable to me. Courses and conversations with Jahan Ramazani, Stephen Cushman, Alison Booth, Vicki Olwell, Victor Luftig, Jon D’Errico, Jim Seitz, and Paul Saint-Amour throughout my graduate school years have been hugely formative, and I thank them for their time, knowledge, and support.

At UVa, I have benefited from the financial support of a Commonwealth Fellowship, a Bradley Fellowship, an Arts, Humanities, and Social Sciences grant from the Graduate School of Arts and Sciences, and generous travel and research grants from the English department, which have allowed to share my work at conferences and to conduct archival research. I particularly thank audiences at the Modernist Studies Association, the American Comparative Literature Association, and the International Conference of the Henry James Society for their helpful feedback, and librarians and 
curators at the British Library, the Victoria and Albert Museum, and the William Andrews Clark Memorial Library of UCLA for their assistance and support. I am also immensely lucky to have joined a wonderful and vibrant community at Columbia University. Thanks especially to my new colleagues Nicole Wallack, Aaron Ritzenberg, Sue Mendelsohn, and Glenn Gordon for their enthusiasm and belief in me, and to my department chair Nicholas Dames.

I have been very fortunate to have had so many intellectually stimulating and emotionally supportive friendships during my time as a graduate student. Thanks to Maggie Solberg, Morten Hansen, Marie Ostby, Carolyn Tate, Walt Hunter, Nathan Ragain, Jenny Le Zotte, Scott Selisker, Eric Song, and Sara Bryant for the bottles of wine, the gallons of coffee, the conversations I never wanted to end, and the laughs that never did. Special thanks, too, to Marissa Nicosia, my partner in academic crime since our college days, without whom I would know nothing about obscure seventeenth-century political pamphlets, the ins and outs of other doctoral programs, how to survive on the academic job market, the importance of care packages containing handwritten cards and themed mix-tapes, or what it really means to be a team.

At countless watershed moments over the course of this project, I have been reminded of how — and when, and where, and why — it truly began: in the early 1980s, in a small apartment on Lexington Avenue, where an eccentric and literary-minded father read Homer out loud to his infant daughter during her 2 am feedings. I could fill pages trying to express my gratitude to my family: for their impeccable taste in everything from 60s pop music to French culinary technique to interior decoration; for having friends like Russell Stern, who saw nothing odd about buying a copy of Dubliners for a nine-year- 
old; for their patience, which I've surely tried; for their generosity, which I've somehow not exhausted; and especially for their love, which seems to know no bounds.

To Dan-for every meal we spent four hours cooking, for every extra minute of every massage, for every time you made me laugh (and for every time you didn't), for every sentence you helped me to write, for every sentence you helped me to cut, for every bottle of champagne you hid in the closet because you never once doubted that there would be cause for celebration: thank you. You are the most loving man I have ever known.

And finally, no set of thank yous would be complete without a nod to Molly Bloom and Dorian Gray, who have been present for-and frequently a distraction fromnearly every moment of the composition of this dissertation. Everyone who spends their days writing should be so lucky as to have cats like you two. 


\section{Introduction}

\section{La Mode ANd Modernité, FABric ANd FAbrication, TeXTILE ANd TeXT}

In a world where geopolitical injustice is pandemic and at a moment when humanistic academic discourse has had to defend itself urgently against accusations of frivolity, the critical study of dress has been dismissed as at best ancillary and at worst antithetical to the recent, vital global turn in literary and cultural studies. Classed high, gendered feminine, and associated with conspicuous consumption and commodity fetishism, fashion is most often viewed as a system of arbitrary differences (such that one year floral prints and skinny jeans are in, but the next decidedly not). In her fieldformative study Adorned in Dreams: Fashion and Modernity, Elizabeth Wilson laments that "the serious study of fashion has had repeatedly to justify itself" (47) as an aesthetic and a political subject, a fact made all the more surprising given that social and material practices of dress are as deeply interwoven with visual, written, and mass-mediated representations of modern life as they are with the social, political, and economic conditions of global modernity. Because of this, fashion energizes styles of reflecting, representing, and refashioning both the conditions and the idea of the world. Situated at the intersection of global cultural and economic processes, fashion is a shadow of global modernity.

Accordingly, cultural theorists from Charles Baudelaire and Walter Benjamin to Roland Barthes, Jean Baudrillard, and Pierre Bourdieu have all observed the ways in which "fashion" is distinct from both "the fashion" (e.g., a dominant trend or style) and 
from haute couture (e.g., custom-made garments); rather, as Wilson writes, "Fashion, in a sense, is change, and in modern western societies no clothes are outside of fashion; fashion sets the terms of all sartorial behaviour" (3, italics in original). In this regard, fashion is always already a global term: since the end of the nineteenth century, burgeoning capitalist systems of mass manufacture, distribution, and consumption have made fashion utterly ubiquitous. Even clothes that are unfashionable are nevertheless not outside of fashion, but rather represent a reaction against what is in fashion; to dress unfashionably is not to escape the discourse. Similarly, to dress fashionably is both to stand apart from and to blend in with the crowd because, as the early twentieth-century sociologist Georg Simmel observed, fashion expresses the tension between the desire for individuation and the compulsion to belong to a group. On the one hand, the modern ideology of bourgeois individualism recasts dress as an articulation of one's individual identity; on the other, dress cements group norms, enables forms of collective selffashioning, and forges unexpected links, affinities, and solidarities between individuals and between communities. ${ }^{1}$ This is one example of the contradictory and often paradoxical nature of fashion, which crystallizes the salience of style in its most material sense - as an imagined mode of redress for the lived, subjective experience of modernity. Puns like "redress" may at first glance appear glib, but they call attention to how completely the language of fashion has shot through vocabularies of global social justice.

\footnotetext{
${ }^{1}$ This is, admittedly, the more optimistic view; as Malcolm Barnard notes, dress is also "part of the process [by] which social groups establish, sustain, and reproduce positions of power, relations of dominance and subservience, ... part of the process [by] which those positions of dominance and subservience are made to appear entirely natural, proper and legitimate" (40).
} 
The etymological ties between text and textile, fabric and fabrication, and la mode and modernité as well as fashion idioms like dressing a wound, social fabric, and selffashioning yield a host of metaphors about the materiality of language even as they show the fundamental inextricability of fashion from the social and political conditions of modern life and their aesthetic representation. In his 1863 essay "The Painter of Modern Life," Charles Baudelaire praises "Monsieur G" (actually Constantin Guys) for bringing art into modernity — which, it turns out, is represented in and through fashion: "that quality which you must allow me to call modernité ... the ephemeral, the fugitive, the contingent, the half of art whose other half is the eternal and the immutable"; to best represent modernité, Monsieur G "makes it his business to extract from fashion whatever element it may contain of poetry within history, to distill the eternal from the transitory" (12), to show the ephemerality of la mode as the most performatively expressed and the most manifestly visible articulation of modernité.

Building upon Baudelaire's analysis, Walter Benjamin calls fashion’s ephemerality the "eternal recurrence of the new" (Selected Writings 179) — a phrase that cannot but echo Ezra Pound's famous modernist directive to "make it new." Dress appears to Benjamin as a "natural and totally irrational, temporal measure of the historical process" (Correspondence 329). With its constant changes and its selfquotations, fashion is a "cultural fragment" that resists linear or teleological narratives of historical progress. For this reason, dress is a key point of reference for dialectics, as Hegel himself had anticipated: "for the body is one thing, the clothing another, and the latter must come into its own independently and appear in its freedom” (747). Fashion does come into its own with Benjamin, who goes on to cast it as "the tiger's leap into the 
past" (Theses 252) - a dialectical image that stitches together a materialist history and offers up the possibility of global freedom. And in fact, fashion's dialectic is at the very heart of Anne Hollander's

global definition of fashion [which] needs to acknowledge the dialectical process of fashion in which anti-fashion is produced and re-integrated (fashionalized). To conceal or negate the interdependence of fashion's oppositions is to operate in fashion's ideological and economic interests, but to fail analytically. This situation is bound to persist so long as fashion is defined according to popular conventional wisdom as what appears by that name in the media and in designers' collections in shops, after first appearing on runways. (10-11)

To Hollander's "global definition of fashion," I add that not only must "the dialectical process of fashion in which anti-fashion is produced and re-integrated" be accounted for, but so too must a broader set of global economic practices, from the hand-crafted weaving of textiles by colonially subjugated peoples at the turn of the century through mid-century large-scale mass production and increasing corporate control, all the way up to contemporary practices of global outsourcing and brand management.

Toward this end, I locate a turning point at the end of the nineteenth century because "by 1860 fashion ... was a global industry, well in advance of the factory production of clothing" (Susan North 53), and as labor economists Frederick Abernathy and John Dunlop show, by 1893 at least half of the clothing manufactured globally came from sweatshop factories. I trace this phenomenon all the way through the present day, as 
the textile and apparel industries are the single largest source of global industrial employment in the twenty-first century (Dickerson 5). Following this historical arc reveals the ways in which the global fashion industry underpins industrialization, economic modernization, and the rise, expansion, and development of globalization.

Recent work in disciplines including history (Maynard, Ash, Peiss, Steele, Adamson), economics (Abernathy, Dunlop, Hammond, Weil) sociology (Crane, König), anthropology (Niessen, Tarlo, Daniel Miller), and visual culture and media studies (Barnard, Eicher, Entwistle) to which this dissertation is deeply indebted has shown how labor, infrastructure, and global trade converge on textiles. Rather than focusing on the study of consumption, which has dominated much research on dress in the humanities, social scientific perspectives turn toward dress "not [as] a topic, but a methodology, one that acknowledges design as a practice and product that exists wherever there is human activity, on axes of time as well as space" (Adamson 3). My own study branches off from this non-literary scholarship as much as it builds upon it, acknowledging the industrial, political, and economic importance of real textiles in and through an examination of the conflicted ways in which narrative fiction internalizes these global realities into itself. In this regard, I treat dress as a method for restoring literature to its rightful place in critical conversations about political and economic inequality.

Sartorial fashion and literary fiction are rarely understood as related modes of cultural production - and, when they have been linked, the emphasis has remained largely on their ephemeral stylistic innovations, the frequency with which they are both classed high and gendered feminine, and their technologies of self-expression. Yet fashion enters into the modern novel neither as a descriptive mode nor as a static term for 
clothing, but rather as a set of relational practices that shape literary texts as they map global cultural and economic processes. Like literature itself, dress too is caught up in fundamental paradoxes between global "sameness" and global "difference," or what Arjun Appadurai has so influentially called "fundamental disjunctures between economy, culture and politics" (6). From the late nineteenth century through the present day, literature has taken up the production, circulation, and everyday experience of fashion not as a motif, but as a parallel aesthetic enterprise whose "function," as Wilson writes, "is to resolve formally, at the imaginary level, social [economic, and political] contradictions that cannot be resolved" (9). Following Wilson and Dick Hebdige, who argue that styles of dress are not a substitute for politics but a way to reinterpret wider conflicts, I consider dress neither another object of representation in writing nor a mere metaphor for literary production; rather, fashion is a double of the work that literature does.

Across the arc of what Giovanni Arrighi calls the long twentieth century, the vast reaches of empire, colonialism, and neoimperial globalization came increasingly to pose representational problems for narrative fiction. These include burgeoning capitalist systems of mass manufacture, distribution, and consumption, wide-spread urbanization, increased social mobility, shifting paradigms and practices of gendered, sexual, classed, raced, and national identities and subjectivities, the acceleration of social agitation and upheaval, and a sense of rapid, seemingly irrational change - all of which the novel represents, revises, and sometimes even refuses in and through social and material practices of dress. Novels fashion aesthetic worlds that respond and correspond to the lived world, and global economic and cultural space restructures the relation between the world inside a novel and the world outside it. This central focus on literary fashioning 
(rather than either on textiles themselves, or on literary descriptions of dress) enables my focus on two disentangleable argumentative threads: first, that dress comes to speak to and for the contradictory experience of global subjectivity, because social practices of sartorial self-fashioning from dandyism to cross-dressing to street style give form to the literary expression of multi-rooted, hybrid identity; and second, that fiction comes to register the exigent conditions of global inequality through material practices of dress from the English cotton industry that presages sweatshop labor to contemporary global outsourcing.

Because dress is produced and consumed across complicated networks of a transforming global economy, it articulates the condition of a supposedly seamless world system. Put forth by Immanuel Wallerstein in the 1970s, world-systems theory has found a wide and receptive audience with scholars of literature including Franco Moretti, Pascale Casanova, and Susan Stanford Friedman, who have seized upon it as a key framework through which to describe global capitalism's uneven circuits of labor, commerce, and consumption. As Bruce Robbins notes, world-systems theory is at its most useful to literary studies as a "theory of power at the global scale" that can account for "the failure of seemingly victorious movements of national liberation to change the basic political and economic inequality between developed and underdeveloped countries" (“Blaming," 49). But for all its strength in articulating, as Wallerstein succinctly puts it, the "axial division of labor that leads to the construction of different zones ... the core, the periphery, and the semi-periphery" (v), world-systems theory does pose a major methodological challenge to literary studies - namely, that cultural production plays a 
relatively small role within a theory primarily committed to the study of the rise, expansion, and development of global capitalism.

And yet, as Thomas Piketty notes in the introduction his recent (and almost universally lauded) study of global economic inequality, Capital in the Twenty-First Century, "novels especially are full of detailed information about the relative wealth and living standards of different social groups, and especially about the deep structure of inequality, the way it is justified, and its impact on individual lives" (2). This is not because novels are merely mimetic, but rather because fictional worlds are theories of and relations to the lived world. Such literary fashioning constitutes what I call "global fabrication": an aesthetically imagined social fabric always placed in relation to lived, subjective experience. It was Kant who first connected the discourse of globalism to the novel, noting that "it is admittedly strange and at first sight absurd to proposition to write a history according to an idea of how world events must develop [...]; it would seem that only a novel could result from such premises" (52, italics in original). Crucially, this is neither the romantic essentialism that produces hyper-aestheticized national allegories, nor the modernist cosmopolitanism that purports to equalize the wrongs of cultural imperialism and economic globalization through experiments in aesthetic form. Rather, the novel — in its global fabrication — can represent the world and the history that fashioned it, even as it in turn refashions that world and its history. Uniquely equipped to make visible both historical processes of globalization and the possibility of global freedom, novels put forth specific imaginaries of the global that reveal the ways in which narrative form is part of modernity's own global form. 
For this reason, the study of literature has undergone a global turn. Within my own field of modernist studies, this has resulted in a much more expansive view of when, what, and where, exactly, constitutes "modernism," and has challenged several longstanding myths about modernism: that it is written by and for elite Western audiences; that its complex formal experimentation marks a radical break with Victorian bourgeois values; that it is apolitical, primarily interested in form over content; and especially that it is cordoned off from the world. While the core historical period of the field remains 1890-1945, the purview of scholarship now encompasses works written from the midnineteenth century through the contemporary moment - a temporal expansion to which my own project is indebted, spearheaded by scholars including Lauren Goodlad, Amanda Anderson, Joseph Allen Boone, Enda Duffy, John Marx, and Susan Stanford Friedman. Groundbreaking studies by Andreas Huyssen, Jennifer Wicke, Michael North, Mark Wollaeger, Kevin Dettmar, Aaron Jaffe, and Paul Saint-Amour have challenged the longheld understanding of modernism as an exclusive and elitist "high culture" movement that stands alternately in opposition to or in disdain of mass culture (and, for that matter, the masses themselves, variously understood as the dupes of "the culture industry"). My own focus on fashion — which forms a hinge between elitist and popular aesthetics — is borne by this research into the myriad and often mutually constitutive relationships between mass media rhetorics and high modernist forms.

Finally, as Douglas Mao and Rebecca Walkowitz note in their treatise on the state of the field, "There can be no doubt that modernist studies is undergoing a transnational turn" (738). But, as Eric Hayot has recently pointed out, because modernist literature is so strongly identified with aesthetic innovation, it lends itself in a manner that is 
"especially obnoxious" to "the struggle to think the possible relevance of the non-West to the history of aesthetics has revolved around the problem of originality" (2). This has produced at least four key kinds of broadening of the field. First, scholarship that explores how modernist authors responded to and resisted imperialism and colonialism (Esty, Peppis, Berman, Rebecca Walkowitz). Second, scholarship that puts transnational circulation at the center of modernist cultural production (Hayot, Edwards, Ramazani, Damrosch, Huggan, Brouilette). Third, scholarship that adds an adjective or prefix to modernism—one might think here of Laura Doyle and Laura Winkiel's "geomodernisms," or of Christian Moraru's “cosmodernism"- and argues that a given particular subcategory of modernist literary production shifts how we think about modernism as a whole. Fourth, scholarship that claims there are many, plural modernisms, thus making the canon less Eurocentric through a focus on literary production from outside of Western Europe and the U.S. Such approaches most often identify an author who is not generally considered modernist and, through close readings, demonstrate that he/she uses modernist techniques. Key examples can be found in the recent collection The Oxford Handbook of Global Modernism, which includes essays on modernist writings in the Balkans, Scandinavia, Cuba, Russia, Turkey, and Vietnam and on non-Anglophone texts written in such diverse languages as Yiddish, Japanese, Russian, and Portuguese.

But because such approaches take an author, an idea, or a location and then turn it into a tool for periodization, this widespread rhetoric of redefining modernism often leads to disappointment upon realizing that this supposedly new way of understanding modernism is not actually as exciting as it might initially seem, frequently because of what Paul Gilroy (tellingly drawing upon the language of fashion) calls "the problems 
involved in producing a worldly vision that is not simply one more imperialistic particularism dressed up in seductive universal garb" (Against Empire 4). My own study does not argue that modernism should be redefined as global through a focus on fashion, because global fashion is already a part of how modernist writing defined itself as such. Likewise, because fashion relates the literary to the non-literary, the representational to the phenomenological, the imagined to the material, attending to this topic does reshape our view of global modernism — but not necessarily by redefining it as global from the outside. Rather, "Global Fabrications" centers on key ways in which dress threads through narrative fabrications of a densely interconnected global modernity, showing how the materiality of dress is interwoven with the materiality of the global novel.

\section{OSCAR Wilde On THE World Stage OF Fashion}

When thinking fashion, modern literature, and global visibility together, one name cannot but jump to mind: Oscar Wilde. I turn now to Wilde as an exemplary case study; his life and work not only model the confluence of my project's three key terms, but so too the kinds of literary analysis and interpretative paradigms that my method yields. Wilde was - and remains - a consummate fashion icon and global celebrity who, as critics including Edward Said, Eve Sedgwick, Jonathan Dollimore, and Jonathan Freedman have all noted, haunts the advent of British modernism. Jonathan Goldman has recently suggested that Wilde "wore his subjectivity on his lapel" (21), arguing that he constituted his celebrity through a series of circulating visual emblems. But because those visual emblems are specific to styles of dress, Wilde's self-fashioned global literary 
celebrity is fashioned by fashion itself, built as much upon his treasured green fur coat as it is upon his enforced prison uniform.

Wilde regularly consulted his copy of E.W. Godwin's Dress and its Relation to Health and Culture, a book that linked costume to the aesthetic theory, ${ }^{2}$ and from his days at Oxford, he had used public events as occasions to call attention to dress: for example, in April of 1877, he attended a private showing with the Prince of Wales, William Gladstone, John Ruskin, and Henry James, to which he wore a bronze coat resembling a cello (Ellmann 78-9). He was an outspoken advocate of dress reform-a movement whose transatlantic history captured Wilde's attention ${ }^{3}$ — and his wife Constance Wilde served as editor of the Rational Dress Society's journal. In the mid1880s, Wilde excitedly took on the editorship of the popular fashion magazine The Woman's World, much to the horror of his friends and supporters who thought his affiliation with a tabloid widely understood to be the equivalent of modern-day US Weekly would ruin his nascent career. But Wilde revolutionized the journal, arguing that

\footnotetext{
${ }^{2}$ Wilde refers to Godwin's “excellent, though too brief, handbook on dress," in his editorial "Women's Dress," The Pall Mall Gazette, November 11, 1884, 56.

${ }^{3}$ The first important generation of dress reformers was a group of American women in the first-third of the nineteenth century who drew inspiration from the actress Fanny Kemble. Kemble had made a celebrated tour of the United States in 1832, often appearing in trousers. The popular press denounced Kemble's clothing, but Amelia Bloomer championed Kemble's “gentlemanly dress” in her temperance journal, The Lily. (See "Mrs. Kemble and Her New Costume" and "Female attire.") Kemble's outfits predate the "bloomer" costume of the 1850 s, which was pioneered and made famous by the very same Amelia Bloomer. Bloomer herself was said to have emulated the look of Elizabeth Smith Miller (a cousin of Elizabeth Cady Stanton), though Miller admitted her own style of dress had been heavily influenced by Kemble. For more on this, see Mullenix and Banner.
} 
"Fashion is such an essential part of the mundus muliebris of our day, that it seems to me absolutely necessary that its growth, development, and phases should be duly chronicled" (“Literary" 84). Alongside those chronicles of fashion, Wilde ran political polemics including impassioned arguments for suffrage and vitriolic critiques of the corset because he recognized their fundamental inextricability: the corset, like the ineligibility to vote, constricted women. Both issues, as Wilde knew so well, emanated from the same antimodern, anti-woman social atelier.

Between his well-documented stance as an advocate for women's rights and his famous dandyism, Wilde is frequently_and inaccurately_ cast as feminine. In fact, as Alan Sinfield has shown, throughout the course of the nineteenth century, aristocrats incorporated a range of feminized dress that signified class position, and was not associated with the gender of the wearer. Wilde himself regularly described his style as masculine, referring to his long, flowing hair as a "Neronian coiffure" and linking his pale blue scarf to sailors' uniforms (qtd. in Schaffer 45). Further, as Talia Schaffer has shown, "there was coherent masculine meaning in [Wilde's] clothing. The cape, lace, and long hair allude to the dashing Cavalier lord. The satin coat and shoebuckles refer to Gainsborough and Reynolds portraits. The breeches, stockings, and lace collar would be familiar to his audience from the controversial trend toward historically correct costume in Shakespeare productions.... Wilde's costume [...] revived already widely disseminated images of men from historical and theatrical vocabularies. It associated him with a tradition of male creativity from the Cavalier poets to Shakespeare" (45-6).

Wilde strove for no less a public profile, and his biographers have long characterized his 1882 lecture tour in America as the pivotal moment of his career, 
cementing his burgeoning fame and solidifying his status as a transnational celebrity. Wilde had set sail for the United States with double purpose. The first was the promotion of Richard D’Oyly Carte's production of Gilbert and Sullivan's latest opera, Patience, which satirized the aesthetic movement in general and Wilde in particular. ${ }^{4}$ Performing the part of the "real life" aesthete upon whom Patience was based, Wilde was contractually required to wear stereotypically aesthetic garb like knee-breeches, ascots, wide-brimmed collars, and flowers, including especially the lilies and sunflowers with which he was associated. Wilde was in effect playing himself — not as a person, but as the personification of his own aesthetic style.

The second purpose of Wilde's tour was the promotion of himself through a series of lectures on interior design, the decorative arts, and sartorial fashion. Before leaving for the United States, Wilde had completed his lecture "The English Renaissance of Art," which sums up the most utopian aspects of aestheticism. During the course of the tour, he wrote two new lectures - one on the modern house, alternately titled "The House Beautiful" and "House Decoration," and another on modern dress, called either "Art and the Handicraftsman" or "The Decorative Arts." Wilde continued to make changes to his lectures, often tailoring them to the particular audience to whom the talk would be addressed. In turn, audiences too tailored their own outfits to the occasion of Wilde's lectures. At Wilde's first lecture at Chickering Hall in New York, "pallid young men in dress suits and banged hair" (Lewis and Smith 57) greeted him in homage, and male

\footnotetext{
${ }^{4}$ There has not been a critical consensus about whether W.S. Gilbert had Wilde in mind when he conceived of the character Bunthorne, an aesthetic artist of "the fleshly school"; more likely, he was thinking of the pre-Raphaelite poet and painter, Dante Gabriel Rossetti. But there can be no doubt that Wilde figured the British aesthete for American audiences.
} 
undergraduates at both Harvard and Yale entered their universities' lecture halls holding lilies and sunflowers, decked out "in all the 'aesthetics' that ingenuity could devise," including "wide-floating neckties of every hue and fashion knee-breeches and black stockings" (qtd. in Lewis and Smith 122); even the bellboy at the Walker Hotel where Wilde stayed in Salt Lake City wore a sunflower as his boutonniere in homage (Finkel 11). More surprisingly, though, many women — who comprised the majority of Wilde's audiences - embraced aesthetic dress to signal their solidarity with Wilde, since through donning aesthetic styles, a woman "could participate in a fantasy that counted her as "progressive"” (Blanchard 143)..$^{5}$

Over the course of his year-long tour across the United States, Wilde fashioned himself into a brand through the cultivation of a trademark style as aesthetic as it was

\footnotetext{
${ }^{5}$ Drawing on press coverage of the tour, Lloyd Lewis and Henry Justin Smith's Oscar Wilde Discovers America — written half a century after the 1882 tour-tracks audience receptivity to Wilde's lectures, from the warm welcome from well-connected families in New York and Boston to female art students in Philadelphia to miners in Colorado, underscoring that across the United States, women in particular were especially eager to hear Wilde's views about aestheticism, modernity, and design. Lewis and Smith ascribe Wilde's popularity with American women to the growing urbanization and accumulation of private wealth in the States that had benefitted married women of middle-to-upper class status, freeing them from the obligations of salaried work and placing them at the vanguard of late nineteenth-century American culture. Women who attended Wilde's lectures—and especially those who donned aesthetic dress for the occasion-were vilified by the American popular press, which registered the silhouette as one step away from nudity. In Denver, for example, women who had worn aesthetic dress in celebration of Wilde's arrival were subjected to accusations of prostitution, and several were arrested for "meretricious display" (Lewis and Smith 285-6). Since no city ordinance prohibited the wearing of sunflowers, lilies, or loose-fitting dresses, they were released.
} 
political and as sartorial as it was verbal. Upon arriving in New York on January 2, 1882, Wilde famously announced to the customs agent who greeted him, "I have nothing to declare except my genius" (Harris 55). ${ }^{6}$ His prototypically witty quip epitomizes the major tropes of Wilde's self-fashioned celebrity, which in turn establishes fashion as an everyday praxis for global visibility. In Wilde's phrase, something supposedly interior and invisible — genius — becomes visible and exterior, and the play on "declare" subverts the institutional language of border crossing. As an Irishman arriving at the major American receiving station for immigrants, Wilde's entry at Castle Gate in New York taps into turn of the century American anxieties about Irish immigration. Although Wilde is often thought of as a British aristocrat, he was actually a middle-class Irish subject who was born to Irish nationalists, and he was an outspoken advocate of Irish Home Rule all his life.

In declaring his genius, Wilde is not announcing his distance from the Irish diaspora - quite the opposite. Rather, he announces the stringencies of global inequality, the urgency of individual visibility, and above all, the fundamental legibility (and, indeed, declarability) of personhood. When we laugh at Wilde's declaration, we are not laughing at him, but with him. The target of the joke is the customs officer-the very figure of global practices of exclusion — who responded to Wilde's declaration, "That, sir, is a commodity which does not require protection in the United States" (qtd. in Fido 50). For the customs officer, the tariffed contents of a suitcase must be announced and then

\footnotetext{
${ }^{6}$ There is some debate as to whether or not Wilde actually said this. While Frank Harris records it, Richard Ellmann is skeptical (152). Either way, as Jonathan Goldman rightly notes, "we need not quibble; even if apocryphal or invented later and elsewhere, the claim makes the case for Wilde as inventor of this particular brand of celebrity. As the legend has indeed become fact, we print the legend" (176).
} 
written into public record. Wilde's witticism shows just how declarable both one's ostensibly invisible personality and one's ostensibly visible clothing and accessories really are. But also, and perhaps more importantly, he shows how such visible sartorial items articulate an otherwise invisible selfhood. If genius is as wearable as frock coat, then it can be written on the body, made legible in and through visual tokens that accrue recognition.

This convergence reemerges in Wilde's lone novel, The Picture of Dorian Gray. When Lord Henry famously says that "it is only shallow people who do not judge by appearances," his aphorism—like Wilde's declaration of his genius_challenges bourgeois notions of the intangible and invisible attributes of the self. Castigating the supposedly "deep" person who sees through the surface into an imagined interior life, Lord Henry suggests instead that surfaces (like both the picture of Dorian Gray and The Picture of Dorian Gray) have paradoxical depth—not because they correspond to an inner truth, but because the exterior is meaningful unto itself. Herein lies a different way to judge by appearances — one that is not about snobbery, but rather about recognition. Surfaces, though superficial, are not without substance, and one's appearance makes visible one's personality. Selfhood becomes a matter of self-fashioning, and selffashioning a matter of style.

And so the novel's eponymous protagonist - the bastard son of an Irish peasant and a conscripted soldier-becomes the ultimate in style. Dorian is usually thought of as a "bad man" rather than a "fashion victim." But because his queer beauty can never be accepted anywhere in terms of its own truth, Dorian's personality remains invisible; it registers instead upon the surface of his portrait, and Dorian is given over completely to 
the image. Because Dorian has no ground to stand on, he comes into the text as figure to ground in a painting — which, it turns out, is a painting of himself. Like Wilde who used costume to perform the stereotype of himself in promoting Patience during his American tour, the image of Dorian dictates the performance of the individual who supposedly originates it. While Basil Hallward's picture of Dorian Gray is representational, Wilde's is not: his draws upon caricature and photography, and even anticipates film insofar as the image alters, shifts, and moves within its frame to register each of Dorian's actions in the world.

Furthermore, Dorian's “mode of dressing, and the particular styles that from time to time he affected, had their marked influence on the young exquisites of the Mayfair balls and Pall Mall club windows, who copied him in everything that he did, and tried to reproduce $[$ his look].... Fashion, by which what is really fantastic becomes for a moment universal, ... is an attempt to assert the absolute modernity of beauty" (99). This is much more than mere trend-setting: whether at high society dances, in department store windows, or on the pages of Lippincott's Monthly Magazine where Wilde's novella first appeared, Dorian Gray's style is mass reproducible. In fact, years later in 1897, Wilde told a friend,

"I want to show you Dorian Gray's photograph," and he took out a photograph of a young Englishman he had met in Rome. "That's the way I imagine Dorian. I didn't find or see him until after I described him in my book. You see, my idea is right, that art inspires and directs nature. This young man would never have existed if I hadn't described Dorian.” (qtd. in Ellmann 574) 
But the "absolute modernity" of Dorian Gray's beauty — like the "absolute modernity" of the beautiful novel that bears his name-has a shadow side. Facing the uncanny mass manufacture of himself, Dorian turns imperialist, and begins to collect exotic, one-of-akind objects from all over the globe. He becomes particularly enchanted by rare textiles, especially "dainty Delhi muslins, finely wrought with gold-thread palmates, and stitched over with iridescent beetles' wings" (105).

Like Dorian, Wilde's image too was mass reproducible, and the man who had insisted that "The dress of the Colonial ... should also be treated" (Letters 199) discovered that the "dress of the Colonial" was often the dress of Oscar Wilde, himself. Because Wilde's style was so distinctive, his image had been used frequently (and often illegally) in advertisements selling cigars, hats, and even ice cream. More surprisingly, though, his image was also deployed in a series of five lithographs (of which I have included two-fig. 1 and fig. 2) by an otherwise obscure American caricaturist that locate Wilde's iconic sartorial style on race-identified bodies that speak to turn of the century anxieties about diaspora. These lithographs, which I discovered while on a grant for archival research at the Andrew Williams Clark Library at UCLA, are from 1882 - the same year as Wilde's American tour-and they were directed at an American audience who would have understood Wilde's celebration of anti-mimeticism, artificiality, ornamentation, laziness, lying, and decay as a threatening affront to American notions of sparseness, work ethic, discipline, and middle-class aspiration.

In the first lithograph I have included, Wilde is depicted as an American Jew, framed on the one side by a sunflower and on the other by a lily-famously Wilde's two 


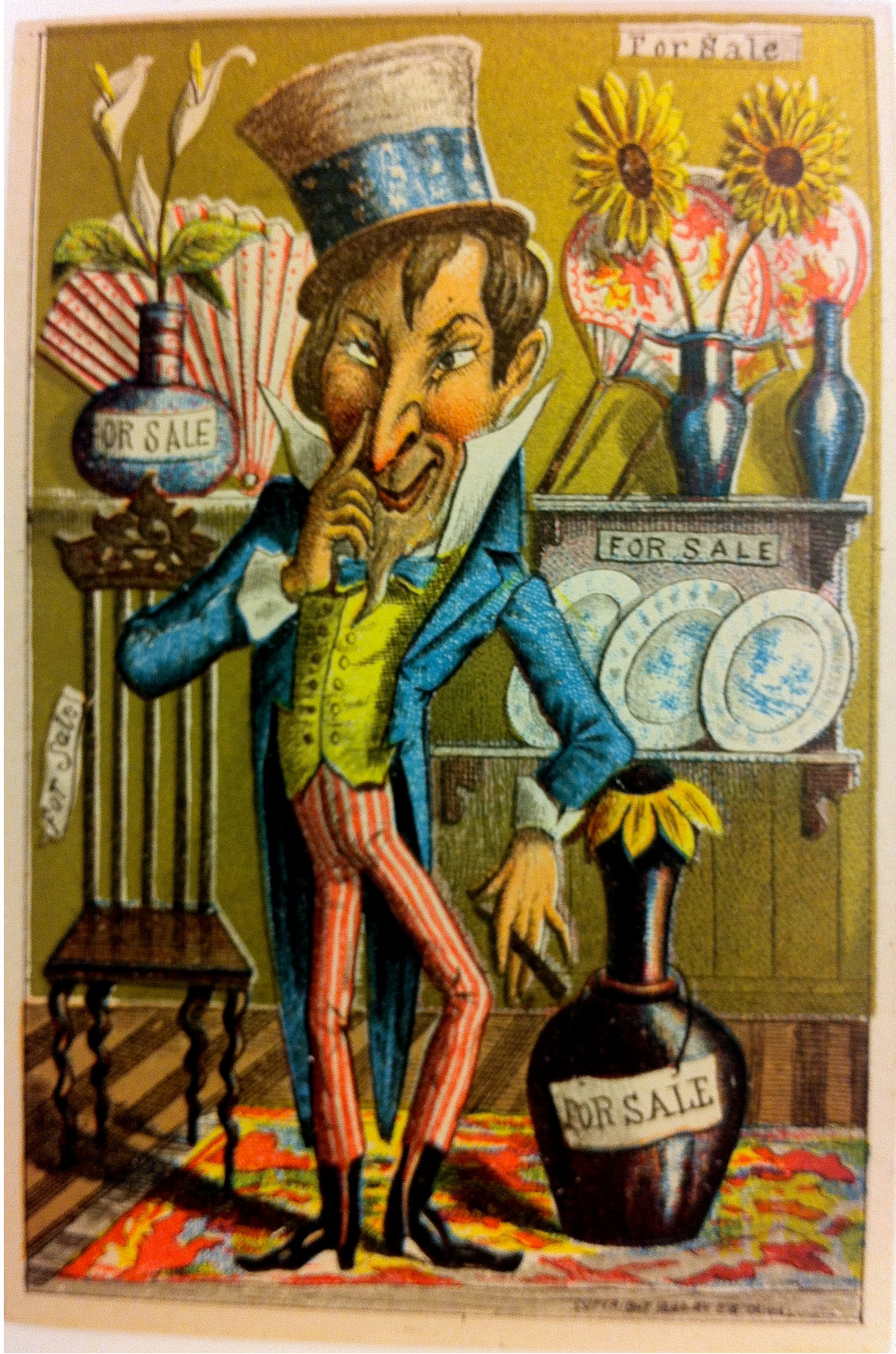

Fig. 1. E.B. Duval, lithographs of Oscar Wilde, 1882, unidentified clippings William Andrews Clark Library, UCLA; Los Angeles, CA 


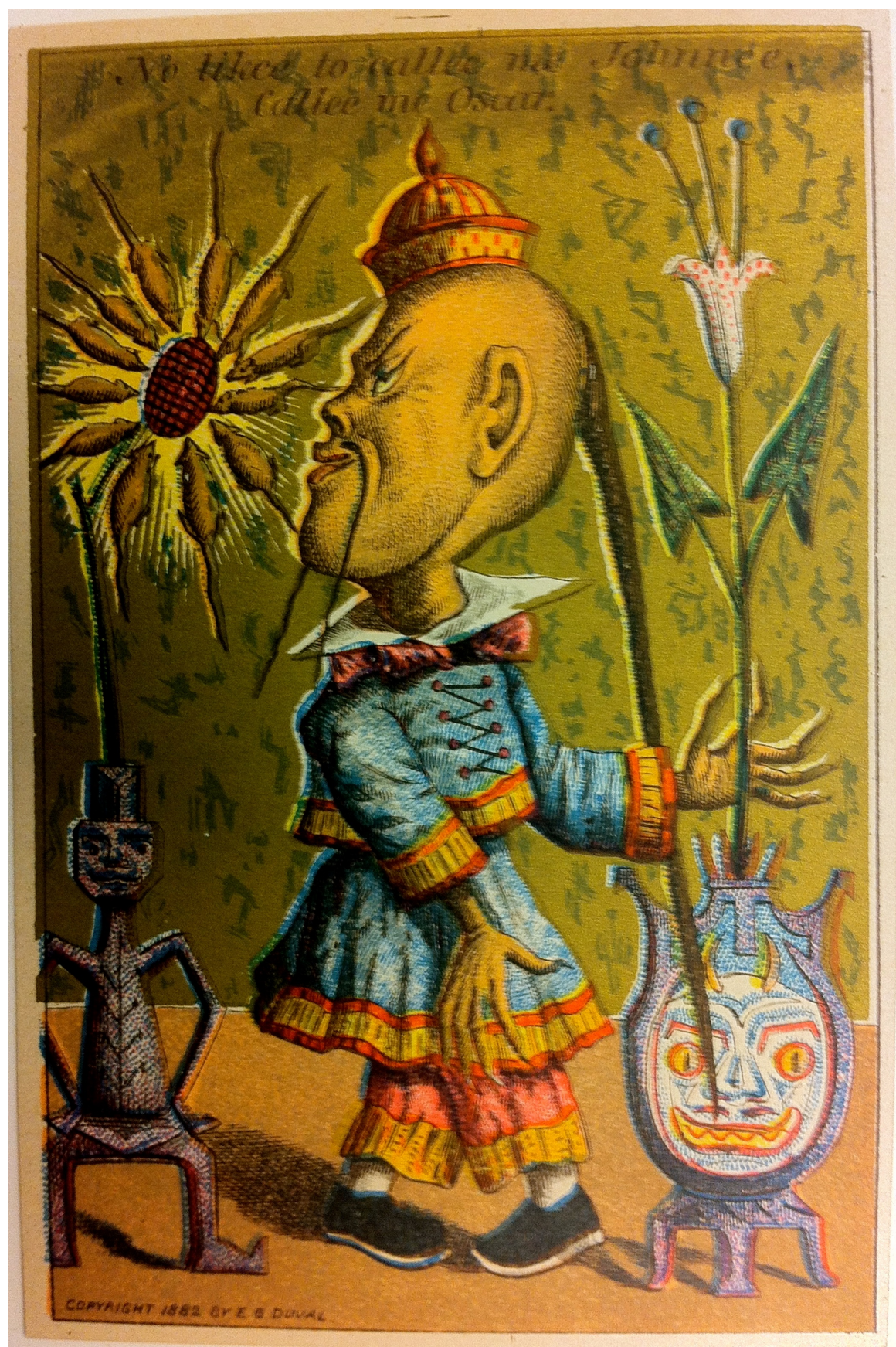

Caption: "No likee to callee me Johnee. Callee me Oscar."

Fig. 2. E.B. Duval, lithographs of Oscar Wilde, 1882, unidentified clippings William Andrews Clark Library, UCLA; Los Angeles, CA 
favorite flowers. The figure, at once sinister and jaunty, points to his Semitic nose, and wears an outfit that fuses the sartorial tropes of a British aesthete with the stars and stripes of Uncle Sam. The items for sale in his shop are exactly those that Wilde had celebrated in his lectures on interior design and sartorial fashion: "curios and knickknacks from India, China, Japan, and elsewhere" (qtd. in Plowman 39). Furthermore, this image connects the late nineteenth-century prominence of American Jews in second-hand goods economies like pawnshops and antique stores with Wilde's own passion for shopping in the emerging new thrift stores. Wilde loved repurposed clothes for the stylish historical inaccuracy in dress that they enabled (which we celebrate as "vintage" today), as well as for the subversion to global circuits of production, consumption, and exchange that thrifted clothes allowed.

In the second lithograph, Wilde is depicted as Chinese, with a Fu Manchu mustache and a long cue that recalls his own flowing locks. He is framed again by a sunflower and a lily in purportedly Oriental vases. The sunflower, which has rats for petals, suggests the stereotype of the Chinese as parasitic vermin threatening to overrun the United States. Because the figure sports Wilde's look, he trades in not only on the Wilde brand, but so too even on the brand name: the caption reads, "No likee to callee me Johnnee. Callee me Oscar." Here, too, we find unexpected common cause between Wilde and the racialized body he is mapped onto. Wilde, who was the greatest of advocates for non-representational art, locates its origins in East Asia: "The history of the [decorative] arts in Europe," he writes in "The Decay of Lying," "is the record of the struggle between Orientalism, with its frank rejection of imitation ... [and] its dislike of the actual representation of any object in Nature, and our own imitative spirit [in the West].... 
Wherever the former has been paramount, we have had beautiful and imaginative work" (979). Wilde's aesthetic values align more with what he calls an Oriental style than with a Western one, and in this way, the lithograph actually registers his deeply held beliefs about art and colonialism - which is to say that, in disfiguring Wilde's face, the lithograph figures Wilde's personality.

In this way, Wilde's trademark image is not actually a stamp of distinction at all, and herein lies the genius of Wilde's declaration of genius made upon arriving at Castle Gate. By entering his own image into public record, he makes it available for public use, insisting that tariffs can and do apply to the import and export of personality. These lithographs traffic in Wilde's iconic look, showing how his self-fashioned identity is constituted in and through visual emblems of fashion that, in turn, allow his image to make visible victims of the global procedures of mass dispersal like the expulsion of Jews from Europe and the coolie slave trade. Wilde becomes a figure for global diaspora, an iconographic patron saint of marginal communities all over the world that converge upon his image and harness his style in a bid for recognition. In this way, the lithographs suggest that Wilde might appear attached to a range of different kinds of bodies, that others might wear Wilde's subjectivity upon their own lapels — and that in so doing, they might become visible not as Wilde, but as themselves. ${ }^{7}$

This is precisely what Wilde had advocated for in "The Soul of Man Under Socialism"- published in 1891, the same year as Dorian Gray — in which he strives to

\footnotetext{
${ }^{7}$ This global Wilde has legs today, as well: one need only think of Junot Díaz's Pulitzer Prize-winning novel of 2007, The Brief Wondrous Life of Oscar Wao, a story about twentieth-century Dominican oppression, genocide, and forced migration.
} 
liberate "the great actual Individualism latent and potential in mankind generally" (1178). "Private property" — of the taxable kind that, according the customs officer at Castle Gate, personality is not_- "has crushed true Individualism, and set up an Individualism that is false... It is a question of whether we have ever seen the full expression of a personality, except on the imaginative plane of art" (1178). What Wilde proposes is a theory that is simultaneously political and aesthetic. Art becomes a corrective to the hierarchically organized and often competing human categories of class, race, gender, sexuality, age, and creed, and it becomes a corrective precisely because it exists on what Wilde calls an "imaginative plane" that enables "the full expression of a personality." Art, then, imagines a world in which self-invention and self-expression are basic human rights granted to all subjects - a world in which all human subjects are artists because, as Wilde so fervently believed, "one should either be a work of art, or wear a work of art" ("Phrases" 434), though of course he himself did both.

Wilde's vision is one of utopian diversity, in which individual acts of selffashioning are recast as collective acts of resistance:

Individualism will also be unselfish and unaffected. It has been pointed out that one of the results of the extraordinary tyranny of authority is that words are absolutely distorted from their proper and simple meaning, and are used to express the obverse of their right signification.... A man is called affected nowadays if he dresses as he likes to dress. But in doing that he is acting in a perfectly natural manner. Affectation, in such matters, consists of dressing according to the views of one's neighbor. (1194) 
Wilde's astute observation about the ways in which oppressive social and cultural institutions distort language speaks, of course, to the very heart of his own verbal style: his biting wit and pithy aphorisms subvert the lengthy, descriptive sentences and middleclass commonplaces of stifling Victorian societies. But here, fashion reveals that the artificiality of authoritarian affectation lies not in dressing flamboyantly or scantily or however one pleases, but rather in subscribing to widely accepted cultural standards of dress simply because they are normative. Selfishness is not dressing as one wishes to dress; selfishness is asking others to dress as you wish them to- - which is to say that selfishness is normativity itself, the tacit demand of complicity with that which oppresses. In this regard, fashion is Wildean individualism in action, and Wilde's own individualism is epitomized in a long, ulster-trimmed fur coat in a shade of "delicate brown with green struggling for mastery" (Lewis and Smith 55). What Wilde himself describes as his "befrogged and wonderfully befurred green over coat" (qtd. in Ellmann 154) was captured in an iconic photograph by Nicholas Sarony, taken just days after Wilde arrived in New York in 1882 (fig. 3). In this image, Wilde quite literally wears his heart on his sleeve: the coat is green for Ireland, for the revolutionary politics of Home Rule to which Wilde was so devoted. In fact, Wilde was often mocked for his unflagging commitment to Ireland, as in a Punch cartoon (fig. 4) where he is shown in an Irish soldier's uniform, and in which the caption of which reads "A Wilde Idea, or, More Injustice to Ireland." Further, as Vicki Mahaffey has shown, green may well have also functioned for Wilde as a code for the oppression of homosexuals, known at the turn of the century as "inverts." Wilde, a celebrated master of punning who spoke fluent French, 


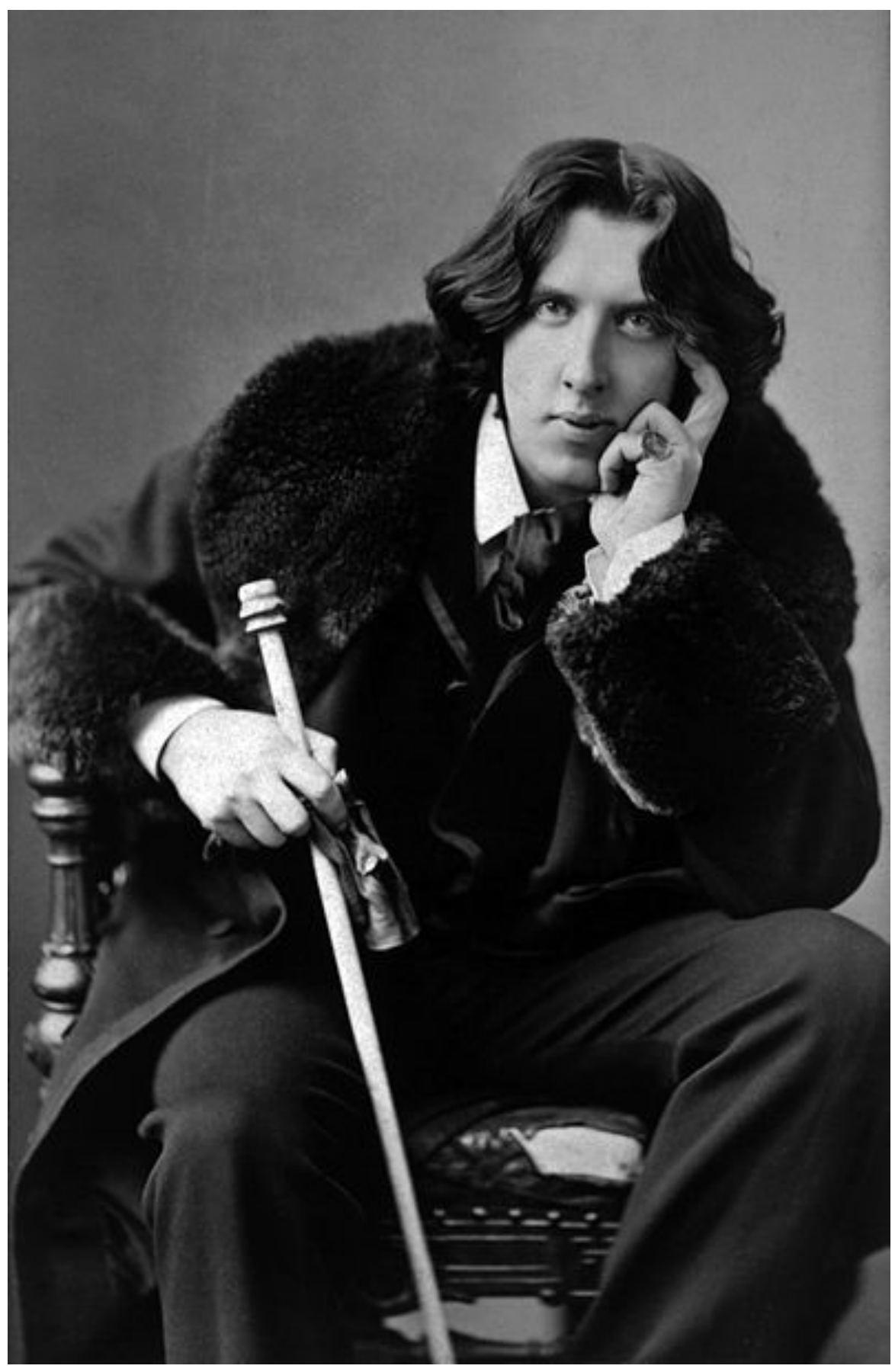

Fig. 3. Oscar Wilde, January 1882, New York Photograph by Nicholas Sarony 


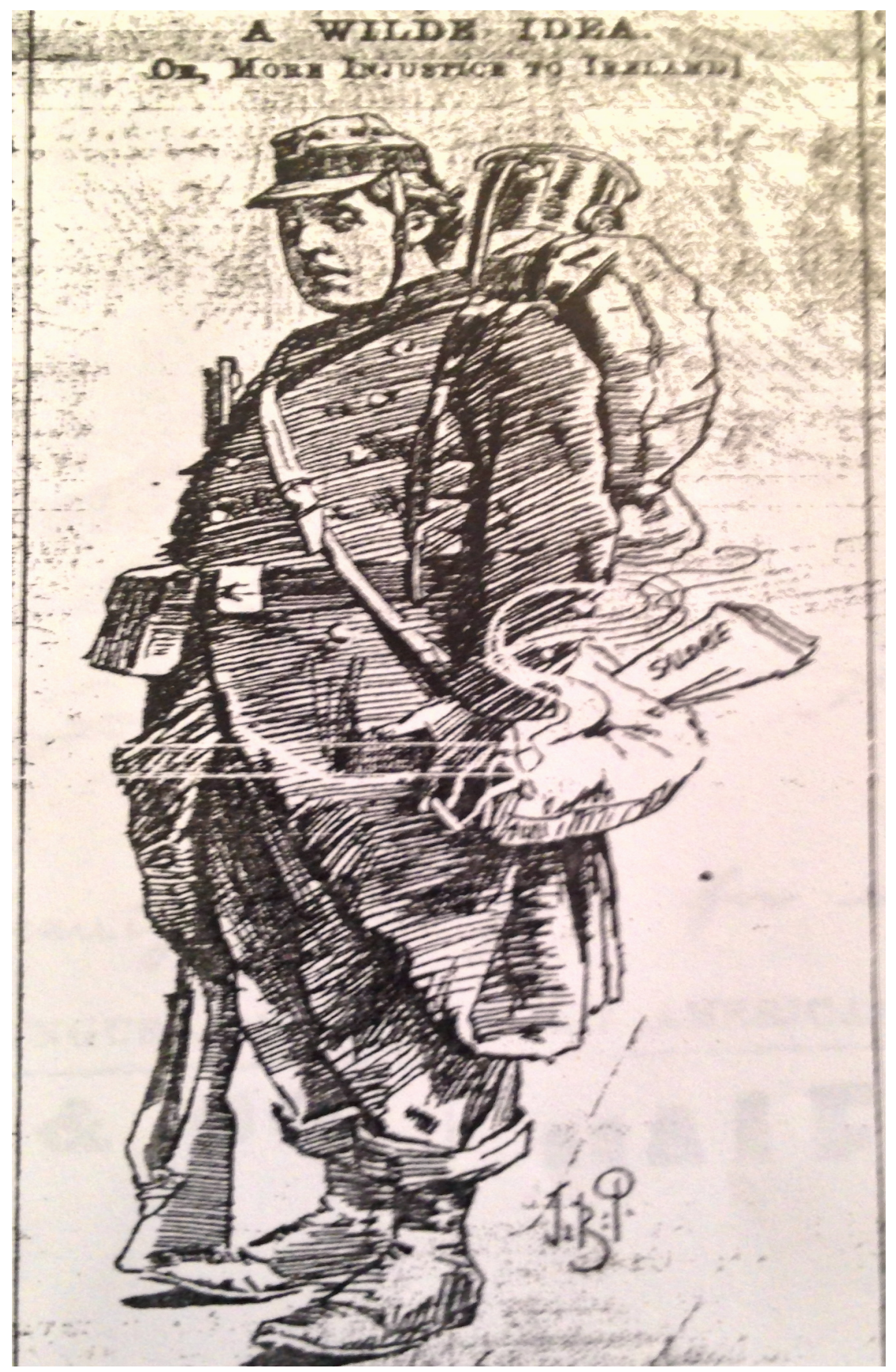

Fig. 4. Anonymous, "A Wilde Idea, Or, More Injustice to Ireland" Punch, July 9, 1892 
may have heard the French "en vert," meaning "in green," in the term "invert," and thus doubly associated the color green with political resistance. Wilde's brother sold his beloved coat while Wilde was serving his prison sentence of two years' hard labor for gross indecency, but Wilde continued to cherish it, describing its centrality to his very sense of personhood even from within the prison walls. As he writes in an uncollected letter, "Also would take it as a great favour if More wrote to the people or person who found my fur-coat since my imprisonment, and ask them from me whether they knew enough to state where it was sold or pawned as I am anxious to have it, if possible get it back. I have had it for twelve years - it was all one dimension with me - it is at all my of my first nights — it knows me perfectly—and I really want it." 8

Wilde was writing, as he describes in De Profundis, "in this dark cell in convict clothes" (4). But even in the prison uniform, Wilde will not criminalize his sexuality; instead, he focuses on fashion, recalling that he "once was, to many, an arbiter of stylethe supreme arbiter to some" (52). Upon his entry at Pentonville Gaol, the prison guard "made me undress before them ... and put on this livery of shame" (qtd. in Harris 194). Forced to hand over the fashionable clothes he had worn to court-a frock coat, a silk hat, and a pair of patent leather boots (Hyde 139) — Wilde received in their place a striped cotton shirt, woolen underwear and socks, patched-up boots that were not his size, a jacket, a waistcoat, and trousers made out of stiff brown muslin and marked with what Wilde called in his long prison poem, The Ballad of Reading Gaol, "crooked arrows" (894). By regulation, Wilde's abundant curly hair was shorn. The guard tasked with

\footnotetext{
${ }^{8}$ Andrew Williams Clark Library, UCLA. Oscar Wilde Prison Letters [bound manuscript]. Wilde W6721L R825.
} 
cropping Wilde's hair recalls: “'Must it be cut[?]' he cried piteously to me. 'You don't know what it means to me,' as the tears rolled down his cheeks" (Anonymous, "In the Depths," 328).

Forced into the haircut as into the uniform, Wilde is stripped of the expressive mode of dress, and he appears visually identical and undifferentiated from the other prisoners. Further, Wilde had gone from fashion icon to textile worker: sentenced to two years' hard labor, he was assigned to sew mail bags and pick oakum— that is, to painstakingly use his fingers to separate the fibers of old rope into thin threads until his hands bled. But the spectacle of fashion victimization was the most unbearable aspect of imprisonment for Wilde, who writes:

I remember I used to say that I thought I could bear a real tragedy if it came to me with purple pall and a mask of noble sorrow, but that the dreadful thing about modernity was that it put Tragedy into the raiment of Comedy, so that the great realities seemed commonplace or grotesque or lacking in style.... From two o'clock till half-past two on that day I had to stand on the centre platform of Clapham Junction in convict dress, handcuffed, for the world to look at.... Of all possible objects I was the most grotesque-When people saw me they laughed.... Our very dress makes us grotesques. (De Profundis 87-88)

Here indeed is tragedy put into the raiment of comedy: prison clothes turn Wilde's devastation and humiliation into a disgusting and humorless joke. Robbed of its rightful clothes, tragedy becomes grotesque. And yet, as one prison guard recalled, "Not even the 
hideous prison garb ... could altogether hide [Wilde's] air of distinction" (Anonymous, "In the Depths," 328). Wilde's prison dress—which might be thought to corrupt the value of his chicness as prison corrupted the value of his reputation — actually makes visible an otherwise elusive solidarity. Wilde signals his affinity with his fellow inmates through his use of the first person plural, because it is "Our very dress [that] makes $u$ s grotesques" (87, italics mine).

Off the platform into the prison, the Wildean radical individualism of "The Soul of Man Under Socialism" turns into Wildean radical solidarity. The uniform and haircropping that makes every prisoner look alike paradoxically figures a mode of political sociality predicated upon non-appearance - a collective self-fashioning and a form of mass-authorship. During exercise at Reading Gaol one day, another prisoner marching in the circle whispered, "Oscar Wilde, I pity you because you must be suffering more than we are." Without looking to see the man who had spoken to him, Wilde replied, "No, my friend, we are all suffering equally" (qtd. in Ellmann 497). If Wilde's suffering is to be visible, then it is only insofar as it might make visible the suffering of all prisoners. The guard who noticed this exchange called both men up, but insisted that only the initiator of the conversation would face the punishment of three days' solitary confinement. And yet each man insisted that it was he who had spoken first, and in their shared resistance to an oppressive system that would treat only one of them as culpable of the crime of speech, they together distort the very language of authority, replacing it with De Profundis's political aphorism: "Whatever happens to another happens to oneself" (70).

Wilde was released from prison on May 19, 1897, and he died three years later in France in poverty and exile. Most biographers have characterized Wilde in his final years 
as a broken man, but in fact he left prison resolved to spend the rest of his life trying to reform it: "I hope to write about prison-life and to try and change it for others," he scrawled on a scrap of an envelope addressed to the Governor of Reading Gaol. ${ }^{9}$ While in prison, Wilde had read the works of the most current authoritative writers on the penal system, penned articles describing prison conditions for The Daily Chronicle, and corresponded regularly with prison administrators and prisoner reformers. Just nine days after his release, he initiated a campaign for reform in the treatment of imprisoned children. When he published his long prison poem The Ballad of Reading Gaol in the lowbrow Reynolds's magazine, it was because "it circulates widely among the criminal classes to which I now belong, so I shall be read by my peers" (Letters 313). The statement has long been understood as Wildean wit turned self-deprecating, but Wilde's solidarity with his fellow inmates is not only sincere; it is also characterized by a fierce, uncompromising, and relentless advocacy. Although he was living in poverty and exile after his release, Wilde consistently sent money to prisoners he knew were being released. Resolute in his commitment to and identification with the incarcerated community, he wrote to his friend Reginald Turner shortly before his death, "Now Robbie [Ross] has whatever little money I possess, but he is very severe on me for having sent some money to four chaps released last week. He says I can't afford it. But, dear Reggie, I must look after my prison-friends” (Letters 887).

As Wilde looked after his prison friends, so did his friends look after him: they made arrangements such that, upon his departure from prison, "he would not find himself

\footnotetext{
${ }^{9}$ Andrew Williams Clark Library, UCLA. Oscar Wilde Prison Letters [bound manuscript]. Wilde W6 721L R825.
} 
being stared at as he had been at Clapham Junction on his transfer to Reading. He was allowed to wear ordinary clothes" (Ellmann 524), and even before his release he had already been measured for a new wardrobe that included an ulster, a blue serge suit, a dozen brightly colored handkerchiefs, and a polka-dotted necktie (Ellmann 522). His friends More Adey and Stewart Headlam were waiting for him outside the prison gates with a fresh change of clothes, and by the time he had arrived at Headlam's house, Wilde was "talking, laughing, smoking, with waved hair and a flower in his buttonhole.... He greeted Ada Leverson by saying, 'Sphinx, how marvellous of you to know exactly the right hat to wear at seven o'clock to meet a friend who has been away!'” (Ellmann 527). Neither his own signature fashion sense ("waved hair and a flower in his buttonhole") nor his aesthetic appreciation of others' styles of dress had been diminished by prison, and Wilde took as much joy "in the turn of a phrase or the cut of coat" (Ellmann 548) as ever because his very self had never ceased to be a fashion statement.

Wilde immediately went to work on completing The Ballad of Reading Gaol, which was printed only under the name C.3.3., his prison number. Wilde wrote a dedication to the poem (which was eventually cut): "When I came out of prison some met me with garments / .... You met me with love" (qtd. in Ellmann 559). While Wilde's biographer Richard Ellmann believes the dedication "was probably intended to allow Wilde to say to Douglas as well as to Ross, Adey, and perhaps others that the dedication was to each of them" (559), it seems to me that Wilde is here apostrophizing his readers - whether the friends who met him at the prison gates, the fellow prisoners whom he so embraced, the warm audiences who had welcomed him at London theaters and American lecture halls alike, the women who had found the promise of freedom in his 
editorials in The Woman's World, the silenced gay men who dared not speak their names, the colonial subjects who became visible in and through his image, and the generations of readers not yet even born (which is to say, ourselves) — each of whom provided him as much "with garments" as with the very garment of consolation: a love so expansive in its reach that one might even go so far as to call it global.

\section{FASHION STATEMENTS}

Wilde brings to the fore the major areas of convergence between fashion, literature, and the global to which this dissertation will return: gender and sexuality, colonial subjugation, racialized identity, class politics, prison policies, labor practices, mass violence, and the representation, in equal measure, of individual subjectivity and group solidarity. The project reveals an unacknowledged dynamic of dress that threads through both literary fabrications of global interconnectedness and the global inequality that underwrites the very possibility of such narratives, showing the myriad ways in which the materiality of dress is interwoven with the literary materiality of the global novel. Through analyses of how material and social practices of dress inflect novels from the end of the nineteenth century through the beginning of the twenty-first, "Global Fabrications" situates literature within a broader history of global modernity, drawing upon an archive that includes fabrics, photography, advertisements, and brand images and using an interdisciplinary framework that combines aesthetic and narrative theory with political philosophy, cultural history, studies of empire, and economic theories of globalization. Between its literary concerns, its investments in material and visual culture, 
and its close attention to global processes, "Global Fabrications" anchors the aesthetic in critical conversations about economic and political inequality.

To demonstrate how dress comes to speak to and for the contradictory experience of global modernity, the main chapters of the project trace material and social practices of dress as they inflect novels from the fin de siècle through the present day. The first chapter, "Muslin and the Worlding of Thomas Hardy's Tess of the D'Urbervilles," examines how muslin - a fabric that had been extraordinarily popular earlier in the nineteenth century, but which had fallen out of fashion by the $1890 \mathrm{~s}$ - negotiates between economic cores and peripheries, connecting Hardy's rural world of Wessex to the economic conditions of an increasingly global modernity. Hardy's notoriously bleak Wessex novels have most often been understood as participating in regionalism or "local color" writing, but Wessex is no charming countryside filled with heath-dwelling Hodges. It is a heuristic aesthetic world that responds and corresponds to southern England at the fin de siècle through its sustained attention to the global ramifications and reverberations of the late nineteenth-century cotton textile industry in British India, where colonial administrators chopped off the fingers of the female weavers of Dacca muslins to protect Lancashire cotton. In this way, I recast Tess's own rural, classed, and gendered marginality as of a piece with colonially subjugated textile workers, showing that muslin figures the text's famous “ache of modernism” by paradoxically modernizing Wessex even as it enshrouds Tess in her prison uniform made of the very same cloth.

In the second chapter, "Henry James's Social Fabric in The Princess Casamassima's Atelier," I show how modernity enters into James's anomalous novel of working-class London and its anarchist movements - subject matter that James had not 
previously explored, and to which he never returned - through fashion's gendered labor practices. The working-class anarchism practiced by the novel's male protagonists gives way to the materialist feminism practiced by the novel's transnational female fashion industry workers - including a cosmopolitan American princess turned class transvestite, a humble Victorian seamstress, a cockney shop-girl, and an imprisoned French millinermurderess - who together figure fashion's global circuits of labor, commerce, and consumption and, in so doing, recast the affective links between gender and economic inequality. Princess is by far James's most political novel, and in it fashion emerges as a political structure of feeling in Raymond Williams's sense, through which hats, buttons, and cloth-bound books refashion James's famous "international theme."

The third chapter, “Across Dressing: Virginia Woolf”s Global Modernism," traces the ways in which Woolf turns to the materiality of dress throughout her oeuvre, where what she calls "frock consciousness" becomes a global consciousness that provides new vistas for imagining gendered global citizenship in the face of British imperialism, mass violence, and world war. From the double cross-dressing of the anti-imperialist Dreadnought Hoax and its literary counterpart in "A Society" to the insistence that modern clothes shatter realist verisimilitude in "Mr. Bennett and Mrs. Brown"; from Louis's high modernist poem that connects colonial subjects by connecting bowlers in The Waves to Septimus's immaculately styled hat that creates a global gift economy in Mrs. Dalloway; from Clarissa's mermaid dress that arrests the trauma of world war to the twisted finger of Mrs. Ramsay's glove that is the occasion for To The Lighthouse's ontological theory of non-violence; from the hierophantic empty boots at the end of Jacob's Room that elegize a generation torn apart by world war to the anti-fashion 
military uniforms that stand in such stark contrast to the collectively self-fashioned "Society of Outsiders" in Three Guineas, Woolf's "frock consciousness" is transnational, transgendered, transhistorical, and even transindividual, revealing experimental literary form as part of modernity's material globality.

Such Woolfian global consciousness gives rise to global subjectivity, as I show in my fourth chapter, “The Empire's New Clothes: Global Branding and Zadie Smith's On Beauty." As late-century globalization is discursively accompanied by cosmopolitanism, subjective experience can no longer be reduced to familiar categories of identity politics like race, class, gender, sexuality, or nationality; rather, the lives of Smith's cosmopolitan characters are shaped by global cultural flows because, under conditions of late twentieth and early twenty-first century globalization, identity itself has been branded new on a global scale. As such, countercultural global fashion brands like Levi Strauss \& Co. and Jimmy Choo paradoxically signal opposition to the stark conditions of labor that fashioned them. A cultural manifestation of the economic base of globalization, the same modes of global fashion branding that have authorized Smith's own chic, cosmopolitan image underpin On Beauty's position vis-à-vis current trends in both the global literary marketplace and the increasingly corporatized twenty-first century university.

I zero in on this particular group of authors because each one serves as an exemplary case study. The lens of global fashion changes how we understand Hardy, who is frequently misread as a "local color" rather than a global author; James, who is habitually dismissed as stuffy, old-fashioned, and apolitical; Woolf, whose antiimperialist transnational feminism is often misunderstood as elitist; and Smith, whose contemporary global novels actually rebrand cosmopolitanism for the new millennium. 
But the project's methodology also potentially changes how one reads a diverse array of twentieth-century literary texts. While my authors comprise a disparate but representative group, one could easily imagine (as I often have) a shadow dissertation: instead of Hardy, a fin de siècle chapter on George Bernard Shaw's twinned obsessions with the international auxiliary language Esperanto and the politically correct Jaeger suit; instead of James, a transatlantic chapter on how fashionable dress globalizes Edith Wharton's matriarchal gangs of New York; instead of Woolf, a modernist chapter on the global transvestitism of the "Circe" episode of James Joyce's Ulysses; instead of Smith, a contemporary chapter on how dress stages postcolonial tensions between nation and domination in the Caribbean in works by Jamaica Kincaid. Similarly, because the project centers on the global reverberations, ramifications, and aftermaths of British imperialism, my texts are all works of Anglophone fiction. But the dissertation's framework could easily raise productive and provocative questions for an exploration of French colonialism and decolonization, and here too one might envision a project tracing an arc from the fashionable modernity of poems by Charles Baudelaire and Stéphane Mallarmé to the emergence of the department store in Émile Zola's Au Bonheur Des Dames, through Marcel Proust's involvement in the diamond-fabrication "Lemoine Affair" and the role of costume and its design in Alain Resnais's Hiroshima Mon Amour, culminating with the veil in Assia Djebar's Algerian Quartet and Marjane Satrapi's Persepolis.

I consider it a great strength of this project that its interpretative framework is both capacious and supple enough to be applied fruitfully to such a wide range of modern literary texts, and I believe that the project's method is its most significant contribution. Situated at the intersection of global cultural and economic processes, fashion is a double 
of modernity that invigorates a wide range of aesthetic styles and sparks the fabrication in fiction of both individual consciousness and group affinity across almost inconceivably vast axes of time and space. By investigating how a change of dress can engender a change of mind, and even possibly a change of world, "Global Fabrications" shows that fashion is literature's mirror image. 


\section{Chapter One}

\section{Muslin and the Worlding of Thomas Hardy's Tess of the D'Urbervilles}

Although Thomas Hardy called Tess of the D'Urbervilles the cause of his new "adventures in the world of fashion" (Turner 134), he perpetually dresses his heroine Tess Durbeyfield in muslin - a cotton textile that had been extraordinarily popular for women's dresses earlier in the nineteenth century, but which had fallen out of fashion by the fin de siècle. ${ }^{1}$ Hardy dresses Tess in muslin to underscore her rurality, her poverty, and her exemption from modern, urban trends. Yet even dressed in muslin in rustic Wessex, Tess still feels the novel's famous "ache of modernism" (124), because for her the ache of modernism is the ache of fashionability. Fashion - with its rapid acceleration of change, its entanglement with the conditions of mass production, its embedment in modern world-systems, its ties to social mobility and urbanization, and its ubiquityregisters the wide-ranging effects of an increasingly global modernity upon Tess's imagined community of Wessex. Cheap, stiff, ugly, and unfashionable though it may be,

\footnotetext{
${ }^{1}$ It warrants mention that George Moore's controversial 1886 novel A Drama in Muslin, which depicts the Anglo-Irish marriage market, also deploys muslin to challenge the suggestion that — as per its title- those dressed in muslin (like Tess Durbeyfield) couldn’t possibly experience real, dramatic hardship. Like Hardy, Moore's novels deal explicitly with non-marital intimacies and frank sexual content, and also like Hardy, Moore's work was the target of infelicitous reviews and accusations of immorality which caused many of his novels to be banned from Mudie's Circulating Library. Yet despite these overlaps, Moore and Hardy shared a lifelong, mutual animosity. "Heap dustbins on him," Hardy wrote of Moore. "They’ll not meet / The apex of his self-conceit" (Millgate, Thomas Hardy: A Biography, 531).
} 
Tess's muslin is nevertheless thoroughly enmeshed with the "world of fashion" that worlds Tess's imagined community.

Hardy's Wessex novels have most often been understood as participating in regionalism or "local color" writing. But Wessex is no charming countryside filled with heath-dwelling Hodges; it is a perceptual universe and a heuristic world that responds and corresponds to southern England at the fin de siècle through its sustained attention to the global ramifications and reverberations of the late nineteenth-century cotton textile industry. Tess's muslin enables Hardy's material fashioning of Wessex because, like the train's “fitful white streak of steam [that] ... denoted intermittent moments of contact between their secluded world and modern life" (186), fashion too is a mass technology of modernity that forms a hinge between historical conditions and Hardy's imagined world of Wessex. As Eric Hayot has recently argued, aesthetic worlds like Wessex are "always relations to and theories of the lived world, ... always social and conceptual constructs, as well as formal and affective ones.... Aesthetic worldedness is the form of the relation that work establishes between the world inside and the world outside itself" ("On Literary Worlds," 137). Extending its reach across Hardy's otherwise diegetically self-contained texts, Wessex is a kind of aesthetic oeuvre-world. Hardy takes the name Wessex from the medieval Anglo-Saxon kingdom that had existed in the south and southwest of England prior to the Norman Conquest and applies it broadly to his mix of fictionalized and actual locations and place-names that code the Dorsetshire of his childhood; reportedly, he even looked into having the word copyrighted. ${ }^{2}$ Hardy reflects that Wessex is "partly real,

\footnotetext{
${ }^{2}$ Hardy's Wessex has been the subject of many critical studies. See, among others: Enstice, Hasam, Fowles and Draper, Widdowson, and Williams.
} 
partly dream country": there is at once "a modern Wessex of railways, the penny post, mowing and reaping machines, union workhouses," among other markers of an encroaching modernity, but at the same time Hardy instructs readers of his novels to "refuse steadfastly to believe that there are any other inhabitants of a Victorian Wessex outside these volumes" (Personal Writings 9).

Although the exact Wessex of Hardy's novels exists nowhere outside them, Hardy's novels of the 1870s and 1880s did not yet imagine Wessex as fully formed aesthetic world in its own right. It was "in September or October of 1890" (qtd. in Gatrell, "Wessex," 27) while revising the serialized Tess of the Graphic for its three-volume edition published by Osgood, McIlvaine, and Co., that Hardy expanded Wessex into a world that extended beyond Dorsetshire of his childhood. The Tess manuscript evinces that references to familiar Dorset geography throughout the text were revised to account for a wide range of newly imagined communities including Wintoncester, Winchester, Hampshire, Melchester, Upper Wessex, Mid Wessex, and South Wessex. Thus, "the New Wessex announced in 1891" (qtd. in Gatrell, "Wessex," 26) — the year of Tess's publication-maps Tess as much as Tess maps the brave new world of Wessex. ${ }^{3}$

The new Wessex of Tess is a region as far removed from the social and cultural modernity of metropolitan London as from the economic modernity of the northern mill towns in Lancashire - where, by the middle of the century, more than $85 \%$ of the world's cotton goods were manufactured. Lancashire's prosperous economy was due to its modern textile industry, which had fueled the industrial revolution in the earlier years of

\footnotetext{
${ }^{3}$ The Tess manuscript is housed in the British Library, and excellent studies by Laird and Purdy have traced Hardy's revisions to it.
} 
the century and had cemented its status as what Immanuel Wallerstein calls a core country. Arguing that "the production of textiles was possibly the preeminent core-like production process" (World Systems Analysis, 29), Wallerstein shows that:

the rise of the British cotton textile industry [in the early-to-mid-nineteenth century] involved essentially two changes. First, it meant a major shift in the organization of work (the relations of production) in the then prime industry of the world. Second, it was integrally and visibly linked to the structure of the world market. The raw materials were entirely imported and the products 'overwhelmingly sold abroad.' Since, therefore, control of the world market was crucial, Hobsbawn draws the conclusion that there was room for only one 'pioneer national industrialization,' which was that of Great Britain. Cotton textiles were crucial precisely because they restructured this world-economy. (The Modern World System III, 27, italics in original)

The British cotton textile fundamentally restructured the world economy in the first half of the nineteenth century, and it also allowed Britain to escape the Great Depression of 1873-1896. Rather than modernizing the production of cotton textiles at the century's end, Britain exploited the technological innovations it had pioneered earlier in the century and exported cotton goods to satellite economies - especially to British India.

In this regard, muslin stands out especially among other cotton textiles for a few reasons. Although named for the city of Mosul (now in Iraq) where Marco Polo - and, subsequently, Western Europeans - first encountered the fabric, muslin actually 
originated in Dhaka (now the capital of Bangladesh). Bound into imperial pathways by its very etymology, "Muslim cloth," muslin wrapped the mummified bodies of Egyptian Pharaohs, was traded by the ancient Greeks, and was exported to imperial Rome where Pliny noted the "Jhanna muslins used by Roman ladies of high rank" (qtd. in Ghosh, Indian Textiles, 35). The famous Dhaka muslins_or jamdani-were spun primarily by carefully-trained young female weavers, who had the small hands needed to work with such a thin, delicate thread. In the height of the Mughal period, Mughal emperors and nobility patronized the muslin industry quite generously, drawing the attention of many Western buyers; over the course of the eighteenth and early nineteenth centuries, the demand for the famous Dhaka muslins grew domestically as it did abroad in Iran, Armenia, continental Europe, and especially in England.

But by the mid-nineteenth-century the export of Dhaka muslins had significantly declined. Because the weavers had no fixed salary and were paid the market price of the muslins they produced, the British East India Company dictated prices, repressed weavers who refused to sell their cloth at a lower price, and placed high tariffs on the export of India cotton goods in order to protect the Lancashire textile industry. A highranking official of the Company was posted at Dhaka in order to keep records of the best weavers and to watch over each stage of the production of the fabric. Horrifyingly, the East India Company systematically abused these talented textile workers: "British colonial governors ordered the thumbs and index fingers of India's best spinners and weavers chopped off so they would no longer be able to twist and manipulate the delicate threads" (Yafa 37). The British flooded the India market with the massive import of Lancashire cotton goods, and the machine-made English thread was a fraction of both the 
price and the quality of the Indian yarn. The jamdani industry collapsed; India became dependent on British cotton textiles; muslin came to symbolize colonial subjugation in India; and all the while in Lancashire, the production of and export to India of cotton textiles including muslin continued to skyrocket.

Yet muslin was increasingly unfashionable for British women's dresses by the century's end. As Georgiana Hill notes in her 1893 history of English dress, like other cotton textiles "muslin was no longer the prized fabric it had been in the early years of the nineteenth century. Muslin, along with other cotton fabrics, had come to be viewed as cheap and boring" (qtd. in Kortsch 117). It had, however, found a crucial new purpose domestically in England for tailors' drafts of fashionable garments. Thus, the century's end saw not only the rise of mass-produced cotton textiles in Lancashire, but so too the revamping of the tailoring industry, which had to be made modern if it was to survive. ${ }^{4}$ Even as the mass production of garments rose during the course of the nineteenth century, “there was [nevertheless still] a demand for the bespoke tailoring and fine needlework that could only be done by hand, [but] at the same time, [it] was during the period from 1890 to 1910 that the mass-produced clothing industry really took off ... in Britain” (Wilson, Adorned, 76). Nineteenth-century tailors pioneered barely-legal trade unions after the swell modern mass manufacture had rendered them largely obsolete, and by the century's end, the trade unions were circulating cheap manuals that stressed the aesthetic

\footnotetext{
${ }^{4}$ Though I focus here on tailoring practices rather than the tension between couture garments and massproduced dresses, my research is indebted to Langland, Marcus, Rosenman, and Steele, who have traced the proliferation of fashion plates and dress patterns in women's journals in the nineteenth century, as well as the relationship between mass-production of clothing and print media more broadly.
} 
necessity of a theory of standards in modern sewing — standards that were predicated upon a new and distinctly modern use for the dated textile muslin.

Late Victorian tailors' sketch-books in the Victoria and Albert Museum in London contain countless muslin mock-ups, and retail shops also issued muslins with a particular design traced upon it for ambitious middle-class home seamstresses. Barbara Morris writes, "muslin with the design traced on it ready for working was also issued by retail shops such as that of Mrs. Emma Wilcockson of 44 Goodge Street, Tottenham Court Road, London. In her book Embroidery: Its History, Beauty and Utility (London, 1856) she writes: 'I have issued from my establishment upwards of 60,000 square yards of traced and perforated muslin for embroidery"' (Victorian Embroidery 28). Morris goes on to note that "particular patterns were printed in outline on paper and had to be transferred to the cloth by tracing our pouncing, but the firm also produced what they called 'Tilton's Transparent Embroidery Patterns' which were 'by an ingenious process drawn directly onto a prepared muslin.... The muslin serves as a protection in working any delicate material"' (189) by allowing the tailor to draft a dress on cheap material before cutting, sewing, and treating the finer textile to be used in the final garment.

Hardy himself was adept at drafting from his background in architecture, and the idea of the draft was central to his interest in the novel. Having worked as an apprentice to James Hicks, an ecclesiastical Dorchester architect, on and off through the 1860 s and early 1870 s, Hardy oscillated between a professional interest in architecture and one in literature, and his letters from the period, especially those to his beloved sister Mary, are riddled with sketches of his work. His first appearance in print—an essay entitled "How I Built Myself a House," published in Chambers's Journal on March 18, 1865-further 
speaks to the entanglement of writing and drafting in both Hardy's literary and architectural careers. In late summer of 1867, Hardy began writing his first novel in Hicks's drawing office, at his drafting desk (Hardy and Hardy, 57-9). Hardy continued to work in both fields until 1873 when, after the publication of two more novels, he abandoned architecture for literature.

Furthermore, the question of the draft was especially central to the construction of Tess of the D'Urbervilles. Hardy worked on Tess for four and a half years; he had signed a contract for a serial story with Tillotson and Son in 1887, and the text underwent a complex metamorphosis before its publication as a three-volume edition printed by Osgood, McIlvaine and Co. in 1891. Hardy deliberately complicated the text through his successive revisions - including the massively and expansively reconceived Wessex world. He lamented especially the Graphic's treatment of the rape scene, having been forced by his editors to revise the "seduction pure \& simple of the original MS" (Collected Letters, I: 246). When Hardy describes his reintegration of this draft material into the novel for the 1891 three-volume edition, in his preface he offers his "thanks ... to the editors and proprietors of those periodicals for enabling me now to piece the trunk and limbs of the novel together, and print it complete, as originally written two years ago" (4). By describing the dismemberment and reassembly of his manuscript as a violation of a body, Hardy shows that Tess, like Tess herself, has been violently raped. Although Tess is, in a sense, written on the muslin and not the body, the body and its very real materiality are never lost.

Tess no less than Tess has been brutalized by the global capitalist modernity that creates Hardy's "new Wessex announced in 1891," and the assault is as much upon the 
drafted body of text as it is upon the drafted body covered by the textile. Clad in muslin "of no date or fashion, ...Tess walks on; a figure which is part of the landscape" (102), because Tess's muslin is Wessex itself-a contact zone that is paradoxically fashioned without being in fashion. This is why Raymond Williams describes Wessex as an imagined "border country" that "so many of us have been living in: between custom and education, between work and ideas, between love of place and an experience of change" (The Country and the City, 197). A world neither peripheral like India nor core like Lancashire, the fin de siècle Wessex of Tess might be understood in Wallerstein's terms as semi-peripheral, occupying a muslin ground between the draft and the final garment, or between what Hardy calls "their secluded world and modern life” (186). Hardy's new Wessex negotiates a historical moment between economic cores and peripheries just as muslin does.

Because aesthetic, imagined worlds like Wessex are, as Hayot has recently argued, "always relations to and theories of the lived world" ("On Literary Worlds," 137), the worldedness of Tess is a cultural phenomenon - an aesthetically imagined, continuous social fabric always placed in relation to lived, historical, subjective experience. Yet this is not merely a self-reflexive aesthetic; it is a wider and more transitional sense of the novel as only intermittently acknowledging its own provisional and materially fashioned modernity — or better yet, its own muslin worldedness and much as its own muslin draftedness. By retaining both its worldedness and its draftedness, Tess reveals that the muslin is novelistic just as Hardy's novel is muslin-esque. Muslin is as much the basis for one aesthetic strand of modern fashion as it is for one aesthetic strand of modern literature: it insists upon a worlded palimpsest by retaining the draft stage and 
underscoring the seams and selvages of a style as literary as it is sartorial. "The world," thinks Tess as she traverses Wessex's rapidly changing terrain, “was drawn to a larger pattern here" (102) because the pattern, or the worldedness, of Wessex is a continuous social fabric, always placed in relation to the lived, historical, subjective experience of an increasingly global modernity. Tess's muslin skirts modern fashionability as Wessex hovers at modernity's margin, and in this way, muslin worlds Tess.

\section{Cut to RibBons}

Hardy first reveals Tess dressed in her white muslin in the novel's second scene, where a still "unenclosed character to the landscape" (12) prefigures the changes modernity will rain down upon Wessex. Dorset itself was about to undergo the spread of Corn Law repeal and Parliamentary enclosure, which transformed its fields and pastures into individually owned farm plots in the spirit of modern agricultural efficiency. This historical fact speaks to the contemporaneity of Tess: Dorset was one of the last counties to experience the invisible presences of urban modernity in rural England. Further, the enclosure of Wessex is distinctly tied to fashion, insofar as the rapidly changing landscape is set in a dialectic with the rapidly changing styles of female dress. In this early scene of the novel,

The forests have departed, but some old customs of their shades remain. Many, however, linger only in a metamorphosed or disguised form. The May-Day dance, for instance, was to be discerned on the afternoon under notice, ... the members being solely women.... The banded ones were all dressed in white gowns - a gay 
survival from Old Style days.... [T]hough the whole troop wore white garments, not two whites were alike among them. Some approached pure blanching; some had a bluish pallor; some worn by older characters (which had possibly lain by folded for many a year) inclined to a cadaverous tint, and to a Georgian style. (13)

The outdated white dresses_-"Old Style," or "Georgian style"—would have been made of once-fashionable muslin. In contrast to the recently departed forests of Southern England, soon to be subjected to modern Parliamentary enclosure, the muslin dresses "uphold the local Cerealia" that "had walked for hundreds of years, and it walked still" (12). Muslin resists modernization even as modernity encroaches: a far cry from massproduced modern garments, "no two whites were alike among" the muslin dresses. In this way, the girls' muslins share their particularity with the Indian jamdani, a textile characterized by the range of its shades of white, including "bright white fold, tooth white, sandal white, autumn cloud white, and autumn moon white" (Yafa 36).

From the mass of white-frocked women, the novel—employing the prescient cinematic technique for which Hardy has often been recognized ${ }^{5}$ - zooms in on Tess,

\footnotetext{
${ }^{5}$ As early as 1922, Joseph Warren Beach suggested that Hardy might be thought of as a cinematic novelist, thus initiating a lively, nearly century-long discussion of Hardy's relationship to the visual. Since Beach's early study, countless studies of Hardy and film have published; see, among others, Lodge, Niemeyer, and Wright. Further, Hardy's novels have frequently been the subject of cinematic adaptation, both within his own lifetime and after. Wright notes that Hardy was the only Victorian novelist to see one of his own novels — Tess, no less, and starring the famed Minnie Fiske—on the big screen. The Adolph Zukor's Famous Players Company produced a 1913 film, Tess, of which only stills remain; the Progress Film Company shot a 1921 The Mayor of Casterbridge and invited Hardy to spend a day on the set, which he
} 
who is distinguished from the crowd by the "red ribbon in her hair... [She] was the only one of the white company who could boast of such a pronounced adornment" (14). Tess has donned her very best outfit for a special occasion: the May-Day dance, in which she "move[s] on with the whole body to the enclosure where there was to be dancing" (15). The enclosure of the space of the dance-especially in contrast to the "unenclosed character [of] the landscape"-reveals the modernity that encroaches upon the imagined community of Wessex as it does upon Tess, whose individual, muslin-clad body stands out among the "whole body" of white-frocked women. Though Tess is a "fine and handsome girl—[she is] not handsomer than some others, possibly" (14); her distinction from the group relies entirely upon her accessory. In this way, Tess is both the standard and the deviation, insofar as " $[\mathrm{t}]$ he paradoxes of standardization enter into the aesthetic realm no less than the zone of fashion, where the same and the different must coalesce as rapidly as possible" (Wicke, “The Same," 584). The standard, then, becomes both the original and the copy, and Tess's white muslin dress marks her membership in the group of "fine and picturesque country girl[s]" (16) even as her red ribbon signals her distinction from them.

gladly accepted; and the Metro-Goldwyn Company's released a 1924 Tess of the D'Urbervilles, which was set in the jazz age and which offered audiences two endings to choose between: one in which Tess is hanged, and another in which she is granted amnesty. In the nearly one hundred years that have passed since these very first cinematic adaptations of Hardy novels, their popularity among filmmakers has never waned. Some notable recent adaptations, about which a great deal has been written in the volumes mentioned above, include: John Scheslinger's Far From the Madding Crowd (1967), the BBC Series “Wessex Tales” (1973), Roman Polanski’s Tess (1979), and Michael Winterbottom’s Jude (1996). 
Tony Tanner's particularly influential interpretation of Tess, which takes Tess's favorite fashion accessory as indexical to her person, attends closely to Tess's ribbon as definitive instance of Tess's visuality. But Tess's red ribbon is an adornment "pronounced" as much in the visual sense as in the vernacular. Not unlike the Wessex "syllable UR, probably as rich an utterance as any to be found in human speech" (15) which Tess's mouth “pouted-up ... and her lower lip had a way of thrusting the middle of her top one upward" (15) in order to articulate, Tess's ribbon-like Tess's vernacular-is drafted and patterned. Hardy continued to reflect on this even thirty years after Tess's publication, writing to his French translator, Madeline Rolland, in 1921: "I am quite beaten over the UR. You must exercise your ingenuity in thinking of a pattern sound" (Selected Letters 355). Tess's vernacular is in this way a draft, or a pattern, drawn onto muslin — and even thirty years later, Hardy senses that it still has not yet quite been made into a fashionably finished garment. Evident too is Hardy's continued sense of the violence done unto the draft: he feels "quite beaten," as he did in his 1891 preface, where Tess's pattern, or draft material — the "trunk and limbs of the novel" - had been not only beaten, but violently severed.

Tess's favorite fashion accessory makes its second appearance shortly thereafter, when Joan Durbeyfield - dressing her daughter to meet Alec D’Urberville for the first time - spruces up her best muslin dress with a single pink ribbon. (It is worth noting that, in the serialized version of the novel that appeared in Graphic, the ribbon was redpresumably the same one that Tess wears with her muslin dress in the novel's earlier May Day celebration scene.) Because Tess's clothing is so drab, even such a modest ornament significantly alters her outfit; the inexpensive ribbon accentuates Tess's hair, 
ornamenting her outfit as Hardy ornaments the novel's own textual style with vernacular: "Mrs Durbeyfield still habitually spoke the dialect; her daughter, who had passed the Sixth Standard in the National School under a London-trained mistress, used it only when excited by joy, surprise, or grief" (21). The Education Act of 1870 had promoted the spread of a standardized English such that — as Dennis Taylor notes—-"by the 1890s nonstandard dialect was little tolerated in the schools" (83). Here, Hardy equates Joan's vernacular fashion sense with his own literary one: her creative styling of her daughter is not merely a game of dress-up, but rather a modern vernacular that puts the art of fashion on par with the art of writing. Just as the ribbon reconstitutes Tess's outfit, so too does it reconstitute Hardy's aesthetic style. Though “at first there may be a little pretence to’t, ... dressing up more the dand" (49) for the meeting with Alec is no more a form of mere decoration than the ribbon is a source for realist description or Joan's dialect is a form of folksiness.

Further, when Hardy calls Tess's donning of the ribbon a form of "dressing up more the dand," he conjures the aestheticism, decadence, and repertoire of purposefully deviant cultural strategies that dandyism employed. With its emphatic valuing of mobility, transience, and artificiality, cosmopolitan dandyism seems at first blush a far cry from the world of rural, poverty-stricken Wessex. But Tess's modest form of dandyism is a tactic in Michel de Certeau's sense, spontaneously and immediately responding to opportunities as they present themselves and "vigilantly mak[ing] use of the cracks that particular conjunctions open" (37). Tess's outfit reveals just such a crack. Her stocking-heel has a hole that Joan creatively covers up: 
"I declare there's a hole in my stocking-heel!" said Tess.

'Never mind holes in your stockings - they don't speak. When I was a maid, so long as I had a pretty bonnet the devil might ha' found me in heels."

Her mother's pride in the girl's appearance led her to step back, like a painter from his easel, and survey her work as a whole. (49-50)

Tess knows that that hole speaks where, and what, she cannot: "her voice was too choked to utter the bitter sentiments that were in her" (51). Tess's stocking-heel may be hidden from sight — it may not speak — but the hole offers Joan the occasion for a creative "art of the weak" (de Certeau 37), a vernacular styling that revises the dire sign of the Durbeyfields' poverty. Joan anticipates a modernity that will come to despise Victorian ornamentation and will pare fashionable sartorial style down its barest bones. But her less-is-more sense of style is due to poverty rather than a rebellion against the Victorian taste for excess, and as such, it speaks to and for the modernity of rural Wessex.

\section{Through THE LOOKING GLASS}

Because the Durbeyfields are too poor to afford a larger mirror, "the lookingglass was only large enough to reflect a very small portion of Tess's person at one time" (50); Tess cannot see her own image as so many wealthier, well-dressed heroines of Victorian novels do. Tess's body is revealed in bits and pieces because she is quite literally outside the glass of fashion. Like the hole in Tess's stocking-heel that would expose the Durbeyfields' poverty if it spoke, their looking glass reveals that they are unable to afford a larger mirror. Joan tactically " $\mathrm{h}[\mathrm{a}] \mathrm{ng}[\mathrm{s}]$ a black cloak outside the 
casement, and so ma[kes] a large reflector of the panes" (50), which in turn causes the mirror distort Tess rather than reflect her. Tess-like Tess - is dismembered: the "trunk and limbs of the novel," like the trunk and limbs of its eponymous heroine, are severed. In an effort to show Tess more of her own reflection, Joan tactically " $h[\mathrm{a}] \mathrm{ng}[\mathrm{s}] \mathrm{a}$ black cloak outside the casement, and so ma[kes] a large reflector of the panes" (50), and her technique of draping the dark cloth around the looking-glass is almost exactly what Charles Chandler and Arthur Elliott, the editors of the popular Victorian Anthony's Photographic Bulletin, describe in 1887 as a major technological innovation in the world of photography:

This we call artificial diffusion. To obtain such, procure a very thin muslin screen, which place [sic] between the window and the sitter, out of the range of lens in such a manner that all the rays which fall on the face must pass through the gauze. This done, if we expose another plate on our sitter, we will find a very material change has taken place.... Use white muslin for the material. (Chandler and Elliott, 629, 192)

Hardy's plush yet poverty-necessitated backdrop_like the technological innovation of artificial diffusion in photography_-does not reflect material, but rather the drafted materiality of the image, which is itself "a very material change" in visual rhetoric. Paradoxically, despite its non-existence outside of Hardy's oeuvre, Wessex too is photographic world: Hardy collaborated with Dorset photographer Hermann Lea to produce the 1905 A Handbook to the Wessex Country of Thomas Hardy's Novel and 
Poems and the 1912 Thomas Hardy's Wessex. Hardy's, then, is a "fiction in the age of photography" — a realist text indebted to and shaped by the technological innovation that modernized visual rhetoric and displaced the mirror as the central metaphor of fiction.

The commitment to mirroring in fiction was articulated most famously by George Eliot—who, it should be noted, was regularly credited with having authored Hardy's early novels:

I aspire to give no more than a faithful account of men and things as they have mirrored themselves in my mind. The mirror is doubtless defective; the outlines will sometimes be disturbed; the reflection is faint or confused; but I feel as much bound to tell you, as precisely as I can, what that reflection is, as if I were in a witness-box narrating my experience on oath. (Adam Bede 149)

Eliot imagines realist writing as mode that, as Felski has recently argued, "achieve[s] the ideal of styleless style scoured clean of any blemish of particularity" (Uses 63). But the language of realism is anything but transparent, and Eliot's "doubtless defective" mirror is, as Rita Felski shows, a visual metaphor that "enshrine[s] the supremacy of an eyecentered epistemology; the linguistic mediation of experience, it is argued, cannot help but place a massive dent in all such visual analogies" (Uses 78). By contrast, Hardy’s turn toward the materiality of dress focuses the attention on material "massive dents."

\footnotetext{
${ }^{6}$ I take the phrase from the title of Nancy Armstrong's influential book. For more on Hardy's relationship to photography, including his poem entitled "The Photograph," see, among others, Simons, Jackson, Durden, and Tim Armstrong.
} 
When narrative fiction draws upon the materiality of dress as Tess does, it ceases the work of verisimilitudinous description for which Eliot was such a staunch advocate. Rather, Hardy materializes the salience of style as an analog for an increasingly global modernity. Non-mimetic modalities — among them, fashion — are an index of Hardy's own political position as realist literary protocols, mass-produced clothing, and social dress codes are all increasingly put under pressure at the fin de siècle. Further, when Eliot thinks of realism's mirror as affecting "the faithful representation of commonplace things" (Adam Bede 144, italics mine), she prefigures William Jerome Harrison's 1888 sense of the very distinction between mirror and photograph. "The first effect of this cloth," writes Harrison, "is similar to that of a mirror, but by means of its viscous nature the prepared canvas, as is not the case with the mirror, retains a fac-simile [sic] of the image. The mirror represents images faithfully, but retains none; our canvas reflects them less faithfully, but retains them all" (12, italics mine). Harrison senses that the retention of the facsimile image upon the cloth marks a significant break; it moves away from mimetic reflection and toward a more palimpsestic, worlded aesthetic representation that retains the draft stage. Exactly the same shift, enacted by exactly the same "very thin muslin" Chandler and Elliott identify as the method through which "a very material change has taken place" (629) in the history of early photography also characterizes the move from Eliot's to Hardy's modes of realist writing.

Although Eliot and Hardy wrote a generation apart and neither made much more than a few perfunctory remarks about the other's work, Hardy's early novels were constantly compared and often attributed to Eliot. His friend Horace Moule, in an unsigned piece in the Saturday Review on September 20, 1871, writes of Hardy's 
Desperate Remedies that "like George Eliot, the author delights in running off into sentientiae, in generalizing abstractions out of the special point at hand" (Cox, Critical Heritage 6-7), which Richard Nemesvari has noted is actually quite significant: the fact that "this unknown, first-time novelist deserves to have George Eliot mentioned in a review of his work [is] a fairly bold vote of confidence in itself. Eliot's reputation as the dominant novelist of the mid-Victorian period, and as the pre-eminent advocate of realism in English fiction, was already well established" (45). Henry James observed in 1874 that "George Eliot ha[d] met her match" in "Mr. Hardy's novel[s]" (Cox, Critical Heritage 37), and indeed Eliot was rumored to have been the author of Hardy's anonymously-authored 1874 novel, Far From the Madding Crowd.

A January 1875 unsigned review in the Westminster Review — the journal which Eliot herself had edited under John Chapman for many years-compares Far From the Madding Crowd to Eliot's first full-length novel Adam Bede, suggesting that "Mr. Hardy has not reached the splendid heights which George Eliot has attained, nor sounded her spiritual depths, but his new work will certainly in many other respects bear favourable comparison with Adam Bede" (Cox, Critical Heritage 41). Notably, Hardy commented specifically on Adam Bede in an 1898 letter to Edmund Gosse: "It is curious that a woman of the people such as George Eliot shd have carried on the prejudice to some extent in her treatment of Hetty, whom she wd not have us regard as possessing equal rights with Donnithorne" (Selected Letters 124). Hardy's reaction is telling insofar as Tess might fruitfully be read as a radical retelling of Adam Bede in which Hardy has redressed Tess with "the equal rights" denied to Hetty Sorrel. Like Hetty before her, Tess is an uncannily pretty, rural milkmaid heroine. Both women are seduced and 
subsequently impregnated by dandyish, upper-middle class distant family relations who happen to share the same initials, Arthur Donnithorne and Alec D'Urberville; both of their babies' deaths are accompanied by devastating refusals of baptism; both women might have had, but ultimately fail to find, supportive marriages with lovable if selfrighteous men, both of whose names - Adam and Angel—cast heavy-handed, ironized sideways glances at the Bible; both women are accused and convicted of murder, and both are sentenced to death.

Yet for all these similarities between Tess and Adam Bede, and for all that Hardy admired Eliot as "a woman of the people," Hardy was less than thrilled with the comparison. Eliot and Hardy fundamentally disagreed about both ethics and aesthetics, and Hardy called Eliot at best "not a story-teller" and at worst "a moral essayist who had mistaken her vocation" (Interviews and Recollections 143, 17). "The highest vocation of the novelist," writes Eliot in Adam Bede, is "not to represent things as they never have been and never will be. Then, of course, I might refashion life and character after my own liking" (193, italics mine). Eliot's system of aesthetic valuation hinges upon fiction's mimetic capacity to reflect the world outside itself. Hardy shatters such techniques of mirroring with Tess's muslin, which self-reflexively registers fiction's fabrications, opening literature out into the real even as it is realist.

Because the Graphic, which published Tess serially, was a news magazine that had "its reputation for social realism" (Mallet 82) at stake in printing Hardy's controversial text, his relation to realist fiction has been thought through (and perhaps most forcefully rejected) by Peter Widdowson, who argues that it is "perversely inappropriate to critically recast [Hardy's] fiction in the formal-realist mode" (164). 
Linda Shires's more supple claim that "Hardy is fundamentally anti-realistic....[but] he does not abandon mimesis completely" (147) recognizes Hardy's relation to Victorian fiction as neither perverse nor inappropriate, but as both vexed and vexing. The 1890 symposium on "Candour in English Fiction" in The New Review, which included one of Hardy's most famous treatises on the state of the late Victorian novel, identified all of its contributors as proponents of realist fiction. Yet in the essay he contributed, Hardy insisted that the realist novel was not yet equipped to confront Victorians with their own aesthetic and social hypocrisy. ${ }^{7}$ In order to do so, he claimed, realism would need to shift its gears by recalling its roots in Greco-Roman epic or Elizabethan drama, becoming "mainly impassive in its tone and tragic in its developments" (16). The realist novel, Hardy argued, needed to become modern, to distance itself from the limited scale and scope of Eliot's brand of mimesis. And in order to register and to represent a larger, increasingly global modern world, it would need — as Hardy realized while revising Tess in 1891 - to create one.

Hardy crafted only a few essays on the theory of fiction, but in a prophetically modernist comment made during the Tess revisions, he argues that

\footnotetext{
${ }^{7}$ Walter Besant and Eliza Lynn Linton, the other two contributors, suggested more middle-of-the-road solutions to the problem of what Hardy dubbed "the censorship of prudery in Britain." Besant argued for protecting young readers, claiming that the censorship to which Hardy so vehemently objected was good for both for public morals and for public morale. Linton hedged her bets; neither authors nor adult readers, she maintained, should compromise their standards to protect the young. But she believed the young needed to be protected nevertheless, and suggested that libraries might install locked bookcases to prevent young people from accessing novels inappropriate for them.
} 
Art is a disproportioning-(i.e., a distorting, a throwing out of proportion) — of realities, to show more clearly the features that matter in those realities, which, if merely copied or reported inventorially, might possibly be observed, but would more probably be overlooked. Hence 'realism' is not Art. (Life and Work 249)

Hardy here rejects the realist mimesis of an Eliot novel, seeking to create instead an aesthetic world that responds and corresponds to lived material conditions not by mirroring, but rather by "throwing out of proportion," those conditions. In so doing, the novel may be able "show more closely the features that matter in those realities." Raymond Williams's powerful reading of Hardy points out the "continuity not only of a country but of a history and a people" (The Country and the City, 214), which is to say that Hardy achieves the creation of a world that responds and corresponds to historical realities without mirroring them. The worldly "features that matter" to Tess are the marks of an encroaching modernity, figured in and through fashion, to which "Tess was so susceptible that the few minutes of contact with the whirl of material progress lingered in her thought" because "no object could have looked more foreign to the gleaming cranks and wheels than this unsophisticated girl, with ... the print gown of no date or fashion" (186-7). Unfashionable Tess in her shabby muslin is set in contrast to the blooming, buzzing confusion of economic, industrial modernity. But for all that "material progress lingered in her thought," it is nevertheless not Tess's thought that Hardy represents. Tess is not a subject perceiving so much as an object perceived, and perceived by modernity itself: "no object could have looked more foreign to the gleaming cranks and wheels." The stylistic, technological innovations of modernity - its cranks and wheels no less than 
its photographic artificial diffusions or its changes in styles of dress - perceive Tess, and not the other way around. Hardy's worlded realism is fashioned not by the omniscient narrator one might find in an Eliot novel, but rather by modernity itself.

\section{SKIRTING THE ISSUE}

Only moments before he rapes her, Alec points out that Tess has "only that puffy muslin dress on." Taking "a druggist's bottle from a parcel on the saddle, and after some trouble in opening it[, he] held it to her mouth unawares. Tess sputtered and coughed, and gasping 'It will go on my pretty frock!' swallow[ing] as he poured, to prevent the catastrophe she feared" (72). But the disaster that terrifies Tess is not that Alec might drug her, much less that he might rape her. What Tess fears is a very real fashion emergency: that her best muslin dress will be stained, just as it was when she "became splashed from face to skirt with the crimson drops" (33) of the horse Prince's blood when he was so violently penetrated. And indeed, the virgin Tess will find her one and only good frock splattered in her own blood after the rape, making it impossible for her to appear in public.

The rape and its attendant stain have often been understood as a mode of writing. Jean Jacques Lecercle points out the "verbal violence" (1-2) of Hardy’s style; J. Hillis Miller reads the scene as "a form of writing" (266); and Susan Bernstein argues that "[t]his figuration of rape as textual inscription ... characterizes writing [itself] as an act of violence" (146). But for all that critics have been quick to point out the ways in which the rape is a scene of inscription, they have neglected what, precisely, it is that is being inscribed: 
There was no answer. The obscurity now was so great that he could see absolutely nothing but a pale nebulousness at his feet, which represented the white muslin figure he had left upon the dead leaves.... Why was it that upon this beautiful feminine tissue, sensitive as gossamer, and practically blank as snow yet, there should have been traced such a coarse pattern as it was doomed to receive[?] (734)

The reduction of Tess to a flat, smooth, blank sheet of paper does not account for the political texture of Hardy's style, which is as textile as it is textual. The coarse, patterned textures of dead leaves, muslin, tissue, and gossamer dominate a scene whose literary violence is shot through with tactile urgency - the sharp pain of the page as the pen carves into it, the cruel flippancy of our own hands as they correspondingly flip the page. Alec's coarse pattern is not merely a written one; it is also the design for a garment marked in tailor's chalk on raw muslin. In turn, Tess is not a page so much as she is a cloth - a white muslin, a feminine tissue, a sensitive gossamer — and when Alec "trac[es] such a coarse pattern" upon Tess's "white muslin figure," he tailors Tess for the global modernity that ravages the novel's eponymous heroine as it does its aesthetic world of Wessex.

Hardy deploys fashion here to represent the material conditions of Tess's social position in and through materials, themselves - specifically, muslin, tissue, and gossamer. That the sartorial descriptions in the rape scene move first from muslin to tissue recalls the tissue paper upon which so many Victorian home dress patterns were printed and sold 
in packets for working-class domestic seamstresses who could not afford a tailor's, much less a Dhaka, muslin. And when, in the final term of the series of fabrics, Tess's body is at last a "sensitive gossamer," fin de siècle readers would have recognized the immense popularity of that white, gauzy material in the construction of wedding dresses and nuptial accessories of just the sort that, despite her mother's insistence on the inevitability of their marriage, readers already know that Alec will never offer Tess.

In fact, Alec offers Tess reparations for the rape not in the form of marriage- " On matrimony he had never once said a word" $(82)^{8}$ — but rather in the form of clothes:

"You know you may clothe yourself with the best, instead of in the bald plain way you have lately affected, as if you couldn't get a ribbon more than you earn." ....

"I have said I will not take anything more from you, and I will not-I cannot! I should be your creature to go on doing that, and I won't!" “One would think you were a princess from your manner, in addition to a true and original D’Urberville—-ha! ha!' (77-8)

\footnotetext{
${ }^{8}$ It is worth noting that Hardy here seems to propose a radical revision to the rape of Richardson's Clarissa: where the rake Lovelace proposes repeatedly to the victimized Clarissa Harlowe, Alec merely offers to buy Tess off. When, on the very same page, Tess tells her mother that "Ladies know what to guard against, because they read novels that tell them of these tricks" (82), Hardy conjures the overwhelming popularity of Richardson's Clarissa, which was regarded by its predominantly female eighteenth-century and nineteenth-century reading publics as a warning manual.
} 
Alec likens Tess's refusal of fashion to royal ("a princess") or aristocratic ("a true and original D’Urberville") affect; her resistance to class cross-dressing is inconsistent with what he expects from an impoverished dairymaid faced with such a rare opportunity to play dress-up. But rather than allowing Alec to dress her with mere clothes, Tess redresses herself with the force of fashion: "some spirit had induced her to dress herself up as neatly as she had formerly done, and come out into the fields" (91) to work, as she had so earnestly hoped she would be doing at the D'Urbervilles' home. Even as the "[s]ymbols of reflectiveness passed into her face" (99), that same "spirit within her rose ... bringing with it hope" (100) as she makes her way toward Talbothays' dairy farm knowing that her face, her muslin, and even "the world [were all] drawn to a larger pattern here" (102).

Tess's face does precipitate the marriage proposal she eventually receives not from Alec but from Angel Clare, who meditates on "[h]ow very lovable her face was to him. Yet there was nothing ethereal about it; all was real vitality, real warmth, real incarnation" (150). Angel's emphasis upon the 'realness' of Tess's face is precisely the sort of reality thrown into disproportion that Hardy argues might "show more clearly the features that matter in those realities." But Angel's infatuation with Tess is just as preoccupied with class transvestitism as Alec's was: the set of attributes that make Tess such an attractive spousal candidate to the middle-class Angel are all bound up in her class position. Angel reveals to his parents that Tess "is not what in common parlance is called a lady... But she is a lady, nevertheless - in feeling and nature" (164, italics in original), if not in fashion. 
Angel offers here a revisionary class politics that fragments around distinctly gendered lines. For all of his interest in Tess's material attributes, he nevertheless claims that what constitutes ladyship is divorced from money, social standing, or the material indicators of either. Rather, a lady is determined by her naturally aristocratic affect, which Alec too had attributed to her. While Hardy makes sure that Tess's affective existence cannot be separated from her class position, Angel imagines a very different construction:

This belief was confirmed by his experience of women, which, having latterly been extended from the cultivated middle-class into the rural community, had taught him how much less was the intrinsic difference between the good and wise woman of one social stratum and the good and wise woman of another social stratum, than between the good and bad, the wise and foolish, of the same stratum or class. (165)

For all of his concern with the ethical valuation, material interests, and class positions of women, Angel has the luxury of occupying a position of social privilege he never acknowledges: he is male and solidly middle class. For Joan and Tess Durbeyfield, fashion is a tactic, a vernacular aesthetic and "art of the weak." But Angel is a subject of will and power - a user of strategies that capitalize on his own advantages as a middleclass man - and he cannot see that the reason Tess is not a lady of fashion is because her gender and class positions (and not her wisdom or her goodness) are what made her vulnerable to Alec in the first place. 
When Tess first sees her future husband at Talbothay's dairy farm, she immediately notices that despite his working-class attire, Angel's middle-class accoutrements—-so unlike the hole in her own stocking-heel—speak:

He wore the ordinary white pinner and leather leggings of a dairy-farmer when milking, and his boots were clogged with the mulch of the yard.... Under his linen milking-pinner he wore a dark velveteen jacket, cord breeches and gaiters, and a starched white shirt. Without the milking-gear nobody could have guessed what he was. He might with equal probability have been an eccentric landowner or a gentlemanly ploughman. (111-2)

Hardy had long been interested in contemporary rural working class attire, as his 1883 article on the Dorsetshire laborers (parts of which were actually incorporated into Tess) evinces. In it, he argues that working-class dress was illegible to the Victorian middle classes, who assumed that "light colors mean cleanliness, dark colors mean dirt, and therefore misread two homes" ("Dorsetshire Laborer," 172). Angel's pairing of a "white pinner" and "starched white shirt" with "a dark velveteen jacket" and muddied boots are just such a misreading. Unlike Alec, whose rather elaborate "dandy cap, drab jacket, breeches of the same hue, white neckcloth, stick-up collar, and brown driving-clothes" (52) leave no doubt about his social position, Angel is impossible to class in such a confusing costume: "nobody could have guessed what he was." But fashion reveals Angel's class position to Tess as a stocking-hole that cannot be made to shut up, and his middle-class roots are legible to her instantly: "It was true he was at present out of his 
class... He did not milk cows because he was obliged to milk cows, but because he was learning how to become a rich and prosperous dairyman, landowner, agriculturalist, and breeder of cattle" (125) — and, indeed, after having left his provincial home for Cambridge, Angel had discovered an "unconquerable, and almost unreasonable, aversion" to both the provincial life of his childhood and to urban cosmopolitanism. At the time he meets Tess, he has only very recently turned to agriculture and apprenticed himself to Dairyman Crick.

When Angel begins to pay attention to her, Tess, "having a consciousness that Clare was regarding her, began to trace imaginary patterns on the table-cloth with her forefinger" (120). She inklessly drafts their love story on the coarse fabric; she tells through the touch of her fingers on the cloth. Tess has already fallen for Angel and already decided — while "fitfully beginning to peel 'a lady,"” no less— "to lead a repressed life" (125). When Angel does propose to her, Tess initially rejects his offer. He doggedly challenges her answer, until "she stammered-“"'Your father is parson and your mother ... will want you to marry a lady"” (171). Yet Angel refuses to accept her rejection even on class grounds because the very real, material consequences of class are illegible to him. Tess's astute, fashion-based perception of Angel's class position is anything but reciprocal.

Having finally accepted Angel's offer of marriage, Tess “wonder[s] whether he would like her to be married in her present best white frock"- - her muslin — "or if she ought to buy a new one" (206) for the wedding. But Angel has already ordered her a fashionable, modern wardrobe from "a tradeswoman in London" (206). Tess tries on the outfit that Angel has purchased for her in the novel's second mirror scene: 
She did return upstairs, and put on the gown. Alone, she stood for a moment before the glass looking at the effect of her silk attire; and then there came into her head her mother's ballad of the mystic robe-

That never would become wife

That had once done amiss,

which Mrs Durbeyfield had used to sing to her as a child, so blithely and so archly, her foot on the cradle, which she rocked to the tune. (206)

Tess's outfit, free from stocking-holes, no longer require Joan's material mediation; she is now able to see the full reflection of her body and its "silk attire." And yet her reaction is still inflected by an immediate thought of her mother. Upon seeing herself as a lady of fashion, Tess recalls the eerily prophetic lullaby Joan sang her as a baby. Tess's mirror scenes are bound up in a vexed maternal mediation that produces not misrecognition, but rather revelation. Her new silk cannot but be a "mystic robe," foreboding all the ways in which "this robe" — and not her having "done amiss"_- "should betray her" (206).

\footnotetext{
${ }^{9}$ Further, Tess's silk figures the Indian-Chinese-British triangular trade. In the early seventeenth century, China and Bengal had competed as the main suppliers of raw silk to the international market. But Chinese silk turned out not to be a profitable import to Britain due to freight charges, and because Britain had not developed any domestic sericulture, the East India Company took an interest in Bengal silks. The British launched the cotton trade from India to China and silk trade from China to India in the late eighteenth century, but because silk is already a thread, the silk textile industry was not nearly as affected by the industrial innovations that reshaped the cotton textile industry at the beginning of the nineteenth century.
} 
On their wedding night, Tess hears "noises as of silk smartly rubbed; the restful dead leaves of the preceding autumn were stirred to irritated resurrection" (218). The textile descriptions and textures of dead leaves harken back to the scene of her rape, but so too do they conjure the silk she wears in the second mirror scene, connecting it aurally to Joan's lullaby. Decking Tess out in his family's diamonds in their conjugal bedroom, Angel—suddenly turned fashion consultant—exclaims that "the gown isn't right!" (220), and proceeds to pin and tuck the fabric of Tess's white muslin dress around her body as if she were a mannequin:

As everybody knows, fine feathers make fine birds; a peasant girl but very moderately prepossessing to the casual observer in her simple condition and attire, will bloom as an amazing beauty if clothed as a woman of fashion with the aids that Art can render; while the beauty of the midnight crush would often cut but a sorry figure if placed inside the field-woman's wrapper....

"I think I love you best in the wing-bonnet and cotton frock-yes, that's better than in this, well as you support these dignities." (220-1)

Angel recognizes Tess as exemplary of that first category, but insists that he nevertheless prefers her in her muslin. What Angel elides in this formulation is that Tess actually is still in her muslin. He has simply taken on the role of the tailor, drafting Tess's wedding gown by pinning and tucking the muslin she is already wearing. Angel is not alone in his anxious overlooking of the fact of the fabric: the actress Gwen Ffrançgcon-Davies, in preparing to play Tess in a theatrical adaptation of the novel, asked if she might "add 
some lines she had written about Tess's new clothes which Angel had bought her for the wedding (so that the audience would not think she was over-dressed)" (qtd. in Michie 307). Angel proves to be a much poorer tailor than Alec. He does not know that the muslin should be a draft. Still dressed in her mock wedding clothes, Tess confesses her rape to Angel, though the novel elides this scene of "a woman telling her story" (180). In its place is Angel's reaction: he abandons both Tess and the world of Wessex for Brazil.

\section{ON THE RUNWAY; ON THE RUN}

Angel's imperial emigration takes him a peripheral nation crucial to the global textile industry of the fin de siècle. Brazil had emerged as a key site for the cultivation of cotton over the course of the nineteenth century, and Eric Hobsbawn goes so far as to suggest that Brazil "saved the British cotton industry in the first half of the nineteenth century, when it became the single largest market for its exports - reaching thirty-five percent of them in 1840, mainly to Brazil" (Industry and Empire 125). As coffee and sugar cane production had radically declined and tariffs on textile machinery imported for use in Brazilian factories had been eliminated entirely in 1847, plantation owners invested increasingly in the cotton textile industry in the middle of the century. Brazil became the single largest market for British exports, and the interchange between textile interests of both nations had led to many expert English spinners, weavers, and textile technicians being relocated to Brazil in the second half of the century after the Brazilian slave trade ended in $1850,{ }^{10}$ which improved conditions for textile production even further. This was “especially so after 1870, when depression and foreign competition had forced large numbers of British cotton mills to close.... Many of the managerial jobs [in

\footnotetext{
${ }^{10}$ The institution of slavery in Brazil was not abolished in 1888.
} 
Brazilian factories] were held by English workers, who brought with them a kind of global knowledge of the industry, as well as technical expertise to run imported machinery" (Delson 96).

When Angel moves to Curitiba to take up agriculture, he imagines that he will "acquire a practical skill in the various processes of farming ... or the tenure of a homefarm" (114), envisioning the global South as an agrarian political utopia. But in reality, the abandoned coffee and sugar cane lands of southern and southeastern Brazil had already been given over to cotton cultivation, and Curitiba and its environs would have been dominated not by agriculturalists, but by textile workers - many of them English. Further, "Angel's original intention had not been emigration to Brazil, but a northern ... farm in his own country" (340-1) near Lancashire, which of course also would have been dominated by the cotton textile industry. The global specter of muslin haunts Angel. He can no more escape it in Brazil than he can in northern England, and so Angel returns to the muslined world of Wessex.

"While on the south of the Equator, it had seemed the easiest thing in the world [to Angel] to rush back into her arms" (369), but Tess's circumstances - and by extension, Wessex's - have undergone upheaval in his absence. Due to her mother's life-threatening illness, her father's death, her family's subsequent eviction from their home, the evenmore-extreme poverty to which the Durbeyfield family has now been reduced, and her abandonment by Angel, Tess has been forced to accept Alec's help. Tess is now "pass[ing] as a married woman" (377) with her rapist at Sandbourne, a 
fashionable watering-place, with its eastern and its western stations, its piers, its groves of pines, its promenades, and its covered gardens, ... like a fairy place suddenly created by the stroke of a wand.... An outlying eastern tract of the enormous Egdon Waste was close at hand, yet on the very verge of that tawny piece of antiquity such a glittering novelty as this pleasure city had chosen to spring up. Within the space of a mile from its outskirts every regularity of the soil was prehistoric, every channel an undisturbed British trackway.... Yet the exotic had grown here, ... the winding ways of this new world in an old one. (375-6)

Sandbourne seems to Angel as if it has sprung up magically by the swift "stroke of a wand," but in fact the rural, "prehistoric" Wessex landscape has been reshaped by an increasingly global modernity. Sandbourne is chic and cosmopolitan —a "pleasure city" whose two train stations and pretty pedestrian parks signify much more than urban development. Wessex's formerly "undisturbed British trackway[s]" have been given over to "the exotic" - the unfamiliar, global modern world. But this "new world in an old one" is the "new Wessex announced in 1891," and its "winding ways" are as much marked by the "glittering novelty" of "its piers, its groves of pines, its promenades, and its covered gardens" as by the rapid and seemingly irrational changes of modern fashion.

Angel wonders " $[\mathrm{w}]$ here could Tess possibly be, a cottage-girl, his young wife, amdist all this wealth and fashion?" (376), finding that she is

not at all as he had expected to see her-bewilderingly otherwise, indeed. Her great natural beauty was at last rendered full justice by her attire. She was loosely 
wrapped in a rich cashmere dressing-gown of gray-white, embroidered in halfmourning tints, and she wore slippers of the same hue. (378, emphasis added)

Hardy's searing and bitter irony makes clear that Tess, now paraded out as a lady of fashion, has hardly been done justice. The chic clothes in which Alec has dressed her are a woefully inadequate form of reparation for the rape. Rather Alec has, as Tess accuses him, "made me a victim" (381) of fashion, unable to seek redress for either her sexual fall or her marital abandonment at the hands of these two middle-class men. Alec has preyed on Tess, who is vulnerable to him a second time because of the harsh social realities of the class and gender positions she occupies - positions that Angel, with his theory of natural aristocracy, still does not recognize. He is too caught up in his own concept of Tess's innate ladyship, which he now sees reflected now outwardly in her dress. Tess cannot fathom how Angel could be so daft ("Yet how do you come here if you do not know?" (379) she demands, bewildered), and when she does reveal to him finally the circumstances of her fashionable appearance, Angel once again abandons her after her confession.

Just as Hardy refused to narrate the scene of "a woman telling her story" (180) on Tess's wedding night, so too does he refuse the reader direct access to the novel's climax. The devastated Tess returns to the room she shares with Alec, where

Over the seat of the chair Tess's face was bowed, her posture being a kneeling one in front of it; her hands were clasped over her head, the skirts of her dressinggown and the embroidery of her nightgown flowed upon the floor behind her, and 
her stockingless feet, from which the slippers had fallen, protruded upon the carpet. (380-1)

Tess's face — or "her trump card" (53), as her mother had called it—is hidden, buried in the seat of a chair. Because the face, as Levinas suggests, is what forbids us to kill, Hardy's cloaking Tess's face here prefigures the danger to come. ${ }^{11}$ The position of her body, described in such acute detail, resembles that of prayer. But Tess's hands are clasped around her head where her signature red ribbon had once reigned supreme. Swathes of embroidered fabric stretch out from the back of her body, trailing behind her like the sweeping Victorian wedding train she never wears. Where Tess's stocking-heels once had holes in them, her feet are bare now, revealing a poverty of justice that eclipses what had once been merely a poverty of material.

Tess rushes out to find Angel, who, once again,

did not recognize her under the totally changed attire in which he now beheld her... "I have killed him!... I have done it -I don't know how," she continued.... "I feared long ago, when I struck him on the mouth with my glove, that I might do it some day for the wrong he did me.... My heart could not bear it.... And then I dressed myself and came away to find you." (384-5)

\footnotetext{
${ }^{11}$ In Totality and Infinity, Levinas argues that the human face is the work of justice, enacting of a signification so speedy that its subtle cues can hardly be detected. Building upon this, Deleuze and Guattari argue in $A$ Thousand Plateaus that the face is a white wall/black hole system based on the prototype of black marks etched on a white surface, linking faciality and its demand for justice to textuality.
} 
A fashion accessory - the glove with which she had once smacked her rapist, demanding justice like an eighteenth-century dueler-precipitates the homicide and enables Tess's foreknowledge that she "might do it some day for the wrong he did" her. Killing Alec is a mode of redressing that wrong, but it is unrecognizable as reciprocal justice under the Victorian legal standards would cast Tess's retribution as murder without even so much as a trial, but would not criminalize Alec's rape even despite case law precedents like $R$. $v$. Ryan, R. v. Mayers, and R. v. Young. Hardy's notebooks evince his familiarity with these rape cases, as well as several others; he had researched these trials, and he had mourned their rulings and statutes with righteous rage. ${ }^{12}$

\section{CRIMES OF FASHION}

This tragic culmination brings to the fore the fashion dynamic at the very heart of Hardy's sense of social justice: Tess literalizes redress, donning the lady of fashion clothes that enable her escape by making her unrecognizable even to her own husband. Hardy tags this in her otherwise elision-riddled account of events: Tess “do[es]n't know how" she has killed Alec and the weapon itself is notably absent from her narrative, but

\footnotetext{
${ }^{12}$ R. v. Ryan (1846) affirmed that "where a girl is in a state of utter unconsciousness, whether occasioned by the act of the prisoner, or otherwise, a person having connection with her during that time is guilty of a rape" (Cox, Cox's Criminal Cases 2:115); R. v. Mayers (1872) put forth that "if she was asleep it is against her will ... and he is guilty" (Cox, Cox's Criminal Cases 12:312); and R. v. Young (1878), an appeal case, affirmed the conviction John Young: "that the prosecutrix did not consent before, after, or at the time of the prisoner's having connection with her" (Cox, Cox's Criminal Cases 14:115). Although biographies rarely mention the fact, Hardy served as a local magistrate in Dorchester from 1884-1916, hearing cases ranging from theft to sexual assault.
} 
her "totally changed attire" marks both Hardy's and her own perception of what is most important about her act. Further, because Tess looks so refined on the lam, it does not occur to anyone in Sandbourne or its environs that anything might be amiss. She and Angel pass through inns and manors as they make their way toward London, and even when they are caught squatting, "the caretaker was so struck ... with the elegance of Tess's gown hanging across a chair, her silk stockings beside it, the ivory parasol, and the other dainty habits in which she had arrived, that her first indignation at the effrontery of tramps and vagabonds gave way to a momentary sentimentality" (391). While neither Alec's fancy clothes nor his death can redress the wrongs he has done to Tess, fashion can: her clothes authorize her innocence.

The late nineteenth-century tailor S.S. Gordon, one of the foremost advocates for the modern muslin tailoring method, bemoaned that "thoughtful cutters have, by the force of their experience, become a law to themselves" (6) —not unlike Alec, whose rape of Tess's white muslin figure goes unpunished and unpunishable under the law. Though the issue of correctly tracing and measuring three-dimensional proportions onto twodimensional muslin plagued the new method of tailoring, which was still being perfected in the 1890s, Gordon nevertheless argues that "it is folly to condemn either, per se" (6). Neither set of these mutually exclusive tailoring standards can be entirely done away with precisely because they are no more separate than the set of contradictory justice standards that would hold Tess guilty of murder without even so much as a trial and Alec free from blame for her rape despite case law precedent.

After much running, a physically and emotionally exhausted Tess lays herself on an ancient altar at Stonehenge, where she is squatting when the police arrive to arrest and, 
subsequently, execute her for Alec's murder. The background recalls Hardy's insistence that the novel return to its roots in tragedy and in epic, but it also prefigures the free midsummer solstice Stonehenge Festivals of 1974-1986, where 'New Age' identity was forged. Like Tess, “'New Age’ people have traditionally had a preference for sequestering themselves away from city life, escaping to some form of allegedly benign pre-modern existence.... Many were, and indeed still are nomads" whose "easily identifiable clothing ... are collaged together to create a recognisable identity for the wearers, a form of transnational identity" (Maynard 119-20) like Tess's own muslin forges for her, linking her subjugation to the subjugation of textile workers in India and Brazil. In fact, the Stonehenge Festival helped to shape 'New Age' style, which is, of course, characterized by a return to the long, flowing, cotton garments that "nostalgically embrace the old, the forsaken, the supposedly individualistic, the hand made and the imperfect ... and certain kinds of cheap, imported ethnic textiles” (Maynard 124) like muslin. The annual Stonehenge festival was eventually shut down due to "problems with squatting and other legal infringements [that] caused travelers to be exiled from the site" (Maynard 128) just as Tess herself, a nomad squatting at Stonehenge, is arrested at and exiled from Stonehenge.

Hardy gives us the scene of Tess's arrest, but he never shows Tess in her prison uniform — which, as it were, would have been made of muslin. In addition to its use for tailors' drafts, muslin had found a second, albeit less common, purpose by the century's end: in prison uniforms. One of the few modes of turn-of-the-century fashion exempted from mass manufacture, mass consumption, and aesthetic style, carceral dress "diverges from the history of fashion when the focus is on the quality of design as increased social 
inclusion.... Prison dress only becomes modernist by default" (Ash 5-6), thus sharpening its contrast to the history of fashion and to the history of literature, both of which become modernist through a set of aesthetic techniques. Different modes for the provision of prison uniforms prevailed through most of the nineteenth century, but the Prison Act of 1877—-which transferred direct control of local prisons to Central Government — also standardized British and British colonial carceral clothing. Prison uniforms were now made of stiff cheap, coarse, cotton textiles like muslin, which was "used as a visible bodily punishment inside British prisons during the latter half of the nineteenth century and into the early twentieth century" (Ash 49) until it was abolished in 1920.

Prison uniforms' link to capital punishment had made a strong impression upon Hardy, who often recounted the two executions that he himself had witnessed. ${ }^{13}$ Notably, his memories are absolutely shot through with fashion:

Once I didn't go to see it at all; and I was walking about two miles from Dorchester, and I thought to myself it must be about time that man is being hung,

\footnotetext{
${ }^{13}$ In addition to the account included here, Marie Adelaide Belloc Lowndes - a popular and profilic author, and a dear friend of Hardy's - also recollects an account Hardy gave her of witnessing hangings in which he is similarly preoccupied with a fashion accessory: "Hardy once told me that in his life he had seen three people hanged — two men and a woman — and he had been surprised to note how very quietly and unemotionally they behaved when on the scaffold. But he had been told of a murdered who at the last moment had shaken his feet loose of his shoes, crying out as he did so, 'My mother told me I should die in shoes - and now I have given her the lie!' In those days a condemned man was always hanged wearing his shoes. This seems to have made a painful, indeed a terrible, impression on Hardy. He kept repeating how fearful it was a man, at such an awful moment, should have said such a thing" (Ray 202, 156).
} 
and I had my glasses with me; so I looked at the jail and there I suddenly saw something white drop above the wall. It was the man; he was dressed in white fustian.

The other was as follows: I went there really for a jaunt. The hanging itself did not move me at all. But I sat on after the others went away, not thinking, but looking at the figure (it was a woman) turning slowly round on the rope. And then it began to rain, and then I saw - they had put a cloth over the face- - how, as the cloth got wet, her features came through it. That was extraordinary. (qtd. in Ray 202 , italics in original)

Both executions are curiosities to Hardy until fabric does justice to their affective and social impact. Hardy's nonchalance over the hanged man- "it must be about that time that man is being hung" — quickly gives way to a weighty grief when he sees the man's body dressed in the rough cotton textile. Likewise, Hardy's spectatorship of the second execution "did not move [him] at all" until fabric gives her a face, and in turn, a face value. Fabric turns what had been "really a jaunt" into something "extraordinary" because the materiality of these executed bodies becomes legible in and through material itself.

And so the fabric that Hardy describes at Tess's hanging is not her prison muslin, but rather "something mov[ing] slowly up the staff, and extend[ing] itself upon the breeze. It was a black flag" (397), signaling her execution. Tess's hanged body-like the bodies that Hardy himself had seen executed — is legible only in terms of fabric, but Hardy puts forth a black flag instead of white or, indeed, a broad arrow-marked muslin because both 
the world of Wessex and the world outside of it fail to redress Tess in terms of social justice. Shortly after its publication, Hardy wrote to his friend Frederic Harrison of Tess "justice has never been done to such women in fiction" (Selected Letters 68). In the novel's final paragraph, “Justice' was done” (397)—but not ironically, as that merciless line has so often been read. Tess has "at last [been] rendered full justice by her attire," because by refusing to show her in prison muslin Hardy refuses to criminalize her act.

Tess is executed against the backdrop of a rapidly modernizing "city they had just left, its more prominent buildings showing as in an isometric drawing.... Against these far stretches of country rose, in front of the other city edifices, ... one blot on the city's beauty" (397) — a blot that is Tess Durbeyfield's executed body swinging from the gallows. Tess's body punctuates the "landscape beyond landscape" (397) of an earlier, pre-modern Wessex that recedes into history because "it was with this blot, and not with the beauty" that Hardy is most concerned. Tess's muslin thus makes possible Hardy's simultaneously political and aesthetic experiment: Hardy stitches muslin into Tess, and in turn, muslin stitches to Tess into a world. Tess becomes Hardy's angel of history, and her muslin rouses the Victorian novel from the nightmare of history from which it is trying to awake. 


\section{Chapter Two}

\section{Henry James's Social Fabric in The Princess Casamassima's Atelier}

“Come here, little boy, and show me your extraordinary jacket!” said the celebrated English novelist William Makepeace Thackeray to the precocious, elevenyear-old Henry James in 1854. In A Small Boy and Others, James recalls that

the great Mr. Thackeray had come to America to lecture on The English Humorists, and still present to me is the voice proceeding from my father's library, in which some glimpse of me hovering, at an opening of the door, in passage or on staircase, prompted him to the formidable words.... My sense of my jacket became from that hour a heavy one-further enriched as my vision is by my shyness of posture become the seated, the celebrated visitor, who struck me, in the sunny light of the animated room, as enormously big and who, though he laid on my shoulder the hand of benevolence, bent on my native costume the spectacles of wonder. I was to know later on why he had been so aroused and why, after asking me if this were the common uniform of my age and class, he remarked that in England, were I to go there, I should be addressed as 'Buttons.' It had been revealed to me thus in flash that we were somehow queer [.] (46)

The encounter yoked together for James a series of complex relationships that he would spend much of The Princess Casamassima-his anomalous 1886 novel of working-class 
London, the New Woman, transatlantic cultural flow, economic inequality, and anarchist revolution - disentangling: the legacy of a Victorian realist tradition he both honored and resisted; the shifting politics of national identity formation at the turn of the century; the inextricability of class from the construction of gender; and one powerful social practice through which they coalesced-dress. Thackeray's nickname did not stick when James did find himself living in England over thirty years later, but James's "heavy" sense of clothing did. And so it was to jackets and buttons that he turned his attention in Princess — which, as James writes in his 1908 New York Edition Preface, "proceeded quite directly, during the first year of along residence in London, from the habit and interest of walking the streets" (33) as a newly minted and self-consciously "somehow queer" American ex-pat.

Those streets were often the very same ones that Thackeray himself had wandered. In early December of 1885, while writing Princess, James signed a twenty-one-year-long lease in Kensington - a neighborhood that he would describe one year later as "Thackerayan, with its literary vestiges" (qtd. in Edel 159). Kensington was in transition: a few decades earlier, when Thackeray had lived there, it had been a distinctly suburban neighborhood. But by the time of James's residence, it had become much more cosmopolitan, and James describes its "pompous red palace, its square of Queen Anne, its house of Lady Castlewood, its Greyhound Tavern” (qtd. in Edel 159). Although James's description of Kensington hardly resembles Princess's working-class East London, the "attentive exploration of London, the assault directly made by the great city upon an imagination" (33) that he articulates in his 1908 preface to Princess brought him, imaginatively, from Kensington to Lomax Place. 
Because Princess thematizes the denizens of a poverty-stricken East London, it comes as no surprise that scholars including Nies, Kimmey, Oltean, and Scanlan have compared it to Dickens's Victorian novels of the London poor. But James actually turns to Thackeray and not to Dickens in his preface to Princess to explain his interest in London's working-class communities — in the "heavy sense" of feeling "somehow queer," in the Victorian social effects of "the hand of benevolence" and "the spectacles of wonder" that he himself had experienced in his youth at Thackeray's pronouncement. For Princess, "the most general state of one's most exposed and assaulted" (38) self is akin to James's own experience of Thackeray's fashion policing — that "condition," he writes in the preface, "on which Thackeray so much insists in the interest of his exhibited careers" (39, emphasis in original). Thackeray's brand of Victorianism would make Lomax Place into a slum. But James's modernism makes Hyacinth Robinson's childhood home a place where, as Kent Puckett argues, "smutches and streaks signify poverty more than gross us out" (136, italics in original) because every description the interior of Lomax Place is directly tied to its dual status as both a domestic space and as the atelier of the dressmaker Amanda Pynsent, Hyacinth's adoptive mother. Fashion enters into the novel in its opening scene not as a descriptive mode, but rather as a shadow of a modernity in which aesthetics and politics are inseparable. The novel's second sentence reveals "the humble dressmaker" (53) Pinnie's

small parlour, which she had been ashamed to exhibit in so untidy a state, with paper 'patterns' lying about on furniture and snippings of stuff scattered over the 
carpet - she came out of this somewhat stuffy sanctuary, dedicated at once to social intercourse and to the ingenious art to which her life had been devoted. (53)

Pinnie's parlor is "dedicated at once to social intercourse and to the ingenious art," grounded in equal parts upon hospitality and fashion much like Princess, itself. But James worries about the relationship between Pinnie's project and his own. Even as he celebrates an aesthetic so powerful as to be "ingenious" and a social space so empowering as to be a political "sanctuary," he qualifies that optimism by characterizing Pinnie's parlor as "small," "untidy," and "stuffy"-still a distinctly Victorian world of fashion, and not quite yet the modern refashioning of the world for which Princess strives.

James reveals Pinnie's parlor in the novel's opening scene because the "high and rather terrible personage" (53) Mrs. Bowerbank—a prison warden— has arrived in it. ${ }^{1}$ The prison guard visits Lomax Place to alert Pinnie that Florentine Vivier- the birth mother of her adopted son, an impoverished French milliner who murdered Hyacinth's aristocratic English father-is on her deathbed in prison, and that her dying wish is to see her son. The young Hyacinth Robinson does not know anything about his origins because Pinnie has, since the time of his adoption, "use[d] the arts of prevarication; she was a kind an innocent creature, but she told fibs as freely as she invented trimmings" (58). James's somewhat canned foundling plot is a strange fusion of Fielding's Tom Jones and Flaubert's Frederic Moreau, but in the bringing together here of fabrication and fabric in

\footnotetext{
${ }^{1}$ According to Lucia Zedner, there were no female wardens in British prisons until 1883-which means that, historically speaking, Bowerbank could not actually have existed in this scene early in The Princess Casamassima.
} 
Pinnie's concealment of Hyacinth's genealogy, James makes Pinnie the author of a new and modern kind of foundling plot. The aesthetic techniques and methods she has mastered through her work in dressmaking ("she told fibs as freely as she invented trimmings" (58)) serve her equally in the intricate weaving of a story about Hyacinth's birth, the "untrimmed truth" (68) of which her trusted friend Mr. Vetch has already guessed when she consults him for advice about the dying inmate's plea. Vetch questions the extraordinary generosity of Pinnie's adoption of Hyacinth in the first place, and Pinnie explains that she "didn't want to be good. That is, I do want to, in a general way: but that wasn't the reason then. But I had nothing of my own-I had nothing in the world but my thimble" (71). Pinnie's kindness is not motivated by the Thackerayean Victorian morality that Vetch imagines, because "the humble dressmaker ... had never been conscious of an exemplary benevolence" (53). Rather, her desire to make of her thimble a world leads her to take Hyacinth in; Pinnie sincerely believes that her thimble is enough, in the quintessentially Jamesian phrase, to see them through. Her thimble protects this new kind of domestic space "dedicated at once to social intercourse and to the ingenious art" (53) in which she fashions a modern family.

Vetch recognizes the thimble solely as the sign of her poverty, and somewhat snidely responds that a lone thimble "would have seemed to most people a reason for not adopting a prostitute's bastard" (71). Though she may have "nothing in the world" but fashion, Pinnie's unshakeable faith in fashion's capacity to build social community does not waver, not even when Vetch tells her that if she takes Hyacinth to see Florentine,

"he will, in his imagination (and that will always persuade him), subject 
you to some extraordinary metamorphosis; he will dress you up."

"He'll dress me up!" Amanda ejaculated, quite ceasing to follow the train of Mr. Vetch's demonstration. "Do you mean that he'll have the property—-that his relations will take him up?"

"My dear, delightful, idiotic Pinnie, I am speaking in a figurative manner."

Although well-intentioned and affectionate, Vetch is almost unbearably condescending toward Pinnie, dismissing her literal reading of his "figurative manner" as so much adorable feminine naïveté. But the two modes of "dressing up" are not so far apart, and James shares Pinnie's insistence on making the metaphor material. As Pinnie has pinned and tucked the truth of Hyacinth's birth, telling "fibs as freely as she invented trimmings" (58), so will Hyacinth revise his understanding of his childhood and of his adoptive mother, the little dressmaker whose political work goes unrecognized, after the revelation of his birth. Hyacinth's revision—his “dressing up" of Pinnie—gives form to James's own dressing up, his "subject[ing] to some extraordinary metamorphosis" of modernity the political valence of Pinnie's parlor.

In fact, the opening scene in Pinnie's parlor actually restages James's own vivid memory of Thackeray's fashion policing as he recounts it in A Small Boy and Others. Through Hyacinth, James redresses the social wrongs of Thackeryan Victorianism, throwing Princess, "with a passion, into being 'modern"” (259). Upon Mrs. Bowerbank's arrival at Lomax Place in this opening scene, "the door of the room creaked open and a small boy stood there gazing at her" (61) just as, in A Small Boy and Others "the 
celebrated visitor" Thackeray catches a "glimpse of [the young James, a small boy] hovering, at an opening of the door" (46). Like the "enormously big ... great Mr. Thackeray ... who laid on my shoulder the hand of benevolence" while critically inspecting the young James's "extraordinary jacket," the "high-shouldered, towering" (55) Mrs. Bowerbank observes the peculiarities of Hyacinth's outfit:

her eyes descended to the details of his toilet: the careful mending of his short breeches and his long, coloured stockings, which she was in a position to appreciate, as well as the knot of bright ribbon which the dressmaker had passed into his collar.... [H]er visitor was obliged recognise that she had the highest standard in respect to buttons. (63)

So unlike James's own button-prompted humiliation, Hyacinth, dressed like "a little nobleman" (63), is confident in the excellence of his buttons, which Mrs. Bowerbank identifies as being of "the highest standard." Where the young James's "sense of my jacket became from that hour a heavy one," resulting in his embarrassed selfconsciousness as a young American boy that he was "somehow queer" (A Small Boy 46), Hyacinth responds to Mrs. Bowerbank's fashion policing with "a strange, cool conscious indifference" (61), asking "Do you want to see me only to look at me?” (63). Hyacinth's astute awareness of the modernity of his own appearance "had much of the force of satire, ... for it is a remarkable fact that even at the age of ten Hyacinth Robinson was ironical" $(63,61)$. And much of the modernist irony of Princess lives James's resetting of the 
Victorian scene, his refashioning of its structures of power, and his "throw[ing the novel], with a passion, into being 'modern"' (259).

The (independently wealthy, American) young James had met the (male, English) author Thackeray discussing the (male) "English humourists" in his (male, American) father's library, a space shot through with Victorian literary heritage. But the (workingclass, English) young Hyacinth meets the (female, English) Mrs. Bowerbank discussing his (female, French) birth mother in the "somewhat stuffy sanctuary" of his (female, English) adoptive mother's dressmaking atelier. The encounter with Thackeray is subjected to a four-fold transvestitism that is both literal and figurative: female replaces male; poverty replaces wealth; transnational replaces national; fashion replaces literature. James inverts all the terms of privilege because if Hyacinth Robinson is to be read as a figure for James himself, then he is a figure "save indeed for one little difference":

This difference would be that so far as all the swarming facts should speak of freedom and ease, knowledge and power, money, opportunity, satiety, he should be able to revolve around them but at the most respectful of distances and with every door approached shut in his face. For one's self, all conveniently, there had been doors that opened - opened into light and warmth and cheer, into good and charming relations; and if the place as a whole lay heavy on one's consciousness there was yet always for relief this implication of one's lucky share of the freedom and ease[.] (Princess 34) 
If "the place as a whole lay heavy on one's consciousness," it is in the same way that James's sense of his jacket after the encounter with Thackeray was "from that hour a heavy one." For all that the young James had felt "somehow queer" in the face of Thackeray's fashion policing, his sense of his outsider status is tempered by the knowledge that "[f]or oneself, all conveniently, there had been doors that opened." James is the humbled, heedful recipient of a "lucky share of the freedom and ease" that comes with class privilege, male gender, transatlantic mobility, and his own status as a gifted designer of text and not textiles.

Princess wonders how the modern novel might redress those who hover in doorways, experiencing that same heaviness, "save indeed for one" —or two, or three"little difference[s]" like class, gender, and nationality. If both James and Hyacinth hover in doorways before celebrated visitors who critique their buttons, those doors are ultimately opened to the author and not to his avatar, for whom "every door approached [is] shut in his face." That "little difference" is, of course, anything but small, and James's irony underscores Princess's modernity. When James characterizes Princess as a "more or less gothic text" (36), it is at least in part because the specter of his encounter with Thackeray — which stands in for the quintessentially Victorian, anti-modern mode of being in the world - haunts the novel, in which the "freedom and ease, knowledge and power, money, opportunity, satiety" that modernity promises are hard-fought battles.

This was subject matter that James had not previously explored, and to which he never returned. Deeply engaged with the most pressing social and political questions of its day, James had hoped that Princess would garner both critical acclaim and popular attention. Yet James's most politically radical novel has most often been understood, as 
the title of a contemporary review called it, as "A Slumming Romance" — an irksome and even invidious hiccup in a career all too often understood as apolitical. Recently, a number of scholars have challenged such thinking, reconsidering the claim that James “did not in any way represent that movement as it existed in the 1880's or at any other time" (Woodcock 223) in Princess. Noting that James's dear friend, the celebrated author Ivan Turgenev, had met both Bakunin and Kropotkin and had spoken with James extensively about his encounters with these important leaders of the movement, Barbara Melchiori reads Princess as a "dynamite novel," an 1880s subgenre of sensation fiction that treats political terror. Further, historicist readings like Christine DeVine's have set Princess alongside contemporaneously published articles in the London Times to show the ways in which James was thoroughly aware of political events of the day-including especially an 1884 conspiracy to assassinate the German emperor during a state visit to England, which fell apart when one of the collaborators withdrew-and deployed them as a launching pad for the novel's plot. Similarly, Kent Puckett traces the revisions in James's political vocabulary between the 1885-6 serialized version of the novel in The Atlantic Monthly and New York Edition of 1908 in order to show James's heightened awareness of and sensitivity to the novel's political project and its key terms.

But much of this recent work on Princess has recuperated the novel on the basis of its historicity, rather than tracing the ways in which the aesthetic and political dimensions of the text are disentangleable. This critical preoccupation with James's fidelity or infidelity to historical and political fact is due at least in part to the fact that the novel's thematic concerns are so atypical of James's oeuvre. But to isolate Princess's thematic concerns from its literary ones is to fundamentally misread James because, as 
Margaret Scanlan so aptly puts it, Princess's is "an exploration of a terror shared by novelist and revolutionary that, no matter how they plot, they will never change the world" (382). And as it turns out, the novel's world-changers are not, in fact, its socialist revolutionaries. Rather, they are its transnational female fashion workers-Amanda Pynsent, the forward-thinking "humble dressmaker" (53); Florentine Vivier, the imprisoned but empowered French milliner-murderess; Millicent Henning, the upwardly mobile cockney London shop-girl; and Christina Light, the American fashion icon turned cosmopolitan European princess turned class transvestite.

Most considerations of James's relationship to fashion have been similarly enamored of pointing out the historical accuracies (and inaccuracies) of James's characters' costumes. The paucity of criticism on fashion in Princess in particular is especially striking, given that three of its female protagonists work in the fashion industry. While Mike Fischer notes in passing that Hyacinth uses fashion to "swaddl[e] his past in disguises" (94) and Puckett briefly considers Hyacinth's “idea of dress" (104), only Clair Hughes's chapter on hats in Princess in her ur-text on James and fashion, Henry James and the Art of Dress, offers a sustained reading of the novel's engagement with fashion. Although her work brings an immaculately well-researched costume history to bear on James, she nevertheless "operates within fairly familiar interpretative paradigms, ... [offering] local illuminations rather than revisionary readings" (Rawlings 89.) Hughes ultimately falls into the same argumentative trap as the critics who read Princess on the grounds of its fidelity to historical fact: while it is certainly interesting to reveal the ways in which James himself was (or was not) a meticulous historiographer with a keen eye for 
fashion, Princess is no more a history of political movements than it is a history of styles of dress.

Although Princess is his most fashion-obsessed novel - according to Hughes, the text contains more dress references than any other of James's novels_-James's thinking in the 1880s even before the writing of Princess is notable for its attention to dress as a technology of fabricating modernity. "The only reason for the existence of a novel," writes James in his celebrated essay "The Art of Fiction," "is that it does attempt to represent life. When it relinquishes this attempt, ... it will have arrived at a very strange pass" (166). But James also recognizes that modern "reality has a myriad forms" (161), which are shaped as much by aesthetic style as by historical and material conditions. Thus, "[i]t is as difficult to suppose a person intending to write a modern English novel as to suppose him writing an ancient English novel: that is a label which begs the question" (175). But if modern fiction is to live up to the "only obligation to which in advance we may hold a novel[:] ... that it be interesting" (170), then the question in turn begs the very label "modern."

In his 1908 New York Edition Preface to Princess, James reflects that, "This in fact I have ever found rather terribly the point - that the figures in any picture, the agents in any drama, are interesting only in proportion as they feel their respective situations" (35, emphasis in original). He elaborates on this turn toward affect by employing a fashion simile, making feeling akin to thread in the stitching together of both novels and necklaces: 
My report of people's experience — my report as a 'story-teller' — is essentially my appreciation of it, and there is no 'interest' for me in what my hero, my heroine or anyone else does save through that admirable process [of feeling].... I then see their 'doing,' that of the persons just mentioned, as, immensely, their feeling, and their feeling as their doing... There we have then at once a case of feeling, of ever so many possible feelings, stretched across the scene like an attached thread on which the pearls of interest are strung. (38-9)

Readerly interest, James argues, cannot be emotionally detached, and he articulates the necessity of emotional investment through a fashion accessory. Further, because James equates "feeling" with "doing," affect becomes action — and in this way, James refashions modern forms of social agency in and through fashion, itself. Fashion, then, is a distinctly political structure of feeling in Raymond Williams's sense, negotiating an affective dialectic between material culture and cultural materialism. Detecting impulses and experiences that are not yet organized — that are, like modernity itself, "still in process"fashion allows for the aesthetic representation of what Williams calls "specifically affective elements of consciousness and relationships: not feeling against thought, but thought as felt and feeling as thought" (Marxism and Literature, 132). Williams's turn of phrase echoes James's own from the preface to Princess: “I then see their 'doing'... [as] their feeling, and their feeling as their doing" (38). And like James, Williams chooses "feeling" carefully; structures of experience, he acknowledges, might serve as an alternate definition. But "experience" conjures "that past tense which is the most 
important obstacle to recognition of the area of social experience which is being defined" (Marxism and Literature, 132), necessarily, as modern.

Similarly, James writes in his preface to Princess that "[e]xperience is our apprehension and our measure of what happens to us as social creatures" (37): it carries with it all the weight of that which has been understood and categorized, apprehended and measured, rather than that which Williams notes is "often indeed not yet recognized as social, but taken to be private, idiosyncratic, and even isolating" (Marxism and Literature, 132). Because of this, both James and Williams think structures of feeling have a special relevance for literature. Williams goes on to explain that,

This process can be directly observed in the history of language.... What really changes is something quite general, over a wide range, and the description that often fits the change best is the literary term 'style'.... Similar kinds of change can be observed in manners, dress, building, and other similar forms of social life.

Style is for Williams as for James a dialectical product, "a way of defining forms and conventions of art and literature as inalienable elements of a social material process" (Marxism and Literature, 133) of representing aesthetically the lived, subjective experience of modernity. Because Williams traces historical shifts in styles of representation, he recognizes literary style working in parallel with sartorial style insofar as "[s]imilar kinds of change can be observed in ... dress." 
But James's analysis has a slightly different valence. He sees style as a term that is as deeply embedded in the sartorial as it is in the literary. This, as he writes in Princess's preface, "is the charming, the tormenting, the eternal little matter to be made right, in all the weaving of silver threads" (41, italics in original). James understands literature's relation to those "social material process[es]" (Marxism and Literature 133) of modernity as one of redress - that "eternal little matter to be made right" — which might be achieved through literary mediation, or "the weaving of silver threads" of fiction. If narrative style is best equipped to represent modern social consciousness, Princess asks, might sartorial style be best equipped to materialize it? Might material culture and material conditions in this way together form the social fabric of modernity? How can the novel write social wrongs — and can it, in so doing, help to right them?

\section{The Fashion Police}

Elizabeth Carolyn Miller convincingly argues that the opening scene of The Princess, in which Mrs. Bowerbank visits Lomax Place and critiques Hyacinth's clothes, stages fin de siècle female criminality. But the scene also stages fashion itself as the "somewhat stuffy sanctuary" (53) where aesthetic and political feeling are inseparable from one another. Further, fashion makes female criminality legible as such because a dressmaker's atelier is the site of the revelation that Florentine was convicted of the murder of Hyacinth's aristocratic father. As Scanlan writes, "[Hyacinth's] mother, the murderess with the knife, is substituted for Pinnie, the seamstress with her needles and scissors" (Scanlan 390). But Florentine, who had worked as a milliner before her imprisonment, has quite a bit of professional expertise with needles and scissors too, and 
her previous employment in the fashion industry is underscored by the site of the revelation and by Pinnie's own profession. Even Mrs. Bowerbank, who delivers the news of Florentine's impending death in prison, is sized up as a mannequin: "Amanda reflected that she must be very difficult to fit, and had a sinking idea of the number of pins she would take" (55).

The fact of Florentine's crime is cloaked in the idea of redress from its very introduction: Pinnie insists that Florentine "wasn't low when I worked at the same place with her" (57), and upon learning that Florentine's dying wish is a kiss from her son, Pinnie, "with her pity gushing up again," murmurs "“Ah, poor desolate woman!"” feeling that "the arm of the law was stretched out to touch her" (59), too. To deny Florentine her son's kiss seems to Pinnie a form of cruelty so profound that it would constitute crime, and "Miss Pynsent defended herself as earnestly as if her inconsistency [in deciding whether or not to bring Hyacinth to the prison] had been of a criminal cast" (71).

Pinnie had agreed to adopt Hyacinth nine years earlier, while Florentine had been imprisoned at Newgate, a Victorian facility that was located close to the Old Bailey criminal courts and one at which prisoners were held while awaiting trial during the Victorian period. Florentine "was [now] serving out the sentence that had been substituted for the other (the unspeakable horror) almost when the halter was around her neck" (65), a death sentence that—in James's turn of phrase — would have made her a victim of fashion and its halter neckline. Florentine is instead sentenced to lifelong imprisonment, but James never names the particular dreadful institution at which Florentine serves out her sentence. "All [Pinnie] knew, all she wished to know" of 
Florentine's post-trial whereabouts "was that [she was] in one of the dreadful institutions constructed for such purposes" (65).

As Pinnie and Hyacinth approach the prison, "they saw it lift its dusky mass from the bank of the Thames, lying there and sprawling over the whole neighbourhood" (79). The description echoes Millbank — the prison James himself had visited in early December of 1884 to research the scene-which was located on was on the left bank of the Thames, close to Vauxhall Bridge. The land had been purchased for the building of a prison in 1799, though the construction did not begin for two more years. In 1890, only seventy-four years after its opening and only four years after the publication of Princess, Millbank Prison closed its doors. It reopened seven years later as the National Gallery of British Art — today, the Tate Britain. The prison was modeled from Jeremy Bentham's designs for the panopticon prison, shaped like an octagonal asterix with eight different buildings radiating off of a common center-a structure of surveillance that Foucault famously charted, examining the regime of disciplined bodies. ${ }^{2}$

Millbank was the site of a Benthamite experiment not only in architectural design, but so too in fashion. Bentham's panopticon extended bodily discipline to prison uniforms. He had argued that prisoners should be dressed according to the crime for which they had been convicted, making their particular crimes immediately identifiable

\footnotetext{
${ }^{2}$ Mark Selzer, following Foucault, has claimed that panoptical surveillance is Princess's most fundamental organizing principle. Selzer grounds his argument in what he reads as James's emphasis on vision in the novel; I want to suggest, by contrast, that a focus on touch and feel reveals a very different relation to panoptic surveillance in the novel. Furthermore, Selzer neglects to mention that Millbank was a women's prison - a fact that cannot but implicate gender in the forms of panoptic surveillance he traces.
} 
to guards and treating fashion as a form of regulation and policing. In 1819, Parliament enacted a bill entitled "Rules and Regulations to be Observed and Enforced from the Government of the General Penitentiary, Millbank," which included a section that specifically addressed prison uniforms. Prison dress, the bill proclaimed, was to be "made of cheap and coarse materials, with such marks or peculiarities, as may tend to facilitate discovery in case of escape. The two classes of prisoners shall be distinguished by different clothing” (qtd. in Ash 45). James biographer Leon Edel notes that on James's own visit to Millbank, he "was conducted through a stony court in which female figures dressed in brown misfitting uniforms and hoods marched in a circle" (Henry James: The Middle Years, 148), their bodies regulated by a disciplinary drill as much as by a disciplinary dress.

Unlike many other nineteenth-century prisons, it was common practice at Millbank to use punitive dress for female prisoners. Prison dress historian Juliet Ash explains that, "at Millbank, there was an inherent disjuncture between the visually nonpunitive servant's dress and the material restraint of the straight jacket that constrained women behind closed doors. This gender distinction is consistent with Bentham's Utilitarian system whereby the authorities registered knowledge about the nature punishment appropriate to the individual prisoner within the broader ideological construct of groups of male and female working class criminals" (45). Further, Henry Mayhew's 1862 Criminal Prisons of London and Scenes of Prison Life offers a particularly 
harrowing account of the use of straight jackets on female prisoners, ${ }^{3}$ but also tellingly reveals that the form of fashion policing most troubling to women convicts was actually the shaving of their heads:

"Oh, yes, they'd sooner lose their lives than their hair!" said the warder, in answer to our question as to whether the females were cropped upon entering the prison. "We do not allow them to send locks of the hair cut off to their sweethearts; locks, however, are generally sent to their children, or sisters, or mother, or father, and leave is given to them to do as much; they are allowed, too, to have a lock sent in return, and to keep it with their letters... The locks of hair sent out," adds the officer, "must be stitched to the letters, so as not to come off in the offices." (272)

3 "This dress was fastened by a belt and straps of the same stuff, and, instead of an ordinary buckle, it was held tight by means of a key acting on a screw attached to the back. The girl had been tearing her clothes, and the coarse canvas dress was put on to prevent her repeating the act.

The matron had a canvas dress brought out for our inspection; and while we were examining it a noise of singing was heard once more, whereupon the warder informed us that it proceeded from the lady in the dark cell, who was getting up a key or two higher. The canvas dress we found to be like a coarse sack, with sleeves, and straps at the waist — the latter made to fasten, as we have said before, with small screws. With it we were shown the prison strait-waistcoat, which consisted of a canvas jacket, with black leathern sleeves, like boots closed at the end, and with straps up the arm.

The canvas dress has sometimes been cut up by the women with bits of broken glass. Formerly the women used to break the glass window in the penal ward, by taking the bones out of their stays and pushing them through the wires in front." (272) 
The raped locks of female prisoners are quite literally sewn into text; their letters reveal the material trace of their bodily refashioning. Thus, the woman inmate's material body is not lost in the text, because her style of writing — like James's own in Princess — quite literally weaves the snipped scraps of felt material into literary style.

As Mrs. Bowerbank leads Pinnie and Hyacinth down the labyrinthine halls of the prison, Pinnie is preoccupied with the unmerciful cruelty of female prisoners' dressespecially their awful headwear: "dreadful figures, scarcely female, in hideous brown, misfitting uniforms and perfect fright of hoods ... with dowdy untied bonnet[s, ]... whitefaced women in tight, sordid caps, on whom, in the stale, ugly room, the sallow light itself seemed to rest without pity" (82-3). Pinnie notes the absence of style, of beauty, of fashion, which is itself a social crime against "white-faced women." Florentine in particular strikes Pinnie as “cruelly misrepresented by her coarse cap and short, rough hair" (84), as she is likewise cruelly misrepresented in the English language — which she refuses to use. "She won't speak nothing but French" (85), Mrs. Bowerbank explains to the bewildered pair, who cannot understand Florentine's speech. When Hyacinth, under pressure from a traumatized Pinnie, finally kisses the dying woman he does not know is his birth mother, Florentine's "rude crop of hair" is visible as "the poor dishonoured head pressed itself against his young cheek" (88).

Miller points out that "Pinnie remembers Florentine Vivier as the lively woman that her name suggests, 'pretty' and 'her idea of personal [. . .] brilliancy,' now 'there was no beauty left in the hollow, bloodless mask that presented itself.' These descriptions tap into late-Victorian social scientists' theories of female deviancy" ("Inward Revolution," 150). Furthermore, these descriptions are also linked to James's fashion-feeling dialectic. 
For example, what Mayhew describes as the "peculiar brown cloth cap, and the peak of this hangs so low down as to cover the face like a mask" (141) which was often used as a tool of bodily surveillance at Millbank appears in Princess when James describes

Florentine's face as a "hollow, bloodless mask," suggesting that her face has taken on the shape of the cloth that would hide it. The mask was designed to degrade the prisoner, obliterating facial affect and thus dehumanizing its wearer. Florentine has so thoroughly internalized the feeling of her corporeal fashion victimization that she has actually externalized it.

Pinnie's horror at Hyacinth's refusal to kiss her is borne at least in part from her sense of the criminality of her own equivocation: "She had told him that the poor woman was good" (84), but "Pinnie says she stole a watch!" (87) — a lie that upsets Florentine so profoundly as to prompt her only speech in English. "[W]ith dilated eyes and waving hands," Florentine screams out, “'Ah, quelle infamie! I never stold a watch, I never stold anything — anything!'” (87). Florentine insists upon the fundamental dignity of her crime: petty theft, she insists here, is a far greater offense than her murder of Lord Frederick. In this regard, Florentine's murder resembles a revolutionary political assassination, insofar as it involves a French proletarian assailant, an aristocratic victim, and a premeditated stab in the back. And like a revolutionary political assassination, Florentine's act is founded upon a theory social justice: the murder of a jilting, wealthy lover is a form of redressing the political circumstances of a patriarchal capitalism that allowed him to treat her as a prostitute and then abandon her.

Hyacinth and Pinnie's visit to Millbank occurs when Hyacinth is ten years old, which - since the novel is contemporaneous to the moment of its writing, and since 
"nearly ten years" (98) pass between this episode the rest of the novel's diegetic frameplaces their prison trip roughly in the early 1870 s. This timeline is actually quite significant for James's and Pinnie's shared preoccupation with the female prisoners' headwear. As Trevor May notes, by the fin de siècle "[a]ttempts made by prisoners to improve their physical appearance were generally approved as a sign of returning femininity"; by 1907, "the Visiting Committee at Aylesbury prison reported ... that women should be encouraged "to do their hair in any becoming and neat way they please"' (35). Situating the trip to Millbank at this particular historical moment in the early 1870 s - one where hair-cropping was on the cusp of eradication, but had not yet been fully done away with — brings to the fore a series of debates that swirled around Victorian women's hair at the turn of the century.

Preraphaelite art had made long, cascading, Botticelli-esque curls—reminiscent of Hyacinth's own "abundant curly hair, which grew thick and long, had the golden brownness predestined to elicit exclamations of delight from ladies when they take the inventory of a child" (62) — wildly popular among Victorian women during the 1870s. Galia Ofek has argued that, “in Victorian England, women's hair turned into a salient focal point as fashion dictates and social mores prohibited bare hands, legs, and other parts which were covered for modesty's sake, thereby turning hair, neck and shoulders into the 'focus of sexual interest"' (3). In fact, hair was bound up not only in the eroticization of middle-class Victorian women, but so too in the emerging figure of the cosmopolitan New Woman. In 1881, Household Words published a short piece entitled "Cropped Hair," evincing the pixie cut's increasing association with the figure of the 'mannish' New Woman and her destabilization of gender, underscoring the voluntary 
cropping of hair as a historical phenomenon particular to the fin de siècle: "Only a few years back it was all the fashion to wear a great deal more hair than one head could possible grow at once; now ... [it] is to wear no hair at all, to cut it off short like a man's... Why, in the name of common sense, should all girls in Britain cut off their beautiful hair?" (456).

The Household Words article, much like Ofek's contemporary study of hair in Victorian culture, rarely considered cropped hair in its enforced context: as a form of corporeal punishment. By 1885 — the same year as Princess's publication-Herbert Spencer understood women's hair as a sign of "both political and domestic loyalty" (I: 268), inextricably bound up in questions of nation, empire, and treason. Although he never discusses female prisoners in particular, Spencer's point is hugely salient for the practice of hair-cropping in English prisons: if the long, flowing curls of Victorian women's hair styles marked female loyalty to the state and the short, cropped locks of the New Woman marked female rebellion against Victorian norms, the practice of prison hair-cropping signals the bodily disfigurement that attends perceived betrayal of state ideologies. Female prisoners' pixie cuts were hardly the stuff of the New Woman's political fashion statement; rather, as Mayhew's interview with the warden reveals, haircropping executed the incredible trauma of state-enforced humiliation.

In addition to stripping female inmates of a sense of national identity, haircropping further stripped women prisoners of their gender identity on two distinct levels: first, it was a corporeal punishment applied unilaterally to both sexes - " [o]n entry to prison, women (like men) were obliged to have their hair cut" (May 35) — and second, it refigured female bodies to resemble those of prepubescent boys of just Hyacinth's age 
when he makes his visit to the prison. The resemblance between Hyacinth and Florentine_-“It's the very face of her over again!” (62), exclaims Mrs. Bowerbank—is further underscored by Florentine's boyish hair cut in contrast to Hyacinth's wavy, flowing mane. And in fact, Mrs. Bowerbank's appeal to the pleasures of seeing Hyacinth's hyacinthine hair is what finally had convinced Pinnie to bring him to Millbank: "“Certainly, in her place,"” she says, "'I should go off easier if I had seen them curls"' (63-4).

Where Thomas Hardy refuses to recognize Tess Durbeyfield's murder of the aristocrat who rapes and impregnates her as criminal by never showing her in prison clothes, James presents Florentine — who commits precisely the same act - as "disfigured and ugly" in her "coarse cap and short, rough hair" (84). Princess shows Hyacinth his mother, and explains thereby why fashion should mean so much to him. James insists vehemently in this scene that the fashion policing to which Florentine is so brutally subjected in prison does not redress any of the wrong that she may have done in murdering Hyacinth's father. The punishment seems hardly to fit the crime, as Pinnie herself thinks when she and Hyacinth approach the prison: "why," she wonders, "should a prison ... have such an evil face if it was erected in the interest of justice and order - an expression of the righteous forces of society[?]" (79). And Pinnie's thoughts echo James's own after his visit to Millbank: "Millbank Prison," he wrote, "is a worse act of violence than any it was erected to punish" (qtd. in Edel, Henry James: The Middle Years, 148).

“DON'T BREAK THE THREAD" 
Princess's fourth chapter, immediately following Hyacinth and Pinnie's visit to Millbank, is temporally dislocated; the novel jumps into the diegetic future, but it does not become clear until the end of the chapter just how much time- -"nearly ten years" (98), as it turns out—has actually passed. This is especially unsettling because while the passing of time has altered the physical appearances of Princess's cast of characters quite dramatically, it has not changed the setting a bit. At Lomax Place, "nothing was changed except Miss Pynsent" (90), and when the now post-adolescent Millicent Henning returns to Pinnie's atelier, the "little dressmaker" is flummoxed by her visitor: "with majestic blankness ... she couldn't imagine who she was" (91). When Pinnie does at last make the connection-“'Bless my soul, you must be the little 'Enning!' Miss Pynsent exclaimed" (92) - she is as awestruck by the change in Millicent as by her own misrecognition of the girl.

Pinnie finds herself most preoccupied with the same accessory that had so consumed her upon her visit to Millbank nearly ten years (and only a few paragraphs) earlier. She gawks at Millicent's "hat, which was a wonderful composition of flowers and ribbons; her eyes had travelled up and down Millicent's whole person, but they rested in fascination on this ornament" (90). Pinnie's own headwear has come, in the years that have passed, to resemble Florentine's prison dress: "She had lost her hair, and wore a cap" (90). Like the female inmate, Pinnie's hair is cropped now, and covered with a tight cap. Millicent wonders "if that were a specimen of what she thought the fashion" (90), but actually it is old age — its own form of corporeal punishment — that has rendered this strength of resemblance between Hyacinth's adoptive mother and his birth mother. Where the years have transformed Millicent into a fashionable young woman, they have 
made Pinnie "bald and white and pinched" like the female prisoner whose son she adopted ten years earlier. And like Florentine before her, Pinnie's "hideous cap did not disguise her meagerness" (93). Millicent notes that "Miss Pynsent's 'cut,' as I have intimated, was not truly fashionable" (97), just as Pinnie recognizes that Millicent's bonnet is of-the-moment, and the datedness of Pinnie's shop ("the tinge of which revealed years of washing, and surmounted by a coloured print ... in the manner of 1853 " (91)) is all the more pronounced in contrast to Millicent's cutting-edge modern style. James's narrator "should be sorry to impute to Miss Henning any motive more complicated than desire to amuse herself" (95), explaining that "Millicent was touched by the dignity" (97) of the little dressmaker. Yet Pinnie "felt that the girl was cruelly, scathingly well dressed" (91). Millicent's chic bonnet and Pinnie's ugly cap together form what seems to Pinnie like a punishment for "a hideous mistake.... She had sown in her boy's mind the seeds of shame and rancour" (98) on their visit to Millbank. Pinnie's self-flagellation has taken the form of a refusal of fashion: "it seemed as if she should never be able to touch a needle again" (98) in the decade that has passed since her visit to Millbank, and Pinnie has "ceased to notice or to care how sleeves were worn, and on the question of flounces and gores her mind was a blank" (98). She retreats from fashion because her guilt over the Millbank visit—which she now regards as "a hideous mistake [with] the deep conviction of error" (98) —has unraveled her parlor and its political project. Once equal parts aesthetic style and political asylum, Pinnie's atelier is now, ten years later, "covered with a light, shrunken shroud" (91).

But if Pinnie's Victorian fashion project has been killed, Millicent's modern fashion project "enjoy[s] beautiful "ealth" (92). Her fundamental "good-nature" (105) is 
rendered through her flamboyant modern fashion sense. Millicent's look is “indescribably fresh, successful and satisfying" (92), characterized by "her feathers and ribbons" (100), "her flounces" (522), and "her multitudinous silver bracelets" (528), signaling her ten years" self-fashioning into "a magnificent young woman" (90). She now works in "a more exciting, a more dramatic department of the dressmaking business" (93) than Pinnie, having taken "a high position at a great haberdasher's in the neighbourhood of Buckingham Palace; she was in the department for jackets and mantles; she put on all these articles to show them off to the customers, and her on her person they appeared to such an advantage that nothing she took up ever failed to go off' (96).

Millicent is fashion's present, placed by James at the vanguard of a new form of female labor and of an emerging consumer-friendly fashion space: the department store. The increasing employment of pretty, single, young women like Millicent in urban department stores marked what James calls an "evolution" (532) in fashion at the Victorian fin de siècle on both sides of the Atlantic. During an 1883 visit to Boston, he had noted the "pale, familiar, delicate, tired faces, ... [their] polished hair and glazed complexions" (James, "New England Winter," 67) of American shop-girls, a harbinger to James of a new and modern female type. Further, that type was also distinctly urban, disrupting the gendered power structure of the city. Millicent is "a daughter of London, of the crowded streets and hustling traffic of the great city; she had drawn her health and strength from its dingy courts and foggy thoroughfares" (92-93). The "pleasing freedom [that] was de rigeur" (103) for Millicent is_like Princess itself_-borne from "the habit and interest of walking the streets" (33).

Shop-girls like Millicent marked for James and for his contemporary reviewers a 
historically particular fin de siècle 'type.' Contemporary readers of Princess celebrated Millicent "as a cockney pur sang, a capital study" (Anon., "Four Novels," 728), calling her "a delightful type of the blooming cockney girl" (Anon., "Review," Literary World, 5) characterized by "superabundant health and slang, her scrupulous care for her virtue, and her hopeless, unconscious vulgarity" (Logan, "Recent Novels," 124). More recent critical accounts of Millicent have been similarly enchanted with her, and have also tended replicate the fin de siècle impulse to read her as "not as a unique or exceptional character, but a new urban 'type' of femininity" (Miller, Framed, 178) that had received a burst of representation in late nineteenth-century novels on both sides of the Atlantic. ${ }^{4}$

But while Millicent is exemplary of the turn of the century shop-girl, she is also worthy of an account that would treat her as more than a mere 'type'- that would reveal the strength of her political feeling and the "unique and exceptional" nature of her style. Millicent is "as a good a girl as there is in London!" (105), and her affect-her goodness and her sincerity, which find their expression in her sense of style - makes her an agent for social change. In many ways, Millicent converts Hyacinth's foundling plot along gendered and classed lines. A self-fashioned girl, Millicent quite literally pulls herself up by her bootstraps, using fashion as means of enacting an upward social mobility. But her claim to this urban modernity—her right enjoy the "pleasing freedom" of walking London's streets - derives directly and in equal parts from her twinned statuses as a working-class woman and a "good girl" whose sincerity is never called into question.

\footnotetext{
${ }^{4}$ Shop-girls figure prominently in many turn-of-the-century naturalist literary movements, including American naturalism (Dreiser), British naturalism (Gissing), and French naturalism (Zola).
} 
Hyacinth, like James's contemporary reviewers, finds that Millicent has 'touched him exceedingly" (387). Yet for all that he finds Millicent touching, he cannot touch her-and for all that Pinnie worries that the omnisexual Millicent will seduce her adopted son, both she and Hyacinth fundamentally misunderstand Millicent's feeling for him, which is neither romantic nor erotic. While Wendy Graham, Hugh Stevens, and Joseph Litvak have all compellingly shown the ways in which Hyacinth's marginal masculinity and ambiguous sexual desire mark him as a proto-queer, "cast in the mold of the fin de siecle aesthete" (Graham 63), Millicent's vibrant, vital sexuality seems only to signal to Princess's characters and its critics alike the powerful threat of female desire. Like so many fin de siècle social reformers, Hyacinth worries that shop-girls like Millicent are selling themselves as much as their goods, that "the great temptation of excessive love of dress" (Hamilton 129), as one 1893 journal article called it, will lead inevitably to prostitution. Admittedly, this concern was not entirely unfounded: Judith Walkowitz notes the 1887 "false arrest" of a shop-girl named "Miss Cass for streetwalking ... [which] epitomizes the charged and ambiguous nature of gender encounters in London's West End, an urban center that was traditionally male territory, an eroticised zone of commercial sex, yet also a fashionable shopping area for ladies" (128-29).

Nevertheless, James resists this assumed position of conscription, objectification, and forced self-commodification for the shop-girl. For all that Millicent exudes sexuality, she also takes great care "to keep her skirts clear and marry some respectable teamerchant" (160). Although "[s]he was crude, she was common, she even had the vice of unskillful exaggeration" (531), the affective force of Millicent's spirited sexuality is in her immaculate crafting of personal style as a defiant mode of defense and an aesthetic 
form of agency. Millicent's sexual integrity is only in question when Hyacinth misreads her enthusiasm for her work as a shop-girl (and the opportunities for self-fashioning with which it has presented her), by suggesting that "“it's a good job [since] you're so handsome"" (112) — rather than a good job since she is so possessed of genuine talent. Hyacinth thinks that because Millicent "had never a scrap to do with making [clothes] up, but just with talking about them and showing them off, and persuading people of their beauty and cheapness," (532) that her labor is about selling, not creating, and thus is devoid of any aesthetic value or social feeling.

But Millicent sees her work rather differently: "Millicent had never discovered wherein the art he practiced differed from that of a plumber, a glazier.... She looked down on such conditions from the summit of her own intellectual profession" (531-2). The phrase is unironic; James uses it to signal the genuine significance of Millicent's work, which is fundamentally_or rather organically, in Gramsci's sense — intellectual. But fashion and the political affect it inspires are lost on Hyacinth. He imagines Millicent is utterly oblivious to his social cause, and "amuse[s] himself with asking her if she were satisfied with the condition of society and thought nothing ought to be done for the people" (388). He does not see that her self-fashioned personal style is a political act both more effective and more powerful than the assassination with which he has been tasked by the socialists (and which he cannot bring himself to commit). His misunderstanding of Millicent's profound dissatisfaction "with the condition of society" and the creative, intellectual redress she seeks through fashion is why Hyacinth is "never really satisfactory to [her] — not as one friend should be to another" (526). 
And when Hyacinth does try to imagine Millicent as a political actor, he ceases to see her as a modern style icon; instead, he dresses her "with a red cap of liberty on her head and her white throat bared so that she should be able to shout the louder the Marseillaise of that hour" (161). His vision of Millicent at the barricades smacks of a century-old French revolutionary spirit — one that, of course, Hyacinth and his friends in the political underground have naïvely idealized. Further, his understanding of her personal style could not be farther from the thoroughly modern way in which Millicent dresses. Her headwear is, as Pinnie notes at length, anything but "a red cap," and the elaborate jewelry with which she accessorizes her outfits conceals her throat with necklaces. Hyacinth's vision strips Millicent of her historical and national particularity, a fact especially striking insofar as Millicent lives up in so many regards to her characterization as the 'type' of "the blooming cockney girl” of 1880 s London.

Millicent is no Marianne, as Hyacinth finally realizes at the novel's end. He peers into a boutique's window, "not that of her own shop—when a vision rose before him of a quick flight to her, for an undefined purpose, to an undefined spot” (584). Rushing over to Millicent's store on this whim, Hyacinth is surprised to find Millicent modeling a dress for the aristocrat and occasional socialist Captain Sholto:

with his eyes travelling up and down the front of Millicent's person, [Sholto] frowned, consideringly, and rubbed his lower lip slowly with his walking-stick. Millicent stood admirably still, and the back-view of the garment she displayed was magnificent. Hyacinth, for a minute, stood as still as she. At the end of that minute he perceived that Sholto saw him, and for an instant he thought he was 
going to direct Millicent's attention to him. But Sholto only looked at him very hard, for a few seconds, without telling her he was there; to enjoy that satisfaction he would wait til the interloper was gone. Hyacinth gazed back him for the same length of time - what these two pairs of eyes said to each other requires perhaps no definite mention - then turned away. (585)

Hyacinth is deeply troubled by what he intimates is a sexual relationship between Sholto and Millicent—one that would epitomize sinister relationships between gender, class, and power about which Princess is so concerned. With regard to this anxiety, Katherine Mullin compellingly argues that, "Millicent's relationship with Sholto more convincingly fits into an emerging paradigm of erotic barter, where young women workers traded the endlessly deferred promise of sexual favors for a taste of the high life, and maybe more.... This mode of erotic exchange may not now seem an obviously liberatory mode of conduct for a young woman[. Y]et during the late 1880s and 1890s, this kind of buccaneering was nonetheless at the heart of a self-consciously new sexual culture, and through it James foregrounds the intimacy of Millicent's association with modernity" (220). Although Mullins is astute in her analysis, the more urgent question is not whether Millicent may or may not be deploying her sexuality toward a feminist subversion of sexual power; rather, it is: why and how does Hyacinth comes to the conclusion that a sexual relationship — be it barter-oriented or otherwise — exists between them?

Mullins's reading usefully recasts Millicent and Sholto's relationship, but it nevertheless still accepts the premise of Hyacinth's perception as accurate- a premise that falls apart at the seams if Hyacinth's status as "a youth on whom nothing was lost" 
(190) is understood ironically. Hyacinth imagines that he is "the interloper" in this scene, figuring the exchange as a fantastic betrayal. But Hyacinth's assumption about Millicent and Sholto's relationship is awfully hasty. His interpretation is grounded flimsily upon a series of exchanges of looks between the three parties, which does not amount to much evidence at all. All he can know for certain is that "the back-view of the garment she displayed was magnificent," and that Sholto appreciates her sense of style. Hyacinth seems not to realize that in modeling for Captain Sholto, Millicent Henning is just doing her job. Millicent's “queer mixture” (526) cannot be so easily unmixed, and Hyacinth's impossible efforts to isolate one strand from another blind him entirely to her labor, which is as aesthetic as it is political.

Hyacinth is incapable of practicing the readerly technique that, years later, James would lay out for his friend the Duchess of Sutherland, who struggled with his The Ambassadors. To read his prose, James tells her, requires an understanding of style as being embedded in fashion as much as in literature:

Take, meanwhile pray, the Ambassadors very easily and gently: read five pages a day — be even as deliberate as that—but don't break the thread. The thread is really stretched quite scientifically tight. Keep along with it step by step — and then the full charm will come out. I want the charm, you see, to come out for you—so convinced am I that it's there! (Letters IV: 302, emphasis in original)

The instructions are especially striking read alongside James's proclamation in Princess's preface that style itself "is the charming, the tormenting, the eternal little matter to be 
made right, in all the weaving of silver threads" (41). Years later, the ambivalent Master was still "so convinced" of the feeling of style; he still believed that the torment of representation might be overcome, that "the full charm [might] come out," that the silver thread might not be broken. But Hyacinth's reading of Millicent does finally break the thread of Princess, and so too does it ultimately break Hyacinth: immediately after his misreading of Millicent Henning, Hyacinth Robinson takes his own life.

\section{JUDGING THE BOOK BY ITS COVER}

While the scene of Hyacinth in Pinnie's Victorian dress-making parlor dominates the novel's opening pages and the scene of Hyacinth in Millicent's modern department store dominates its closing, the bulk of the novel centers on Hyacinth's relationship with Princess's eponymous heroine Christina Light, the self-fashioned cosmopolite who has "thrown herself, with a passion, into being 'modern"” (259). When Christina first appears - a surprising one-third of the way in to a novel that bears her name - she has long since "been married by her people, in a mercenary way, for the sake of fortune and a title, and it had turned out as badly as her worst enemy could wish.... [S]he considered that she too was one of the numerous class who could be put on a tolerable footing only by a revolution" (249-50). In James's first full-length novel, Roderick Hudson (1875), Christina had been married off by her mother to the Italian Prince Casamassima (a theme to which James returned in his last full-length novel, The Golden Bowl, where Maggie Verver likewise finds herself in an unhappy marriage to an Italian prince), and in his 1908 New York Edition preface to Princess, James discusses his bringing back of 
that extremely disponible figure of Christina Light whom I had ten years before found left on my hands at the conclusion of Roderick Hudson. She had for so long, in the vague limbo of those ghosts we have conjured but not exorcised, been looking for a situation, awaiting a niche and a function.... Why should the Princess of the climax of Roderick Hudson still have made her desire felt, unless in fact to testify that she had not been —-for what she was - completely recorded?

Christina is the only James character who recurs in multiple texts, although the technique is not unprecedented, as James himself notes: "Balzac first of all systematically went on [with a character], ... as Zola more or less ingeniously went on" (46). ${ }^{5}$ Notably, James accredits the technique to Zola's brand of French naturalism - a fact especially striking because after his own visit Millbank to engage in field research for Princess's prison scene, James had written to his friend Thomas Sergeant Perry, "you see I am quite the Naturalist" (Letters III: 61).

\footnotetext{
${ }^{5}$ The technique also prefigures a modernist fascination with figures who reappear in multiple texts, and marks Princess's own modernism in that regard. Notable examples of reprieved characters in early twentieth-century texts include: James Joyce's Stephen Dedalus, who figures prominently in both $A$ Portrait of the Artist as a Young Man (1916) and Ulysses (1922); Joseph Conrad's Charles Marlow, who appears in Lord Jim (1900), Youth (1902), Heart of Darkness (1902), and Chance (1913); D.H. Lawrence's Brangwen sisters, Gudrun and Ursula of The Rainbow (1915), who recur in Women in Love (1920); Dorothy Richardson's Miriam Henderson, who figures prominently in the thirteen-volume Pilgrimage (1913-1967, posthumously); and, of course, an enormous number of the residents of William Faulkner's Yoknapatawpha County.
} 
This oft-quoted line is usually taken straightforwardly as James's expression of a genuine interest in naturalism and its methods. But Millicent Bell reads it as playful and ironic, "only half-serious. He does not claim to have composed the novel by the naturalist method when, a quarter of a century later, he introduces the revised novel in the New York Edition.... He talks a good deal about 'notes' and taking them, and the reader may be reminded of those notes set down by Zola and his followers, who sedulously collected data and transcribed into their novels what they had recorded, like newspaper reporters, 'on the spot"' (152). By contrast, Hughes - reading the novel in the context of its relation to Victorian social dress codes - argues that while Princess's prose is not "weighted with information about its society in Zolaesque style," it is "the closest James gets to writing a novel of social realism" (90). James very genuinely admired the French naturalists and expressed interest in their technique, and the naturalist legacy that both the princess and The Princess inherit is linked, in this way, to Zola. James connects both authors to fashion in his Literary Criticism: French Writers, Other European Writers, etc: "the most personal shell of all, the significant dress of the individual, whether man or woman, is subject to as sharp and deep a notation [in French naturalism]" (148) as any affective elements of consciousness. Hyacinth shares James's fascination with both the fashionability and the modernity of French naturalism. ${ }^{6}$ Swooning over Lady Aurora

\footnotetext{
${ }^{6}$ Furthermore, Hyacinth himself might be fruitfully understood as James's own experiment with a naturalist theory of hereditary, scientifically predictable types. Hyacinth is equal parts French and English, working-class and aristocratic, and "the reflection that he was a bastard involved in a remarkable manner the reflection that he was a gentleman" (175). But Hyacinth, like James, is torn about naturalist theory as it applies to himself. On the one hand, he feels himself the product "so far as was possible, of his heredity" (173), but on the other, he recognizes that the possibility only extends so far. Hyacinth's conflicted identity
} 
Langrish's library, Hyacinth is enchanted with volumes by "certain members of an intense modern school, advanced and scientific realists of whom Hyacinth had heard and on whom he had long desired to put his hand.... [S]he did possess a couple of Balzac's novels, which, by ill-luck, happened to be just those that Hyacinth had read more than once" (264).

When he meets the Princess Casamassima for the first time at the opera, Hyacinth imagines that he is living out his very own naturalist fantasy, the sort of adventure "endured gracefully enough by the heroes of several French novels in which he had found a thrilling interest" (188). For all of his passion for French naturalism, Hyacinth does not produce much writing himself; in fact, the only time Hyacinth writes is when he composes a letter to the Princess, which is notable for its use of naturalist style. In his letter, Hyacinth eschews "vague phrases, protestations, or compliments" in favor of "the realities of his life, the smallest, most personal details. He therefore treated her to the whole business of the break-up of Lomax Place, including the sale of the rickety furniture" (384). Rather than overblown, romanticized description, Hyacinth sticks to the cold, hard facts in all their intimately rendered banality — which is to say, Hyacinth writes in the naturalist style. The Princess is more ambivalent about French naturalism than Hyacinth; while she values its precision, its accuracy, and its social force, she worries (much like her author does) that its prosaicism might make its "pearls of interest" (38) too dingy and dull for fiction. "Don't be banal, please," she asks Hyacinth in one of their early

exposes social contradictions of a classed society, but the "dim, dreadful, confused legend of his mother's history... was at once too much and too little - this stupefying explanation had supplied, first and last, with a hundred different theories of his identity" (172). 
conversations. "That's what other people are. What's the use of my looking for something fresh in other walks of life, if you are going to banal, too?" (253, emphasis in original). The Princess, like James himself, hesitates to embrace Hyacinth's stylized banality, because as James writes of Christina in his preface to the novel, "nothing could be of an effect less banal, I judged, than her intervention in the life of a dingy little London bookbinder" (45).

Ultimately, Hyacinth's relationship to naturalism is not rendered through his writing of text, but rather through his dressing of text. He is a bookbinder, a quite literal "weav[er] of the silver threads" (41) of the novel—but he does not see the connection between the styling of a novel's prose and the styling of its cover. He is introduced to his future profession by way Mr. Vetch, who buys the young Hyacinth a volume of essays by Lord Bacon (very likely his "Idols of the Marketplace") that Vetch has had rebound for him. Here, James explicitly links bookbinding to fashion: "It became a question of fitting the great Elizabethan with a new coat" (115). Bookbinding is a textile dressing of text, and the Bacon essays are not merely wrapped, but clothed and cloaked. Hyacinth's profession surprises his childhood playmate-turned-shop girl Millicent, who had "always thought he would have something to do with books" (97) in a more writerly sense. Hyacinth, in response, thoroughly insults and disdains her work in the fashion industry, unable to recognize that his own profession participates in the very same debates-which is why Millicent is so deeply amused to hear Hyacinth insist so vehemently that "he considers [bookbinding] one of the fine arts" (97).

Hyacinth is a "painstaking craftsman, [who] symbolizes the value, authenticity, and 'aura,' in Benjaminian terms, of original creation," while Millicent, who works as a 
shop-girl and model of fashionable clothes in a department store, "is associated with cheap, homogenous, mass-produced goods" (Miller, Framed, 176). Just as the fashion industry had begun to experience an enormous tension between tailor-made and massmanufactured garments, "by 1885 bookbinding was itself an anachronism ... on the verge of becoming obsolete" (Scanlan 385, 389). Like the fashion industry, the publishing industry too had largely relegated this work to machines. While Hyacinth's bookbinding work is, as Michael Anesko and Collin Meissner have argued, a commentary on William Morris and his politics, the Arts and Crafts movement, and the demands of the fin de siècle literary marketplace, those same demands were also to be found in the fashion marketplace, where the "manufacture of clothing in the industrial societies of the nineteenth century developed in two different ways. There was a demand for the bespoke tailoring and fine needlework that could only be done by hand; at the same time, the mass production of clothes was beginning" (Wilson 73-4). If Millicent's work epitomizes the mass-manufactured clothing industry, Hyacinth's bookbinding is akin to bespoke tailoring.

The Princess, meanwhile, offers to pay Hyacinth to "bind all my books. I have ever so many foreign ones, in paper" (322), indicating that her collection likely includes at least a few of the French naturalists of whom Hyacinth is so fond. Indeed, Madame Grandoni, Christina's constant companion, is forever "nurs[ing] in the hollow of her arm ... a French book, with a pink cover" (319) borrowed from Christina's library. But Hyacinth's bookbinding practice, if not his book-reading practice, is largely limited to English writers. After his initial childhood enchantment with the rebound volume of Bacon essays, Hyacinth, now an apprentice bookbinder, makes a present for Christina 
after their first meeting of a collection of Tennyson's poems. Hyacinth reflects that book "seemed to create a sort of material link between the Princess and himself" (254). Noticing a "certain knot of light blue ribbon, which formed part of trimming of her dress," Hyacinth "now took one of [the ribbons] up and carried it to his lips" (323) as he gives her his gift. He tells her: "“What decides me is that I shall do it so well; at least it shall be better than any one else can do — so that if you employ me there will have been a reason. I have brought you a book—-so you can see.'” (323). Hyacinth will not accept Christina's money in exchange for his bound books until she recognizes his talent for bookbinding as he has (supposedly) recognized hers for ribbons; he wants her to see that as a dressmaker, Hyacinth expresses Tennyson. But Christina does not struggle with the question of whether the blue ribbon expresses her or her dressmaker nor whether Hyacinth's cover expresses himself or Tennyson, because Christina does not see the two as a mutually exclusive. Rather, for Christina, the political power of fashion's aesthetic is that it can express both simultaneously and inextricably, a mode of collective self-fashioning that, in its capacity to create surprising and unpredictable links, fundamentally refashions political affinity.

Because of the suppleness and flexibility of her understanding of material selfexpression, Christina does not care about Hyacinth's talent for dressing up Tennyson. "Give it to me to-morrow," she says dismissively, more interested in "fill[ing] up the inconvenient gulf that yawns between [her] position and [his]" (324) - a hole in the social fabric. The gulf between them, she thinks, might be filled by their shared commitment to both textile and social redress. "I ought to let you know," she tells him, 
"that I have very little respect for distinctions of class - the sort of thing they make so much of in this country. They are doubtless very convenient in some way, but when one has a reason — a reason of feeling — for overstepping them, one allows oneself to be deterred by some dreary superstition about one's place, or some one else's place, then I think it's ignoble.... I take it that if you are a socialist you think about this as I do[.]" (247-8)

But Christina is mistaken; Hyacinth does not see the class question-much less the woman question — as she does, because he does not realize that through fashion and its promise of collective self-fashioning, an East London bookbinder and a Princess might be brought together. Hyacinth may have felt the ribbon tucked into the fold of her dress, but he still hasn't Christina's "reason of feeling." Instead, he thinks that "if you employ me there will have been a reason" (323), not of feeling but of goods for services.

James characterizes the gulf between them as a yawn because it is Hyacinth's mouth that touches her ribbon. Hyacinth thinks that "[t]he cup of an exquisite experience ... was at his lips; it was purple with the wine of novelty, of civilization, and he couldn't push it aside without drinking" (325). It is not a glass of red wine, but rather a strand of blue ribbon, against which Hyacinth has brushed his mouth. Christina's ribbon is as much a "material link between them" as Hyacinth's cloth-bound volume of Tennyson-much more so, in fact, because Christina refuses the book. As Hyacinth reflects on how "he would have for evermore in his mouth the taste of nectar" (325), he runs into Madame Grandoni, who "had donned her dressing-gown ... [but] still had her pink French book under her arm" (325). A better reader of French naturalism than Hyacinth, Madame 
Grandoni urges him to leave Medley. She sees that Hyacinth cannot convince Christina to accept his gift of a redressed book, because what she wants, rather, is "to take hold of the great question of material misery" (530) — that is, the misery of an East London bookbinder as much as the misery of an American fashion icon turned princess, because fashion allows Christina to see that they are both part of "the numerous class who could be put on a tolerable footing only by a revolution" (249-50).

\section{This Bridge Called the Clothes on My BaCK}

Christina wants desperately to "ascertain what is really going on; and for a woman everything of that sort is so difficult" (166). Her burgeoning interest in socialist revolution is born out of an impassioned desire to redress the forms economically determined gender oppression to which she has been subjected, and when her Hyacinth finds the glamorous, cosmopolitan Princess abruptly transformed into a working-class woman, she tells him that "There are no things in my house now.... I have nothing in the world - nothing but the clothes on my back!” (412). James, as ever, constructs the sentence meticulously: Christina's home may be divested of tchotkes and china, but the clothes on her back are not "nothing in the world" - in fact, quite the opposite. They are a world unto themselves, an aesthetically imagined social fabric placed in relation to lived, historical, subjective experience. Structurally, qualifying "nothing” with "but" underscores the significance of that which follows it: if Christina's dress is all that she has, it is most certainly not nothing; rather, it is something - indeed, everything - that she has, because her clothes become, as Hayot argues of literary worlds, "social and conceptual constructs, as well as formal and affective ones" (“On Literary Worlds,” 137). 
While there is no technical term in poetics for sentence constructions that involve the phrase "nothing but," it tends to be used as a means of saying "all" (e.g., "nothing but net" means "all net"; "the truth, the whole truth, and nothing but the truth" means "all truth"; and so on). Although the rhetorical effect is similar to the double negative - a kind of emphasis-by-way-of-understatement — “nothing but” nevertheless does not quite work like litotes, which would be better represented in a phrase like "not nothing," indicating "something" but not necessarily "all" in the manner that "nothing but" does. For this reason, perhaps, Hyacinth "made no attempt, for the moment, to reconcile the contradiction" (412) in Christina's statement.

The distinction that Christina draws here between fashion and mere clothes is as crucial to the Princess's political project as it is to Princess's, because Christina's transformation into a working-class woman is fashioned by fashion itself:

“I don't like to be surrounded with objects I don't care for; and I can only care for one thing — that is, one class of things — at a time.... I must confess to you that my heart is not in bibelots. When thousands and tens of thousands haven't bread to put in their mouths, I can dispense with tapestry and old china.”... He had observed that, though the lady in question could dispense with old china and tapestry, she could not dispense with a pair of immaculate gloves, which fitted her like a charm. (412-3)

Scenes like this one that have steered much of the criticism on Princess to wonder alongside Hyacinth "whether this singular picture of her denuded personality were not 
one of her famous caprices, a whimsical joke, a nervous perversity" (412). Indeed, critics have gone much further than Hyacinth, who only suggests that the Princess may be hypocritical, or blind to her own class position; contemporary reviews of the novel on both sides of the Atlantic hurled at Christina the cruel accusation of slumming, calling her "a monument of sincere insincerity" and "a bundle of inconsistencies" (Logan, “Recent Novels," 124). More recent criticism has followed suit, attributing the Princess's interest in and commitment to socialist revolution alternately to boredom and ennui (Howe), or to romanticized ignorance (Betensky), or to philanthropic sadism (DeVine), or even to nymphomania (Morris, Double Jeopardy), rarely pausing to take seriously Christina's political feeling as a form of committed activism.

In this scene of her class cross-dressing, Christina quite literally redresses herself - and for all her method of redress is politically problematic in many of the ways that critics of the novel have been so quick to point out, James nevertheless describes her transformation as "exquisitely human, sentient, pitying," insisting that "it was easy to see, from the meagre line of her garments, that she was tremendously in earnest" (407). Through her clothes, the novel articulates the instability of Christina's gender and class positions, the strength of her political commitment to socialist revolution, and above all, the earnestness of both the Princess's and Princess's feeling. Though James does not quite celebrate Christina's class transvestitism, he is certainly more ambivalent about her methods than his critics have been. Because Christina's "heart is not in bibelots," but rather in "the clothes on [her] back," James reveals through her sense of fashion just what it might mean to care genuinely about "one class of things." Fashion, epitomized here by 
the "immaculate gloves" with which she cannot dispense, shows the Princess's genuine feeling as a mode of world-fashioning.

Although fashion is most often cast as the frivolous pass-time of wealthy women, caring about the poor and caring about fashion are not only not incommensurable in Christina, they are actually deeply intertwined. This interanimation of material conditions and material culture is just what the working-class, militant male socialists-especially the paradigmatic and appallingly misogynistic Paul Muniment, with whom Christina allies herself - never recognize, and their failure to recognize the relationship between aesthetics and politics, as figured by fashion, renders them politically impotent. Because fashion remains, for them, quintessentially frivolous, feminine, and bourgeois, they cannot see how it might relate to the goal of socialist revolution, nor how socialist revolution might have anything at all to do either with women or with fashion:

Presently [Paul] observed, "I don't know that I quite understand what you mean by that question of taking a woman seriously."

“Ah, you are very perfect," murmured the Princess. "Don't you consider that the changes you look for will also be to our benefit?"

"I don't think they will alter your position."

"If I didn't hope for that, I wouldn't do anything," said the Princess....

"[T]he most amiable women [are] just kind of an ornament to life." 
Paul misreads Christina's personal stake in socialist revolution as a poor little rich girl's romantic escape, rather than a commitment to fighting the patriarchy that has repeatedly victimized her. Paul cannot take seriously, as Christina does in the tradition of Marxist feminism, that socialism will improve the lives of women. Instead, he assumes that Christina's position (and the position of women more generally) cannot be "altered," like a garment, because she is merely an accessory_-"kind of an ornament"- to forms of communitarian life. In his formulation, the struggle for social change is not 'women's work' in the manner that he thinks fashion is. His distrust of women ('I don't trust women-I don't trust clever women!" (456)), his willful blindness to the effects of patriarchy ("Women pretty well do what they like" (452)), and his devaluing of "any devotion, any intelligence" (166) that female allies might bring to the social struggle is the cause of his extraordinary political impotence.

Paul is extreme in his chauvinism, but even the gentle, woman-loving Hyacinthwho reflects that "the sex in general have been very nice to me.... It's wonderful the kindness they have shown me, and the amount of pleasure I have derived from their society" (529) — nevertheless “didn't think people could really come out of their class; he held that the stamp of one's origin is ineffaceable and the best thing one can do is to wear it" (488). The phrase is not, as it seems at first glance, fatalist or passive; rather, if one's class can be worn, it can also be fashioned. But for all that Hyacinth is the child of fashion, born to a milliner and raised by a dress-maker, he misses this entirely — and together, Pinnie, Florentine, Millicent, and especially Christina fundamentally challenge Hyacinth's sense that a change of dress cannot signal a change of class, much less a change of heart. 
In his preface to the Princess, James writes that to "find [Hyacinth's] possible adventure interesting I had only to conceive his watching the same public show, the same innumerable appearances, I had watched myself, and of his watching very much as I had watched" (34). This sentence that has led many readers of the novel to take Hyacinth as a figure for the author himself, and indeed Hyacinth is one of James's most "intense perceivers" (42, italics in original)_-“a youth," in James's famous and oft-quoted phrase, “on whom nothing was lost" (164). The phrase finds its origin in James's famous treatise on novel-writing, "The Art of Fiction," in which he advises novice writers to "Try to be one of the people on whom nothing is lost!" (170), although critics of Princess have not acknowledged this source text. But where James's advice to aspiring authors is genuine, its reuse as description of Hyacinth is ironic. What is lost on Hyacinth is, precisely, the clothes on Christina's back, Pinnie's “stuffy sanctuary, dedicated at once to social intercourse and to the ingenious art" (53), Florentine's having been dishonored more by her haircut than by her crime, and Millicent's "intellectual profession” (531-2) as a shopgirl.

James writes in "The Art of Fiction" that "the only condition that I can think of attaching to the composition of the novel is ... that," like Christina Light, "it be sincere" (182). And because she is sincere, Christina's style — and not Hyacinth's — figures James's own. Upon meeting Christina for the first time at the opera, Hyacinth had quickly concluded that "this was no time for going into the question of the lady's sincerity" (186) - a question that is as crucial for Christina's condition as it is for the condition of the modern novel. Christina's estranged husband the Prince Casamassima- 
as obtuse as any of the male socialists - cannot understand Christina's sincerity either, nor the fresh hell to which patriarchy has subjected her:

"The Princess considers that in the darkest hour of her life she sold herself for a title and a fortune. She regards doing so as such a horrible piece of frivolity that she can never, for the rest of her days, be serious enough to make up for it." "Yes, I know she pretends to have been forced. And does she think she's so serious now?"

... "Sometimes she calls it by another name: she says she has thrown herself with passion into being "modern."' (259)

Fashion does not fit into Christina's understanding of "a horrible piece of frivolity"; rather, the power structures of modernity — and her capitulation to those structural lines of patriarchal, capitalist power "in the darkest hour of her life" - are what Christina rails against as unserious, insincere, and antiquated. The Prince, like Hyacinth and Paul and many of the novel's critics, maintains that Christina Light "pretends to have been forced" into her marriage. He cannot see how patriarchy has worked upon her, nor how her efforts to make its effects legible through fashion to rewrite the very idea of "being 'modern.'”

Hyacinth's refusal to ask the question of Christina's sincerity, like the Prince's refusal to ask the question of her modernity, are repetitions of Paul's refusal to ask the broader question of taking a woman seriously — and indeed, "I am very serious," (200), Christina tells Hyacinth of her political commitment in their very first conversation. Yet 
Christina's sincerity and seriousness are lost on that "youth on whom nothing was lost." The very first words she says to Hyacinth in that initial meeting are, "you'll see and hear beautifully" (190), as that "intense perceiver" (42) most certainly does. But for all that Hyacinth sees and hears beautifully, he never quite touches or feels. When Christina asks Hyacinth moments later if he thinks the socialist revolutionaries will "make yourselves felt," Hyacinth can only mumble vaguely in response that he "doesn't quite know what [she is] talking about" (202-3). And when Hyacinth visits her for the last time over four hundred pages later, he still doesn't quite know—much less feel—what she is talking about. He observes "a dozen objects around him which seemed as much a part of herself as if they had been the folds of her dress" (567). But to Hyacinth, that link still requires a simile: he fails to recognize that those dozen objects - her bibelots, her old china, her tapestries, the folds of her dress - actually are a part of herself. They constitute her very fashionability, and in so doing, they recast the ethics of her feeling, her mode of social agency, and her role in the political community that, together with Pinnie, Millicent, and Florentine, is the novel's recuperative political gesture of redress.

\section{The Thread ANd The Damage Done}

In Princess's final pages, the nervous Christina Light paces outside Hyacinth's apartment building, making anxious small talk with the German socialist revolutionary Schinkel. "At the end of ten minutes the Princess broke out," unable any longer to contain her feeling:

“Mr Schinkel, this won’t do. I'm intolerably nervous." 
"Yes, that is the nature of ladies," the German replied, imperturbably.

"I wish to go up to his room," the Princess pursued. "You will be so good as to show me where it is."

.... "What will you do when it's locked?" he inquired.

"You must break it down."

"It is very expensive."

"Don't be abject!" cried the Princess. (588-9)

Christina's genuine feeling is, once again, dismissed by the male socialist as so much blubbering, a feminine frivolity as silly to him as fashion is to Paul Muniment. But standing before Hyacinth's door, "anxious" (586), "in a fever" (586), and "baffled" (587), Christina fulfills James's promise of the hero who will figure the author in his youth, standing in a doorframe while being subjecting to Victorian fashion policing, "save indeed" for the little difference of having experienced the abjection of closed doors due to class, gender, mobility, and nationality. When finally "the door collapsed: they were in the light; they were in a small room, which looked full of things" (590). The novel ends as it begins: with a tiny, cluttered room that, through fashion, tries to offer a "stuffy sanctuary, dedicated at once to social intercourse and to the ingenious art" (53). But if Pinnie's parlor equips the novel with an alternative social logic wherein political community is inseparable from its aesthetically styled representation, Hyacinth's bedroom reveals how his own blindness to the role of fashion necessitates his suicide. Fashion would have reconciled the politics and the aesthetics that Hyacinth cannot—and in this sense, it is the very absence of fashion that kills him. 
The socialist revolutionary Schinkel coldly muses that the pistol with which Hyacinth has committed suicide "would certainly have served much better for the Duke" (591), just as the fashionable Christina Light would certainly have served much better for assignment of assassination. But the Princess's style—like The Princess's own —is still too modern for the Victorian all-boys' club that can read neither her feeling, nor her creative and collective self-fashioning, nor her demand for and enacting of redress. In his preface, James describes his process of resuscitating Christina Light, "which was like the act of clothing her chilled and patient nakedness" (44). And though James does dress her (and in many styles!) in Princess, he cannot quite redress her-cannot yet make right that "eternal little matter"- just by the "weaving of silver threads." James reflects near the end of The Princess's preface:

I may wonder at my confidence now-given the extreme, the very particular truth and 'authority' required at so many points; but to wonder is to live back gratefully into the finer reasons of things.... [T] he effect I wished most to produce were precisely those of our not knowing, of society's not knowing, but only guessing, what 'goes on,' irreconcilably, subversively, beneath the vast smug surface. (478)

Those finer reasons - fine like the "finest silken threads suspended in the chamber of consciousness," reasons like Christina's own "reason of feeling"- are the finer reasons of the "things" in Hyacinth's deathly bedroom. In Hyacinth, James does produce the condition of not knowing that he describes in the preface. James has tried to address "the 
eternal little matter to be made right, in all the weaving of silver threads" of fiction.

Although he cannot redress Christina, nor Millicent, nor Florentine, nor Pinnie, he canand does-refashion fiction itself. His narrative thread is tangled up in the social and economic conditions of modernity, in the politics of the modern novel that will have to acknowledge its own relation to modernity as fashion in the broadest sense.

James weaves a garment of political feeling in the "chamber of consciousness"a chamber that is, of course, exactly the opposite of the unconscious Hyacinth's bedroom. Unable to see that the surface is the substance, Hyacinth takes his own life not-as critics have so often claimed-because he is a Hamlet who struggles to act, nor because he chooses art over politics. ${ }^{7}$ Hyacinth commits suicide because he has broken the narrative thread; he cannot read Pinnie, nor Florentine, nor Millicent, and he certainly cannot read Christina. In this sense, the four women are not characters, per se, but aspects of a fashion dynamic that recasts the links between gendered and classed inequality across transnational lines. Hyacinth's failure to read them as such—-his failure to recognize their imagination, their fashionability, their literariness — condemns him to death. But it also imbues the novel with the power to imagine new forms of gendered and classed affinity, making an alternative modernity appear. In this regard, Princess does much more than represent the social fabric of modern life: it refashions it.

\footnotetext{
${ }^{7}$ Trilling reads Hyacinth's suicide as a heroic act; Hyacinth, he argues, takes upon himself the reconciliation of two irreconcilable ideals: politics and aesthetics. Christopher Stuart takes issue with Trilling's (and other similar) readings, which “describe Hyacinth's dilemma as an inability to reconcile the claims of politics with the claims of art.... James' hero unflinchingly embraces the conservative political implications of his aesthetic ideals" (23). Scanlan claims that Hyacinth (and by extension, James) value art over revolution, arguing that James "fails even to consider the possibility of synthesizing” the two (393).
} 


\section{Chapter Three}

\section{Across Dressing: Virginia Woolf's Global Modernism}

In his collection of essays, Conversations in Bloomsbury, the Indian novelist and political activist Mulk Raj Anand recalls meeting Virginia Woolf. Anand had arrived in Bloomsbury "after a brief jail-going in the Gandhi movement in the early twenties" (Conversations 5), and had taken a position as an apprentice for the Woolfs' own Hogarth Press, through which he had developed close relationships with Leonard Woolf, Lytton Strachey, T.S. Eliot, and especially E.M. Forster, who famously wrote the preface to his first novel, Untouchable. ${ }^{1}$ Anand was at once excited by "the world of Bloomsbury where the pleasures of literature and art were considered ends in themselves" (Conversations 5) even as he was "fuming inside" (Conversations 23) about his own position within the Bloomsbury intelligentsia. He "had come to learn from not to teach" literary London, but found he "had the irrepressible urge in me out of my own disillusionment with Europe, to show the concave mirror to Western intellectuals, however eminent they may be" (Conversations 169). No wonder, then, that Anand found an ally in Virginia Woolf, who shared his twinned admiration and rage, his antiimperialist politics, and especially his desire to distort the mirror, "making"-as Woolf

\footnotetext{
${ }^{1}$ In light of Hogarth Press's extensive list of progressive, anti-imperialist publications, Anna Snaith notes "It is interesting to speculate, then, why Untouchable was not one of the Press' titles. Perhaps the Woolfs rejected it but, if so, it is curious that there is no mention of Anand in the archive or in Virginia Woolf's diaries." ("Hogarth" 119)
} 
writes - "the world reflect the compass of the soul" (Lighthouse 128) as it navigates the changing landscape of an increasingly global modernity.

Having shared a draft of a short story with Woolf, Anand was "[s]hy and tentative" having a (mistaken) "hunch Mrs. Woolf would not like my stories about low class sons of sweepers, washermen and bandsmen" (Reader x). Anand eagerly sought Woolf's approval and was "afraid of her verdict on my amateurish writing" (Conversations 94) which, it should be noted, Woolf called "enchanting" (Conversations 96)-because he had already sensed the solidarity between them. Much like himself, Woolf too was "crazed by her loneliness in the midst of cynics like her husband and Lytton Strachey, Roger Fry, Clive Bell and John Maynard Keynes... She was soulful, the others were not" (Conversations 98, 100). And like Anand, who dressed as "would-be Tommy aspiring to wear a sola hat on my head" (Conversations 77), Woolf's difference was marked visually by her clothes: he recalls that "She was dressed in a soothing grey longish frock, unlike most other short-dressed Englishwomen young and old" (Conversations 94).

Woolf herself was acutely aware of her own fashion failures, and her personal relationship to the world of fashion was ambivalent: her sister Vanessa was the more stylish Stephen daughter, and Virginia was subjected to constant early criticism of her dress from her older half-brother, George Duckworth. Despite what she characterizes as her own "dress mania" (Diary IV: 229), Woolf had "giv[en] up the hope of being well dressed" (Diary III: 118) herself. Yet she kept coming back to "the eternal, \& insoluble question of clothes" (Diary I: 226) in her writing, reminding herself that "I must remember to write about my clothes next time I have an impulse to write. My love of clothes interests me profoundly: only it is not love; \& what it is I must discover" (Diary 
III: 21). ${ }^{2}$ And discover she did: dress came to articulate for Woolf (as for her friend Anand) the paradox of being simultaneously inside and outside of the world of Bloomsbury, because

people have any number of states of consciousness: \& I should like to investigate the party consciousness, the frock consciousness \&c. The fashion world ... is certainly one; where people secrete an envelope which connects them \& protects them from others, like myself, who am outside the envelope, foreign bodies.... These states are very difficult (obviously I grope for words) but I'm always coming back to it. (Diary III: 12-3)

Frock consciousness is itself an impossible conjunction, insofar as clothes are material and visible, consciousness interior and intangible. Garments like Woolf"s "longish grey frock" mark her as "foreign" and "outside the envelope," and yet she is fully integrated into the "fashion world" because even clothes that are unfashionable are nevertheless not outside of fashion. In Woolf's writing, this "fashion world" actually fashions a world in fiction, creating an "envelope which connects" her characters even as it "protects them from others." Her "frock consciousness" is a collective consciousness, a "fashion world" that she was "always coming back to" as she "gropes for words" through which to fashion a global modernist style as literary as it is sartorial. For Woolf, representing the

\footnotetext{
${ }^{2}$ Her "clothes complex" (D III: 81) seems to have been inherited by her nephew, Quentin Bell, who penned both Woolf's authorized biography and the tract On Human Finery, where he-like Woolf herself-seizes upon fashion's paradoxical "tyrannically democratic force."
} 
social, political, and economic conditions of modernity is as much a matter of fabric as it is of fabrication — as much a "fashion world" as a world fashioned in and through words.

Sara Blair compellingly argues that the Bloomsbury coterie "makes of modernism a contact zone, in which matters of consciousness are visibly inseparable from class conflict, the imperatives of nationalism, the dynamics of colonial self-recognition" (“Local” 835). And as Bloomsbury makes modernism a contact zone, Woolf makes dress a contact zone, in which matters of global subjectivity are visibly inseparable from the trauma of world war, British imperialism, and the experimental narrative forms through which Woolf refashions them. Recent scholarship has explored several arenas of what Woolf called her own "clothes complex" (Diary III: 81). Jane Garrity, Nicola Luckhurst, and Brenda Silver have traced Woolf's celebrity appearance as the very face of fashionable lifestyle in British Vogue throughout the 1920s and 1930s; Christopher Reed and Lily Sheehan have analyzed Woolf's spirited commentary about the dresses designed by the Omega Workshop, founded by Bloomsberries Roger Fry, Duncan Grant, and her sister Vanessa Bell; Randi Koppen and Rachel Bowlby place Woolf's work as a cultural analyst and writer of fiction in the context of consumer culture; and Jennifer Wicke and Christine Froula show how Woolf fashions democratic community on a world stage. These studies show Woolf in her capacities as fashion icon, fashion victim, fashion consumer, and fashion revolutionary. But Woolf is also a fashion theorist, and her meditations on "dress - taken very philosophically" (Diary IV: 230) make "frock consciousness" political.

Although postcolonial readings of Woolf's life and work have sparked exciting conversations about the politics of her work for over twenty years, only very recently 
have critics begun to think of Woolf as a global author. Melba Cuddy-Keane has succinctly articulated the difficulty of reading Woolf in a global context, asking

How can we theorise global consciousness in a writer who does not write extensively and explicitly about travel, geography and cross-cultural encounters? Although Virginia Woolf produced a not insignificant body of travel writing, and although we are accumulating increasing evidence of her connections with people from other parts of the world [and...] while her novels are permeated with global movement ... literal global interactions rarely appear. We must turn to her figurative imaginings of geography, peoples and global exchange. (158)

Cuddy-Keane makes recourse to Woolf's "global consciousness" rather than to "literal global interactions" in her work, "[s]ince globality in Woolf is less literal than rhetorical" (159). Fashion is one of the richest modes of Woolf"s "figurative imaginings" of global interconnectedness because if, as Cuddy-Keane argues, "[a]nalysing Woolf's global consciousness thus requires an approach that is at once textual, situated, relational and comparative" (159), then Woolf's own notion of "frock consciousness" provides just such an approach. Neither a descriptive mode nor a static term for clothing, frock consciousness is global consciousness throughout Woolf's oeuvre, a material interface between modern subjects and the social world.

Woolf weaves the materiality of dress into the literary materiality of her experimental, modernist narrative style. Her "fashion world" fashions worlds, from the double cross-dressing of the anti-imperialist Dreadnought Hoax and its literary 
counterpart in "A Society" to the insistence that modern clothes cannot and will not participate in realist verisimilitude in "Mr. Bennett and Mrs. Brown"; from Louis's high modernist poem that connects colonial subjects by connecting bowlers in The Waves to Septimus's immaculately styled hat that creates a global gift economy in Mrs. Dalloway; from Clarissa's mermaid dress that arrests the madness of world war to the twisted finger of Mrs. Ramsay's glove that is the occasion for an ontological theory that fashions Mrs. Ramsay and Lily Briscoe into a single being; from the hierophantic empty boots at the end of Jacob's Room that elegize a generation torn apart by world war to the hierarchical, anti-fashion military uniforms that stand in such stark contrast to the collectively selffashioned "Society of Outsiders" in Three Guineas. "Frock consciousness" is transnational, transgendered, transhistorical, and even transindividual, revealing literary form as part of modernity's own material and increasingly global form. In this way, Woolf's "frock consciousness" is a global consciousness - one that reforms through form and redresses through dress.

\section{A Woolf in Sheiks' Clothing}

In or about February 1910, Virginia Stephen's character changed-quite literally. Dressed, as she herself recalls, in "royal red satin with a turban on my head" and with black paint on her face, "I became another person" (Dreadnought 187) for the famous Dreadnought Hoax. Virginia Stephen, her brother Adrian, and his friends Horace Cole, Guy Ridley, Anthony Buxton, and Duncan Grant disguised themselves as the Emperor of Abyssinia and his suite and paid a royal visit to the most technologically sophisticated battleship of the British Royal Navy, the H.M.S. Dreadnought. The hoaxers wore 
blackface, slipshod outfits from a theatrical costumier's shop, elaborate wigs, and fake facial hair, and they spoke in a hodgepodge gibberish of Latin and the few words of Swahili they had taught themselves a few days before. Their "deliberately and nonchalantly amateurish" (Koppen 24) performance was riddled with several astonishingly close calls: their forged telegram to the Admiral of the Fleet went undetected, ${ }^{3}$ and amazingly, the flag commander William Fisher did not recognize his first cousins Virginia and Adrian Stephen - a fact especially surprising for the latter, who stood at a striking six-foot-five and was barely disguised as an interpreter in his bowler hat and fake beard. The one sailor on board who knew Swahili just so happened to be on leave that day. While climbing the ladder onto one of the masts in order to see the Dreadnought's impressive wireless equipment, Duncan Grant's fake mustache blew off. Woolf was forced to remain mute the entire time, as she found that she "could easily laugh like a man, but it was difficult to disguise the speaking voice" ("Interview" 201). Because the their make-up would melt off if they ate or drank, Adrian absurdly told to the officers that Abyssinians abstained from food, water, and spirits until after sunset; none of the officers registered the lie. But despite the high stakes and near misses, the hoaxers were never made.

The subversive aspects of the Dreadnought Hoax have been remarked upon by many critics: Hermione Lee reads the Dreadnought Hoax as a "ridicule of empire,

\footnotetext{
${ }^{3}$ The forged telegram was an especially dangerous endeavor, and one that would have landed all of the hoaxers in prison if it had been discovered. As Woolf herself explains, if the Admiral had telephoned the Foreign Office "and if he had learnt that they knew nothing about it of course we should be met by a policeman who would put us all in jail. It was no joke forging the foreign secretary's name to a telegram" (Dreadnought 188).
} 
infiltration of the nation's defenses, [and] mockery of bureaucratic procedures" (279); Phyllis Rose suggests that "the resplendent, uniformed obtusity of the British naval officers [figures] the very image of masculine folly" (102); Barbara Christian interprets the Hoax as a "protest against British policy in Africa" (176); Kathy Phillips argues that Woolf's role in the Dreadnought Hoax figures an early "solidarity with oppressed groups" and shows that Woolf "had already begun to see the common cause uniting women in patriarchy and colonized people in Empire" (248); and Jean Kennard explores how the hoaxers' costumes parody and, in so doing, effeminize naval uniforms (and, by extension, the soldiers and sailors who wear them). But seductive though these readings are, they nevertheless elide that the famous Dreadnought Hoax was, to all but one of the hoaxers, a frivolous (and almost comically poorly engineered) practical joke - and at first, Woolf too was swept up by the thrill of feeling cleverer that the British Navy. By her own account, Woolf enters into the Dreadnought Hoax having imagined common political cause between herself and the hoaxers. Enchanted by "rather dangerous friend" of Horace Cole, who "had a beautiful soft voice; and a very wheedling way. And he had plenty of money; and any amount of time on his hands.... [W]henever he came, my brother would make some excuse and take him off to his own room; and shut the door with a slam-by way of a hint, I felt, that I was not to follow them. I was certain that something was up; but I didn't know what; and perhaps I never should known, if I hadnt [sic] been for an accident" (Dreadnought 183-4). From behind the slammed door of white, wealthy, masculine exclusion, Woolf had been enchanted by the charm of the soon-to-be brotherin-law of Neville Chamberlain and his daring prank. ${ }^{4}$

\footnotetext{
${ }^{4}$ Further, for Cole, the Dreadnought Hoax was merely one in a string of practical jokes. In March of 1905,
} 
For this reason, Jane Marcus agonizes over "Woolf's part in the Orientalism of modernism" ("Britannia" 149) and Steven Putzel worries that the Dreadnought Hoax is "a kind of minstrel show" (107).In fact, "the group's romanticized, orientalist view" (Putzel 107) is revealed to Woolf in and through fashion. She comes to realize- "to my horror" (Dreadnought 195) — how completely the playboyish flair of the wealthy, white, Cambridge all-boys' club in which she had been momentarily included (and even then, only by necessity: one of the original male participants had dropped out at the eleventh hour) is imbricated in the very system their hoax had purported to subvert. Telling the waiters on board that "it was quite out of the question for them to serve dinner unless they wore white gloves.... There was soup steaming in the plates, but we werent [sic] allowed to eat it until those wretched men had dashed out into the town and bought white gloves" (Dreadnought 195), Cole's grotesque demand makes suddenly, painfully clear to Woolf that her affinity lies not with the privileged hoaxers, but with those they have humiliated - people whom she would dub, in Three Guineas, a "Society of Outsiders." Doubly cross-dressed in drag and blackface, Woolf's re-self-fashioning makes these affinities appear, because when“"i]t was clear that everybody believed we were Abyssinians; and one began to believe it too" (Dreadnought 187). Woolf "became another person" (187) because her drag and blackface became powerful tools of alliancebuilding - powerful tools, indeed, of redress for the imperialist chauvinism that

he and Adrian (among others) dressed as the Sultan of Zanzibar and his suite to trick the Mayor of Cambridge. Adrian and Cole had collaborated on other elaborate hoaxes, as well: they pretended to be navies and dug up Piccadilly; they threw a party in Birmingham where all attendees had "bottom" attached to their surnames. 
victimized white working-class English servers, black Abyssinian princes, and the “daughters of educated men" like herself.

Woolf's participation in the Dreadnought Hoax loomed large in her memory right up until her death. In 1940 - thirty years after the hoax, and one year before her suicideWoolf chose the Dreadnought Hoax as the subject of her talk for the Rodmell Institute, a rural women's education collective that had asked her "to speak about books" (Johnston 2). ${ }^{5}$ At first blush her choice might seem off-topic, dated, or even flagrant; she was, after all, asked to discuss literature and not a long-since-forgotten scandal. But in fact, the Dreadnought Hoax might best be understood as a kind of modernist literary innovation. When Woolf describes her nervous excitement during the Hoax-

It sometimes cheers me to remember my own state of mind when I read of people doing dangerous things; one simply feels nothing. One feels its [sic] too late to begin thinking. Thus I was in a kind of trance, not afraid of anything, as the train slid into Weymouth Station. (189)

— she employs the same language of intense transfixion, immobile intoxication, and steely calm affect to which she had so often made recourse when discussing her

\footnotetext{
${ }^{5}$ Until very recently, only three pages of this speech—which were published in Quentin Bell's 1972 biography - were extant. The manuscript was found in a box in Women's Library of London Metropolitan University $(5 \mathrm{fWI} / \mathrm{H} / 45)$, and is now housed in Archive of the National Federation of Women's Institutes, where Georgia Johnston uncovered it in 2006. She published the typescript in 2009 (see Georgia Johnston, "Virginia Woolf's Talk on the Dreadnought Hoax"). A cleaned-up copy of the talk is also published in S.P. Rosenbaum's second edition of The Platform of Time.
} 
relationship to the literary: "how I read myself into a trance" (Moments 123) or found herself "writing a novel in a state of trance" ("Professions" 281) or how, upon finishing The Waves, she was "almost afraid, ... sitting these 15 minutes in a state of glory, \& calm" (Diary VI: 10). Further, Woolf's experience disentangles enchantment, or trance, from romantic glorification and locates it squarely within material history, tied equally to modern technological advances in public transportation as it is to the reading and writing of modernist literary texts. Woolf here seems to anticipate Rita Felski's compelling case about reclaiming enchantment: "If enchantment is to be rendered a plausible concept for literary and cultural theory, it needs to be pried away from such a romantic-messianic vision and acknowledged as part of modernity rather than antithetical to modernity" (Uses 67). Woolf's own experience of enchantment is anything but antithetical to modernity; rather, enchantment becomes the aesthetic mode through which Woolf experiences modernity as modernist style.

This modernist style - and what Woolf understands as "the different aspects it can wear" ("Mr. Bennett" 321) - is famously inaugurated ten months before the Dreadnought Hoax, "in or about December 1910" (320):

In or about December 1910, human character changed.... The Victorian cook lived like a leviathan in the lower depths, formidable, silent, obscure, inscrutable; the Georgian cook is a creature of sunshine and fresh air; in and out of the drawing room, now to borrow the Daily Herald, now to ask advice about a hat. Do you ask for more solemn instances of the power of the human race to change? .... And when human relations change there is at the same time a change in 
religion, conduct, politics, and literature. Let us agree to place one of these changes about the year 1910. (320-1)

These "solemn instances," of change play out on a fashion dynamic: the once-invisible, working-class woman enters modernity by "ask[ing] for advice about a hat." The hat is a metonym, figuring a shift in the character of the age and standing in for mass-mediated cultural shifts "in religion, conduct, politics, and literature"-which is to say, fashion in its broadest sense. The modern Georgian cook, who now peruses the Labour paper and keeps abreast of current events as much as popular advertisements, finds in her sartorial accessory an occasion for self-fashioning and an entry point into modernity.

Woolf indexes modernity's beginnings "about the year 1910," and though the date most obviously refers to Edward VII's death and George V's ascension to the throne, it might also easily be glossed for its myriad political links to the Dreadnought Hoax in February of that same year. The first General Election in January 1910 had been waged, at least in part, over the issue of Dreadnoughts. Lloyd George had inaugurated land taxes to finance the building of the ships, which the House of Lords considered confiscatory; the Budget was passed, and the power of the House of Lords remained a fraught question for the rest of the year. From the very beginning of 1910, then, the navy and the Dreadnought had been cast as figures of state power. In that vein, the 1910 acquittal and subsequent compensation of naval cadet and cause célèbre George Archer-Shee, accused and successfully defended against the charge of having stolen a five-shilling postal order, further raises the question of working-class soldiers and sailors' rights - an issue close to Woolf's own heart in 1910, as she was then volunteering with the Adult Suffrage League which insisted vehemently that the right to vote be granted not only to women, but so too 
to returning soldiers and sailors who did not own property. Further, the year's massive technological innovations - including Charles Rolls's non-stop double-crossing of the English Channel in a British-built plane and Dr. Hawley Harvey Crippen's capture by way of wireless communication-conjure the Hoax's dependence on British sea power and the modern telegram.

Most commonly, critics and scholars of Woolf have taken the date as a reference to Roger Fry's exhibition "Manet and the Post-Impressionists," which had opened in November 1910 to the outrage of scandalized British art critics. The exhibit was primarily composed of paintings by Gauguin, Cezanne, and Van Gogh, which — despite their being twenty-five years past the continental standard for avant-gardism - upset critics primarily because of their "primitive" African content. Scathing reviews referred to the "hideous brown women" and the "barbaric colours" of the paintings (qtd. in Goldman 119). Further, Fry too had tied his project to fashion: as Woolf recalls in her biography of her beloved friend, "[u]nder his influence, his pressure, his excitement, pictures, hats, cotton goods, all were connected" (Roger Fry 152-3) in the exhibit; Fry himself collected African masks and cultivated the Omega Workshop's production of "dresses of the printed cotton that is specially loved by Negroes" (Moments 29), interweaving sartorial fashion with painting as Woolf was to interweave it with literature.

Hermione Lee points out the striking resonances between the Dreadnought Hoax and the Post-Impressionist exhibits and balls - the scandal caused, the gossip generated, the publicity catalyzed. Furthermore, both of these key 1910 events hinged upon Bloomsbury's complex sartorial negotiations. For Woolf, Fry's “Manet and the PostImpressionists" of was an exhibition of "the Post Is. \& ourselves" (Letters I: 356) —a 
coming out ball for Bloomsbury and its modernist aesthetic in which Woolf wore anything but the white dress of a debutante. Rather, for the Second Post-Impressionist Exhibition Ball in 1912, she and Vanessa "dressed ourselves up as Gauguin pictures and careered around Crosby street” (Moments 200). “[B]are-shouldered bare-legged Gauguin girls, almost — as it seemed to the indignant ladies who swept out in protest - almost naked" (Bell, Virginia Woolf, I:170) a delighted Woolf wondered "Was I less alarming as a Savage_ or as bad as ever?” (Letters I:455). The Post-Impressionist Exhibits offered Woolf a renewed opportunity to cross-dress: "once again, as in the Dreadnought hoax, [she was] identifying with those whom the West had dominated" (Stansky 211). But that solidarity was articulated, in both cases, through a political and aesthetic experiment with sartorial fashion in the global public sphere, which allowed her to cross boundaries demarcated by gender, class, race, and nation in and through complex and multivalent practices of transvestitism.

\section{A Society FOr OUR Mrs. Brown}

The early feminist fable "A Society," published in the 1921 collection of short stories Monday or Tuesday, ${ }^{6}$ includes a both thinly fictionalized account of the Dreadnought Hoax and an early, sustained riposte against the very same Mr. Bennett of "Mr. Bennett and Mrs. Brown.” In it, a group of pre-war women (whom Woolf would come to call "the daughters of educated men" in Three Guineas) "made ourselves into a society for asking questions" (5) about the deep structures of British imperialist

\footnotetext{
6 "A Society" was out of print for over sixty years. Leonard Woolf did not include it in the posthumous $A$ Haunted House and Other Short Stories because Woolf herself had decided not to include it in the collection of stories she'd planned to publish in 1942. See Leonard Woolf, "Foreword," 7.
} 
patriarchy. The story is, as Woolf herself knew, uncharacteristically didactic in tone. A few weeks before Monday or Tuesday's publication, Woolf had anticipated how the story would be reviewed: "And as for A Society though spirited, it is too one-sided" (Diary II: 98). Her predictions proved accurate, and even her fellow Bloomsberries were ungenerous in their reviews. Clive Bell wrote in the Dial that "'A Society' [is] quite beneath her genius," and Desmond MacCarthy thought that "when, as in 'A Society,' she writes from contempt, her work is not her best" (qtd. in Dick 62). Woolf knew that "they don't see that I'm after something interesting" (Diary II: 106). ${ }^{7}$ Although certainly not as formally innovative as some of the other stories in the volume like "A Mark on the Wall" or "Solid Objects," "A Society" nevertheless develops an aesthetic experiment that prefigures the global modernist style of Woolf's later works through its imaginative rewriting of the Dreadnought Hoax, its argument with Arnold Bennett, and especially its depiction of women entering the global public sphere as a collectively self-fashioned society.

Upon the society's formation, Rose is assigned the task of boarding a British man of war disguised as an Ethiopian prince. The captain who discovers her subjects her to "six lights taps upon the behind" (5) — the very same punishment that Duncan Grant endured for his participation in the Hoax. Grant, who was abducted from his home and brought out to Hampstead Heath in his pajamas for the caning, "doesnt [sic] put up any

\footnotetext{
${ }^{7}$ Most contemporary critics have not seen it either, focusing almost exclusively on the story's prefiguration of Three Guineas's "Society of Outsiders" when they consider it at all. Jean Guiget notes that "the germs of A Room of One's Own and Three Guineas" (342) are contained in "A Society"; Naomi Black argues that “"The story looks like a very preliminary version of Three Guineas" (109); Edward Hungerford claims that “A Society" begins to form "a sub-genre of the essay" (3) by using dialogue and fiction as occasion.
} 
fight," and when the naval officers "at once conceived an affection for him" and offered him a ride home, he refused; "Duncan Grant felt he would much rather go home in the tube in his slippers than be driven back by the officers" (Dreadnought 199). But Rose's response differs dramatically from Grant's. When the Captain arrives to punish her, Rose is still cross-dressed - this time, not as an Ethiopian prince, but as an English gentleman. "If six strokes avenge the honour of the King's Navy," Rose wonders quasi-rhetorically, "how many avenge the honour of a private gentleman?" (6).

After negotiating her retribution with the officer, he agrees that "if she gave him four strokes and a half in the small of the back ... it was his opinion that her honour would be as good as new" (6). Woolf satirizes the ceremonial punishment in part to achieve comic effect, but in so doing she also calls attention to Rose's second male disguise. Rose's masquerade is only partially discovered, and she is never exposed as female. Jean Kennard points out that because Woolf's Abyssinian costume for the Dreadnought Hoax resembled English ladies' dresses, she was effectively a woman disguised as a man in woman's clothing; dressed first as an Ethiopian prince and then as an English gentleman, Rose further complicates the equation. Her gentlemanly drag enables her act of reciprocal punishment — a significant departure from Woolf's own somewhat traumatic experience in the aftermath the Dreadnought Hoax.

Although Woolf was not physically reprimanded for her participation in the Hoax, she was subjected to tremendously unkind scrutiny from friends, family, and loved ones, as well as from the popular press. The newspapers lauded the male hoaxers' cleverness, but were scandalized by a woman's participation. Her brother Adrian recalls that she was dubbed "a common woman of the town" (Stephen 52) by the naval officers, and only a 
few days after the Hoax, Woolf wrote to her dear friend Violet Dickinson that "Two interviewers have already been today, and one wishes for my portrait in evening dress!" (Letters I: 422). "Our friends and relations were furious," Woolf remembers, noting in particular a letter from her cousin Dorothea Stephen accusing her of "the worst of taste, and showed that I was —oh, all sorts of disagreeable things, she must cease to have anything to do with me" (Dreadnought 200). Even members of Bloomsbury criticized her for participating in the Hoax: Vanessa, Clive Bell, and Lytton Strachey all disapproved, and were not shy about letting her (and all their acquaintances) know.

Thus, in rewriting the aftermath of the Dreadnought Hoax in "A Society," Woolf has Rose redress the wrongs done unto herself even while showing, through Rose, the ugly, slippery nature of masculine clemency. She cannot ask how "many strokes might avenge the honour" of a woman condescended to and bullied by the military, mass media, family, and friends. The question is rhetorical, but because "A Society" is ultimately "a society for asking questions," the very form of the rhetorical question gives rise to the story and forms its most central trope. As the society investigates the social, economic, and cultural institutions of British imperial patriarchy_including "the British Museum," "the King's Navy," "Oxford," "Cambridge," "the Royal Academy," "a meeting of business men," "concert rooms," "Law Courts" (5)—one institution remains opaque, impenetrable, mute. The society for asking questions is formed in 1909, but when "it's now 1914" (14) and the war begins, the society's activities (as well as the story's) halt altogether for five years, marked only by an asterisk before "The war was over and peace was in process of being signed" (14). The war does more than merely interrupt; it silences. Not until Three Guineas will Woolf fully attempt to answer the ostensibly rhetorical 
question posed in "A Society”-“"Why,' we cried, 'do men go to war?”” (14). But bookended by Poll's “"Why, why did my father teach me to read?"” (4) at its opening and “"I've done my best,' [Castalia] sighed, 'to prevent my little girl from learning to read, but what's the use?"” (15)) at its close, "A Society" nevertheless insists that for women, there can be no rhetorical questions at all, because all political questions are necessarily questions of the literary.

In this way, "A Society" responds in particular to the conditions of British imperialist patriarchy in the literary world, the subject of Woolf"s celebrated essay "Mr. Bennett and Mrs. Brown." Of the Monday or Tuesday stories, "An Unwritten Novel” is most often linked to "Mr. Bennett and Mrs. Brown," but "A Society" might be understood to prefigure Woolf's dissatisfaction with the systemic Edwardian chauvinism — epitomized for her, as always, in Bennett ${ }^{8}$ — that fails Mrs. Brown even as it shapes the formation of "the society for asking questions." In fact, "A Society" was initially conceived in direct response to Bennett's Our Women: Chapters on the Sex Discord, which had received considerable press (including a favorable review from fellow Bloomsberry Desmond MacCarthy, which had angered Woolf). Shortly after the publication of Our Women in 1920, Woolf tossed around the idea of "making up a paper upon Women, as a counterblast to Mr. Bennett's adverse views" (Diary II: 69), the draft of which eventually turned into "A Society."

\footnotetext{
${ }^{8}$ The story even contains an overt swipe at him: Castalia, who tries to prevent her daughter from learning to read because "our mothers did it, and their mothers, and their mothers before them. And they didn't complain," worries that "she'll ask me whether ... Mr. Arnold Bennett is a good novelist" (14-15). Of course, what Bennett's writing cannot do-as Woolf would show more fully three years later in her essay "Mr. Bennett and Mrs. Brown"—is represent the likes of Mrs. Brown.
} 
In Our Women, Bennett often comments on women's dress, dismissing female fashion as so much frivolity. But he seems not to realize that his argument undermines itself, casting women's fashion as a dynamic and creative aesthetic experiment. "In England," he writes, "the wife's dress 'allowance' is on the average too small; often it is absurdly small, and the wife is therefore constantly engaged in the performance of miracles, and in proving, to the confusion of science, that something can be created out of nothing" (166). Here, women's self-fashioning becomes a kind of magic in Marcel Mauss's sense, where magic is embedded in a specific social universe, a creative faculty that confounds modern scientific practice as it does contemporary religiosity. If, through fashion, women show that "something can be created out of nothing," then no wonder Woolf makes recourse to the same extraordinary ingenuity, innovation, and inventiveness of fashioning female character in "Mr. Bennett and Mrs. Brown":

I let Mrs. Brown slip through my fingers. I have told you nothing whatever about her. But that is partly the great Edwardians' fault. I asked them - they are my elders and betters-How shall I begin to describe this woman's character? And they said: "Begin by saying that her father kept a shop in Harrogate.... Ascertain the wages of shop assistants in the year 1878... Describe _ _ " But I cried: "Stop! Stop!".... This is what I mean by saying that the Edwardian tools are the wrong ones for us to use. They have laid an enormous stress upon the fabric of things. (332) 
The "Edwardian tools" are not at all the tools of redress, because "the wages of shop assistants" are mere fodder for the sort of anti-modern prose epitomized for Woolf in Bennett. Bennett cannot represent Mrs. Brown because he would reduce her to "one of those clean, threadbare old ladies" (322), "poorly dressed" (327), who wears "a brooch which had cost three-and-ten-three at Whitworth's bazaar; and had mended both gloves — indeed, the thumb of the left-hand glove had been replaced" (328).

This descriptive mode disembowels fashion as it does Mrs. Brown; it calls fashion nothing more than mere clothes, and it shrinks the whole of Mrs. Brown's character and consciousness into something as small as a stitched-up thumb-hole. To redress these wrongs, as Woolf shows with her characteristic elegance, modernist literary style will need lay "an enormous stress" not on "the fabric of things," but rather on the thing of fabric. If Woolf seeks to show "character in itself; that you may realize the different aspects it can wear" (321), she does so by way a style as sartorial as it is literary. Characters themselves may wear different aspects, but "human character" is "capable of appearing in any place; wearing any dress" because it is "the spirit we live by, [modern] life itself" (336-7).

If Mrs. Brown is to be "the healthy offspring of a close and equal alliance" (336) between "appearing in any place" and "wearing any dress," she is necessarily the daughter of global fashion. Woolf’s understanding of Mrs. Brown's modern “human character" is shaped by the ways in which "all human relations have shifted" in an increasingly global modernity. This becomes a signature technique of the late Woolf, brought to the fore most fully in The Waves's fluidity and permeability of characters who "have come together ... to make one thing" (172) through their aural echoes and 
seductive rhythms. Although "A Society” lacks The Waves's lyrical prose style, the story's "characters who are for the most part indistinguishable from one another and whose function is to express ideas rather than personalities" (Dick 55) have most often been regarded as the text's great aesthetic shortcoming. But the collective self-fashioning of the women in "A Society" personifies the very idea of modern personhood constituted in and through community, and the "society for asking questions" is itself a personality, as rich and dense and multifaceted as "our Mrs. Brown" (336) or, indeed, as any of The Waves' delicately interwoven interiorities. The characters of "A Society" might be better understood as an early effort at the method of The Waves's soliloquies, which trace the modern experience of becoming a global subject. But as so many readers have noted, its subjectivities bleed out, self-contained and yet ever seeping into one another with an exquisite relentlessness in just the fashion that "A Society"'s do. "The six characters were supposed to be one" (Letters IV: 397), Woolf suggested, casting the very notion of character as an aesthetic experiment, a mode of collective self-fashioning.

\section{Mind ANd Millinery}

If, as Christine Froula compellingly argues, The Waves "abandons conventional ideas of resemblance between image and object ... to explore a more expansive and abstract concept of being" (175), it does so by showing the uniquely intimate interrelation between garments and modern subjectivity that challenges the ontological divide. Woolf writes the very real materiality of the body as a mode of dress that can mediate between being — "the thing itself" - and the language can fashion being into anything at all. Clothes are not merely "things" swirling about The Waves, but rather a material 
manifestation of the tension between desire for individuation and compulsion to belong to a group. Fashion both individuates The Waves's characters and stitches them together, fulfilling the promise of collective self-fashioning in "A Society" and "Mr. Bennett and Mrs. Brown." Self-fashioning in The Waves cannot but be collective, as Bernard realizes that "I do not altogether know who I am-Jinny, Susan, Neville, Rhoda, or Louis: or how to distinguish my life from theirs" (276). Further, Woolf figures transindividual connections in The Waves as a "line that is spun from us lengthening its fine filaments" (66). In this way, The Waves becomes a textile text, "a wandering thread, lightly joining one thing to another" (36).

The Waves's densely interwoven characters thus "became clothed in this changing, this feeling garment of flesh" (124), where the body is cloaked in modernity's rapid pace of change-which is to say, in modern fashion, itself. Randi Koppen observes that, "Quite consistently, the characters in The Waves are known by their relation to clothing, specifically by certain recurring tags or epithets which seem to represent them to themselves and the world" (146), and one might fruitfully trace any of the characters' sartorial signatures: Jinny, thrilled by “the infinite variety of women's dresses” (169); Susan's agonized anti-fashion penchant for "wear[ing] a plain straw hat on a summer's day" (79); Rhoda's constant sense of nudity as she is ensconced in brown serge at school or "trapped in silk" (79) as an adult; the gilt cross on Neville's waistcoat, which allows him to reimagine his body as an "unprotected fibre" (164); and Bernard, whose "summing up" (the title that Woolf gave to the final chapter of The Waves) ultimately takes over the narrative, and who "shall leave only a cupboard of old clothes when I die" 
$(100) .{ }^{9}$ But it is Louis - the postcolonial subject leading the double-life of an agent in a shipping company who extends the commercial reach of capitalism by day, and a high modernist poet-translator by night — for whom the ardently fashioned lyric connects disparate victims of empire across the globe. Like Woolf's own "playpoem" (Diary III: 203), as she called The Waves, Louis's lyric hinges upon a fashion poetics that restructures imperialist power relations, replacing them with charismatic transmission, affective community, and cosmopolitan connection.

Jane Marcus's groundbreaking case that The Waves's “investigat[ion of] the origin of cultural power" ("Britannia” 142) reveals "the complicity of the poet in ... nationalism, war, and eventually, fascism" (Hearts 64) has sparked a slew of rich postcolonial readings of the novel. And yet, as Emily Dalgarno has recently noted, surprisingly the decidedly collusive postcolonial poet "Louis has received relatively little attention in discussions of The Waves" (135)—or at least, in discussions concerned with the cultural logic of empire-making and empire maintenance. An Australian everconscious that his accent marks him as "an alien, external ... who pass[es] so disjectedly" (94), Louis is simultaneously charmed and repulsed by imperialism: "How majestic their order is, how beautiful their obedience!" he thinks of Dr. Crane's schoolboys with the imperialist young Percival as their ringleader, "But they also leave butterflies trembling with their wings cut off" (47). Torn between his desperate desire to be included ("if I could be with them I would sacrifice all I know" (47)) and his acute awareness of their cruelty ("They make little boys sob in dark passages" (47)), Louis figures white male

\footnotetext{
${ }^{9}$ Further, it is notable that Bernard's last word is Woolf's, too: Leonard Woolf chose Bernard's closing line_-“Against you I will fling myself, unvanquished and unyielding, O Death!”-_for his wife’s epitaph.
} 
imperial power in terms of dress and undress: "You are all protected. I am naked" (96). He initially conceives of himself only in the first-person singular ("I") and the imperialists as a powerful, plural sodality (“you"). But as he comes, through poetry, to feel connected to other victims of imperialism, his perspective shifts. Louis imagines an alternative mode of affinity that is predicated upon neither "I" nor "you," neither nudity nor clothedness, but rather upon "us" and fashion, wishing that "some robe, should fold us about" (169).

Louis associates the modern bowler "hats bobbing up and down in perpetual disorder" that he observes on his lunch break with "we who pass so disjectedly, bobbing up and down" (94). He imagines he will "reduce...to order" (94) the diasporic group with whom he identifies. His idea of order at London lunch-hour has led critics including Ruddick, Joplin, and Phillips to misread Louis as a proto-fascist, but in fact Louis is a proto-modernist; he not only echoes T.S. Eliot, the St. Louis clerk-poet upon whom Louis is loosely based, but so too does he conjure Woolf herself, who writes of composing The Waves, "Odd how the creative power at once brings the whole universe to order" (Diary IV: 232). Not a totalitarian system that hierarchizes and restricts, Louis's order is an imaginative pattern designed to organize in every sense of the term. Further, his "creative power," like Woolf's in the "playpoem" of The Waves, takes lyric form in its striving "to make a steel ring of poetry that shall connect ... the bobbing billycock hats" (96). In connecting, or ordering, the hats, Louis yokes the "disjected" to one another through a poetics of fashion that "laces the world together" (127).

An angel of history if ever there was one, Walter Benjamin calls fashion "the tiger's leap into the past. Yet this leap occurs in an arena commanded by the ruling class" 
(Theses 252-3). Apropos of Benjamin, Louis must work within the bounds of imperial power (where "You are all protected. I am naked"), fashioning an alternative history for his global "society of outsiders" out of fashion, itself. Almost uncannily, Woolf makes recourse to the same language as Benjamin does to articulate Louis's crafting of an antiimperial history:

"We differ, it may be too profoundly," said Louis, "for explanation. But let us attempt it. I smoothed my hair when I came in, hoping to look like the rest of you. But I cannot, for I am not single and entire as you are. I have lived a thousand lives already. Every day I unbury-I dig up. I find relics of myself in the sand that women made thousands of years ago, when I heard songs by the Nile.... I was an Arab prince; behold my free gestures.... [I]t is for them that I do these antics, smoothing my hair, concealing my accent.... I am also the caged tiger, and you are the keepers with red-hot bars. That is, I am fiercer and stronger than you are, yet the apparition that appears above ground after ages of non-entity ... [will] make a steel ring of clear poetry that shall connect ... the bobbing billycock hats as I see them" (128, italics mine).

Louis is "the caged tiger" yearning to make the Benjaminian tiger's leap into his ancient past. And indeed, "this leap occurs in an arena commanded by the ruling class," or rather, in a "steel ring of clear poetry" that has excluded voices like his own. Louis's performance of assimilation gives way to an ancient history whose relics - like the "bobbing billycock hats" that are inseparable from "we who pass so disjectedly, bobbing up and down"- enter into an imaginary register, tracing the physical contours of absence. 
Here the material hauntings of history null the distinction between subject and object.

Louis's spectrality, his "non-entity," challenges the ontological divide through the absent presence of his material body, that is "naked" (96) not because it is "protected" as imperialist bodies are, but rather because it is "clothed in this changing, this feeling garment of flesh" (124).

Like Woolf in the Dreadnought Hoax, Louis "was an Arab prince"—and like Woolf in the Dreadnought Hoax, he too comes to identify with disparate affective communities, both ancient and modern, victimized by imperialism and its ideological structures. By excavating his self, Louis finds he is "now Plato companion of Socrates; the tramp of dark men and yellow men migrating east, west, north and south; the eternal procession, women going with attaché cases down the Strand as they went once with pitches to the Nile" (167). For The Waves, connecting the billycock hats necessarily means connecting migrant workers, African royalty, female laborers both ancient and modern, and alienated Australian shipping clerks. In this way, Louis "must weave together, must plait into one cable the many threads, the thin, the thick, the broken, the enduring of our long history" (202) that does the same work as The Waves, making each voice a strand and then stitching them together into a single thread. And yet, "“It breaks,' said Louis, 'the thread I try to spin; your laughter breaks it, your indifference.... This moment of reconciliation ... is to me black with the shadows of dungeons and the tortures and infamies practised by man upon man"” (218-9). Neither recognition nor reconciliation will suffice; what Louis demands is no less than redress - no less, indeed, than the appearance of "the sea-green woman ... contained in slippery satin" who can answer "what is the thing that lies beneath the semblance of the thing?" (162). 
That woman turns out to be Clarissa Dalloway, dressed in her own satin "silvergreen mermaid's dress[, 1]olloping on the waves" (Dalloway 171) of The Waves, who suggests that "the thing that lies beneath the semblance of the thing" might be fashion, itself. As Clarissa “turned, caught her scarf in some other woman's dress, unhitched it" (172), she figures fashion's capacity to connect, disconnect, and reconnect, to link people together like "a wandering thread, lightly joining one thing to another" (Waves 36). Like Louis, who traces lines across a map and "laces the world together," Clarissa's too is a global consciousness:

She felt herself everywhere; not 'here, here, here'.... Odd affinities she had with people she had never spoken to, some woman in the street, some man behind a counter-... [S]ince our apparitions, the part of us which appears, are so momentary compared with other, unseen part of us, which spreads wide, the unseen might survive, be recovered somehow attached to this person or that" (149)

Like Louis's “apparition that appears above ground after ages of non-entity,” Clarissa's "apparition, the part of us which appears" must have a phenomenal status, must give itself over to be looked at. It must appear in Hannah Arendt's sense, insofar as "every appearing thing acquires, by virtue of its appearingness, a kind of disguise" (Arendt 21). That disguise is fashion itself, which makes visible Clarissa's elusive "odd affinities" because it is very the modality through which they appear, attached to some person as her scarf attaches to "some other woman's dress." Thus Clarissa's theory of the self is 
necessarily collective; its appearance is intersubjectively fashioned, stitched into a social fabric that casts its nets across vast reaches of time and space.

Clarissa's sense of affinity, like Louis's, is global in its reach. The "unseen part of us, which spreads wide" in space and time is transgeographical and transhistorical, enmeshed with ancient Egyptian female workers, Arab princes, intellectual laborers from Greece and Rome like Plato and Catullus, "some woman in the street, some man behind a counter" (Dalloway 149) and the global diaspora of "dark men and yellow men migrating east, west, north and south" (Waves 167). Expansive enough to make subjects appear, reappear, and co-appear in unexpected, far-flung places attached to archives of the past and projections of the future, Woolfian affinity is a mode of collective self-fashioning that in turn fashions a world in which one "takes one's bearings from the idea, not the actuality, of being a world citizen" (Arendt, Lectures, 76) who "fe[els one]self everywhere; not 'here, here, here"' (Dalloway 149).

Clarissa's "transcendental theory" nulls the distinction between self and other, presence and absence, because Woolf integrates its politics with everyday praxis and especially with aesthetics. It is Peter Walsh, who recalls "almost thirty years" (149) after this exchange that "Clarissa had a theory in those days" (148), and the "unseen" Clarissa, on top of an omnibus going up Shaftesbury Avenue decades earlier is "somehow attached" to Peter's later self, "recovered" by his memory and by the text, itself. All the while, the "apparitional," appearing Clarissa "is mending her dress; mending her dress as usual, he thought; here she's been sitting all the time I've been in India; mending her dress" (40) an activity that signifies to Peter all the frivolity of her life, but which figures for Woolf 
the novel's practice of densely interwoven intersubjectivity that connects Clarissa even to "people she had never spoken to" like Septimus Smith.

That Clarissa feels "somehow very like him—-the young man who had killed himself" (182) is, in Froula's lovely turn of phrase, "a very garment of consolation, that she spins out moment by moment as her mind tosses up metaphors" (101). The appearing Clarissa mends her "silver-green mermaid dress" for a party even as the unseen Clarissa travels with Peter to India, or to Septimus's window. If Clarissa's appearing apparition is Louis's "slippery satin, the sea-green woman," then her unseen self—attached to Septimus - figures his connecting of the "billycock hats" because Septimus, in his last act before suicide, "look[s] at the fashion papers" and then styles "a hat for Mrs. Filmer's married daughter" (138).

What had she got in her work-box? She had ribbons and beads, tassels, artificial flowers. She tumbled them out on the table. He began putting odd colours together-for though he had no fingers, could not even do a parcel, he had a wonderful eye, and often he was right, sometimes absurd, of course, but sometimes wonderfully right.

"She shall have a beautiful hat!" he murmured, taking up this and that, Rezia kneeling by his side, looking over his shoulder. Now it was finished - that is to say the design....

It was wonderful. Never had he done anything which made him feel so proud. It was so real, so substantial, Mrs. Peters' hat.

"Just look at it," he said. 
Yes, it would always make her happy to see that hat. He had become himself then, he had laughed then. They had been alone together. Always she would like that hat. (140-141)

A gifted stylist, Septimus's "wonderful eye" for fashion guides his fashioning of the hatas-gift; he "put[s] odd colours together" just as Clarissa feels "odd affinities." The hat is the occasion for bringing together Septimus's apparitional, appearing self and Mrs. Peters's unseen self. Just as Clarissa's younger self appears only through its attachment to Peter's memory, Mrs. Peters appears in Mrs. Dalloway only through her attachment to Septimus. Stitching the unexpected together into something "beautiful," "wonderful," "real, "substantial," Septimus connects himself to Mrs. Peters through the hat just as Louis connects people by connecting "billycock hats."

Be it Septimus's "straw hat for Mrs. Peters" (139) or Louis's "billycock hats," the Woolfian hat models an alternative political economy: the value of the hat increases precisely because it is given freely, and because - as Mauss, in his magisterial study of the gift, shows- "to give something is to give a part of oneself" (10). Septimus discovers that in fashioning a hat, he fashions himself: "he had become himself, then," the very "the unseen part" of himself that he can give to Mrs. Peters as a gift that will allow him to appear and reappear. What Septimus most celebrates - what makes him feel that "Never had he done anything which made him so proud"-is that the hat is a gift. Its very fashioning "would always make her happy to see that hat" because the hat attaches his unseen self to hers. As Jennifer Wicke shows, the gift "is apposite in the extreme for Woolf's materialism: that is, the more a totem or fetish or auratic sacred object is given 
away, the more it (or its powers) are kept" ("Frock" 226, italics in original) because the gift collectively fashions its giver and its receiver, stitching them to one another and making them both appear together. ${ }^{10}$ Only moments after "it was finished - that is to say the design" of the hat, Septimus takes his own life. But the hat promises that even if the “apparitional” Septimus ceases to appear, the unseen Septimus "spreads wide, the unseen might survive, be recovered somehow attached to" Mrs. Peters's hat as it is to Clarissa's "silver-green mermaid dress."

\section{Hand in Glove}

As the three extant versions of Mrs. Dalloway's celebrated opening sentence reveal, Woolf initially wrote, "Mrs Dalloway said she would buy the silk herself." Then, she crossed out "silk" and replaced it "gloves." This second incarnation of the line_- "Mrs Dalloway said she would buy the gloves herself"-forms the first sentence of the short story "Mrs. Dalloway in Bond Street," which was initially intended to be the first chapter of Mrs. Dalloway. By the time Woolf revises the sentence a third time for Mrs. Dalloway, her gloves disappear entirely from the novel's opening sentence, replaced by the famous flowers. ${ }^{11}$ But gloves reappear in To The Lighthouse, where Mrs. Ramsay's single glove becomes the occasion for Lily Briscoe's ontological theory. Lily's meditation builds upon Clarissa's global "here, here, here": both hinge upon the phenomenal status of a self that

\footnotetext{
${ }^{10}$ Wicke links the gift to fabric in particular, arguing that "Woolf's writing could derive from a material, historical feature inherent in cloth and clothing ... of fabric as a historically feminized exchange" (226), especially vis-à-vis Annette Weiner's ethnographic research on Samoan fiber mats and Polynesian batiks.

${ }^{11}$ For a genetic approach to Mrs. Dalloway, see Ferrer.
} 
appears in and through clothes, and both insist upon that very appearance as necessarily intersubjective.

Lily wonders, "What was the spirit in her, the essential thing, by which, had you found a crumpled glove in the corner of a sofa, you would have known it, from its twisted finger, hers indisputably?" (52). That “essential thing”— not unlike Louis's "thing that lies beneath the semblance of the thing” (Waves 162) — is Mrs. Ramsay's exquisitely fashioned self. The "spirit in her” becomes a spirit on her: Mrs. Ramsay’s glove externalizes her interiority. If within "the secret chambers of the mind and heart" of Mrs. Ramsay are "tablets bearing sacred inscriptions, which if one could spell them out would teach one everything" (53), then the very translation that Lily craves is to be found in Mrs. Ramsay's glove. The "essential thing” that Lily yearns to know in Mrs. Ramsay cannot be "written in any language known to men" (53), but it can be written in fashion.

Further, Lily’s ontological theory of Mrs. Ramsay’s being makes inseparable “the secret chambers of the heart and mind" and the body of "the woman who was, physically, touching her” (53). Like Septimus's hat, Mrs. Ramsay’s glove—wedged between sofa cushions - conjures her absent body by retaining her body's shape. The glove's "twisted finger" marks it as "hers indisputably," making her body present even as it is absent. In this way, the twist of the glove adds a wrinkle to Clarissa's theory. For Clarissa, "our apparitions, the part of us which appears" (Dalloway 149) are corporeal; apparitions are, for Mrs. Dalloway, bodies presented to the world as images and things cloaked in the clothes that make them legible. For Lily, too, the garment makes the body appear. But Mrs. Ramsay's interior self-her "essential thing," or Clarissa's "other, unseen part of us" (Dalloway 149) — also appears in clothes. Lily's “essential thing” is Louis's “semblance 
of the thing" (Waves 162). Lily enmeshes the thing and its semblance, hoping she and Mrs. Ramsay might "becom[e], like waters poured into one jar, inextricably the same" (53).

And "this was the glove's twisted finger" (53): Lily's ontological theory allows her to collectively fashion Mrs. Ramsay and herself into a single being. Her portrait of Mrs. Ramsay at last provides the "unity that she desired" (53) because- as Wilde so succinctly puts it in The Picture of Dorian Gray_- "every portrait that is painted with feeling is a portrait of the artist, not of the sitter" (10). Lily's painting, much like Mrs. Ramsay's glove, summons forth the absent body of Mrs. Ramsay, disclosing the ontological difference that launched her painting to begin with. But so too does it blend Lily with Mrs. Ramsay, because Mrs. Ramsay’s “essential thing” has "spread wide” (Dalloway 149) across the space of Lily's consciousness as the abstract painting spreads wide across the space of the canvas. Lily paints neither a figure or a landscape as an absence: she "scored her canvas with brown running nervous lines which had no sooner settled there than they enclosed (she felt it looming out at her) a space" (161-2). Making negative space appear, Lily's painting bridges the gap between herself and her subject. Hers is a portrait of the artist as Mrs. Ramsay.

Like the glove, Lily's elegiac portrait captures “the essential thing” in Mrs. Ramsay's present absence. But a different fashion accessory entirely inspires the painting's first strokes. Mr. Ramsay’s "remarkable boots" (157) "unt[ie] the knot in imagination" that has prevented Lily from "actually taking her brush and making the first mark" (161). In a tenderly comic exchange, Lily compliments the grieving Mr. Ramsay’s footwear, and then immediately worries that she has "praise[d] his boots when he asked 
her to solace his soul” (158). But just as Mrs. Ramsay's glove figures her complex interiority, so too do Mr. Ramsay's boots solace both his and Lily's own grieving souls: "Lily thought, looking down at them: sculptured; colossal; like everything that Mr. Ramsay wore, from his frayed tie to his half-buttoned waistcoat, his own indisputably.... Thus occupied he seemed to her a figure of infinite pathos" (157-8). As Mrs. Ramsay’s glove is "hers indisputably," so too are Mr. Ramsay's boots "his own indisputably" (158); his boots, like her glove, capture "the essential thing" that allows Lily to feel "so tormented with sympathy for him" (158). Here, Woolf recasts fashion as inseparable from empathy, and only two pages after this exchange, Lily at last makes the first stroke of her painting of Mrs. Ramsay because fashion has dynamized her vision. As a glove became the occasion for an ontological theory, boots become the occasion for an aesthetic elegy — and not for the first time Woolf's oeuvre, either.

\section{In Someone Else's Shoes}

Just as Mrs. Dalloway very nearly began with Clarissa's gloves, Jacob's Room very nearly did not end with Jacob's shoes. The novel's closing lines_-“"What am I to do with these, Mr. Bonamy? She held out a pair of Jacob's old shoes" (176)—were, in an earlier draft, followed by "They both laughed. The room waved behind her tears."12 Woolf cut the two additional sentences after Betty Flanders's query about her dead son's empty boots, and her revision shifts the emphasis away from Betty grief-stricken response to her son's death and toward the tender, hopeful collective self-fashioning that

\footnotetext{
${ }^{12}$ See Bishop 130. Bishop cites the manuscript in the Berg Collection at the New York Public Library, which has since been transcribed.
} 
Jacob's shoes portend. The revision also reframes the formal bookending that the two cut lines would have enacted, as the novel opens with Betty's weeping and the young Jacob's memento mori, a sheep's skull he finds on the beach.

Woolf agonized over how Jacob's Room, her elegy to the survivors of World War I, would stack up against those of her peers, worrying after a conversation with T.S. Eliot in which he'd praised Ulysses that “what I'm doing is probably being better done by Mr. Joyce" (Diary II: 69). But she maintained that "There's no doubt in my mind that I have found out how to begin (at 40) to say something in my own voice" (Diary II: 186). In turn, Jacob's Room — ventriloquized through the voice of an essayist-narrator who would become the hallmark of Woolf's writing - faces and reconstructs literature of the West by writing without a self at all. Jacob's Room sublimates character and plot to social forces that drive modern lives, "unwrit[ing Jacob's story] to expose the social forces that initiate him into masculinity and leave him dead on the battlefield" (Froula 69). In refusing her readers Jacob's interiority, Woolf renders it impossible to read the life and death of Jacob Flanders as an excavation of his interior self; instead, Jacob's Room refashions narrative form, telling the story not of Jacob Flanders, but of a generation fashioned by war-a mass elegy.

Readers began complaining about the emptying out of Jacob from the moment of the novel's publication, calling it a series of "notebook entries" (Majumbar 99) with "no particular story to tell" (Majumbar 103) and "no narrative, no design, above all, no perspective" (Majumbar 107). Early readers (and even some contemporary critics) attributed the narrative style of Jacob's Room to negligence or failure on the part of the author, but Woolf"s deliberate turn away from the "pins and needles" of "character- 
drawing" (155) allows her to make narrative style material — often quite literally. Woolf wanted to represent how the "shift in scale — the war, the sudden slip of masses held in position for ages - has shaken the fabric" ("How It Strikes" 357) of the world, and in order to do so, she had crafted a new literary form to confront and interpret the gravity, impact, and indeed, the scale of these changes. That literary form takes the form of fabric. A textile text, Jacob's Room is both a model for and a model of "the fabric through which the light must shine, if shine it can - the light of all these languages, Chinese and Russian, Persian and Arabic, of symbols and figures, of history, of things that are known and things about to be known" (42). By patching global languages, aesthetics, histories, and futures into a memorial quilt, Jacob's Room makes fabric its mythic method.

Woolf's "fabric through which the light must shine" casts its nets across deep time and deep space. If it "lace[s] our days together" (93), it makes of past and future a seamless garment; if it "make[s] of life a perfect globe" (93), it does so by stitching "Chinese and Russian, Persian and Arabic" into the pre-war days as much as the geopolitical structures that will drive modern lives in the wake of world war. Casting fashion's relentless futurity as world-historical, Woolf—like Benjamin, who sees "history in the guise of fashion" (Arcades 200) — reads dress as an angel of history crashing through world war. Such is the promise of Jacob's Room, where fashion grasps swiftly upon the past and shifting hemlines signal shifting material conditions:

Fix your eyes upon the lady's skirt; the grey one will do-above the pink silk stockings. It changes; drapes her ankles - the nineties; then it amplifies - the seventies; now it's burnished red and stretched above a crinoline - the sixties; a 
tiny black foot wearing a white cotton stocking peeps out. Still sitting there? Yes—-she's still on the pier. (19)

Upper-class women's wear here enables a kind of time travel, and Jacob's Room touches down briefly on decade-long stepping stones as it propels backward into the nineteenth century. But it skips over the harrowing fashion of its own moment, which would reveal how thoroughly world war had permeated even arenas as seemingly untouched as women's fashion. As the editor of the early twentieth-century fashion magazine Girl's Realm proclaimed, "nothing but black will be possible for some months to come" (qtd. in Potter 18) because — as Rezia so succinctly puts it in Mrs. Dalloway—"Everyone has friends who were killed in the War" (66).

As early as the Second Anglo-Boer War, clothing manufacturers had already started trying to boost sales by way of military association. Women's magazines ran advertisements encouraging smartly dressed grieving alongside columns that appealed to women's patriotic duty to boost British trade during war time by dressing well. Hartley and Co., for example, made a coveted "Lord Roberts Cloth for Ladies," and advertisements in women's magazines were increasingly geared toward officers' widows and the mothers of fallen soldiers, from "Mourning of Today at William Barker's (Islington)" to “Peter Robinson's Mourning Warehouse: Every Requisite for Mourning Attire, adapted to the latest fashion at moderate prices" (Anon., Lady's Pictorial, n.pag.). Although these advertisements are mercenary, insensitive, and even predatory, they also put forth the defiant hope for a future in which a woman appearing in public in a little black dress signals neither grief nor mourning, but versatility and simple elegance. 
Dress's appeal to world war's international survivors-including, of course, readers of Jacob's Room - is to "Detest your own age. Build a better one" (107) as Jacob himself had once planned to do before he was killed on the battlefield.

Like Benjamin, who writes that "it is fashion alone that overcomes death" (Arcades 1234), Jacob's Room's closing lines_-“"What am I to do with these, Mr. Bonamy?' She held out a pair of Jacob's old shoes" (176) —deliver the reader into the future, asking: if Jacob has not died with his boots on, who will fill his shoes? In this way, Jacob's boots recall Heidegger's discussion of Van Gogh's Old Shoes with Laces in "The Origin of the Work of Art." Heidegger suggests that "a pair of shoes for instance ... is a half thing, because characterized by thingliness, and yet it is something more; at the same time it is half art work and yet something less, because lacking the self-sufficiency of the art work" (659-60). Like Heidegger, Jacob's Room asks how the subject of thought arises in and through the world; and like Heidegger, Woolf understands the work of art not as an art-object, but rather as work itself.

Douglas Mao argues that in the last lines of Jacob's Room, "the whole energy of Jacob's Room seems directed toward the culminating scene in which Jacob's mother and Bonamy confront Jacob's relics, only to be left unsatisfied by this mediation, which can never be substitution: "“Jacob! Jacob! cried Bonamy"," (54-5). But importantly, the novel does not close with Bonamy's mourning howl. Rather, Jacob's Room ends with the pair of Jacob's shoes that half-thing, half-art work - a hierophantic relic that can make present Jacob's absent body: 
Listless is the air in an empty room, just swelling the curtain; the flowers in the jar shift. One fibre in the wicker arm-chair creaks, though no one sits there....

"Jacob! Jacob!" cried Bonamy, standing by the window. The leaves sank down again.

“Such confusion everywhere!” exclaimed Betty Flanders, bursting open the bedroom door.

Bonamy turned away from the window.

"What am I to do with these, Mr. Bonamy?"

She held out a pair of Jacob's old shoes. (176)

Despite the presence of Jacob's miscellaneous things, Jacob's room is empty because Jacob is not in it anymore. His "letters strewn," "a bill for a hunting-crop," "the wicker arm-chair," "the flowers in the jar" (176) have all been inventoried, but his boots are "listless" in every sense: they cannot be collected like the rest of Jacob's things, nor neatly categorized like the documents or interior decorations he has left behind, because Jacob's shoes are not a Heideggerian thing. Rather, per Heidegger, the "equipmental quality of equipment was discovered. But how? Not by a description and explanation of a pair of shoes actually present.... The art work lets us know what shoes are in truth" (665). Jacob's Room, Woolf's art work, lets us know that Jacob's absence is "what shoes are in truth." The reason that Jacob's shoes remain in his room at the novel's end is, of course, because Jacob has died in the standard-issue ammunition boots of the British military uniform. But in holding out a pair of Jacob's old shoes, Woolf holds out the promise that 
Jacob might yet still appear_- "somehow attached," as Clarissa Dalloway says, "to this person or that" (149), because the very form of Jacob's Room, which from the first evacuates Jacob from the novel that bears his name, leaves no doubt that Jacob has never been in Jacob's Room.

Putting forth the possibility that even without Jacob himself, Jacob's shoes can still be laced, Woolf suggests that those very same shoes might yet "lace our days together and make of life a perfect globe" (93). As Woolf weaves the materiality of Jacob's shoes into the literary materiality of Jacob's Room's experimental form, Heidegger weaves the materiality of such aesthetic forms into material conditions. Like Heidegger, for whom art grounds history because it shows how subjects understand, maintain, and transform their historical moment, Woolf reimagines and reorients historical ontology in Jacob's Room's closing lines. Heidegger writes that "the work opens up a world and keeps it abidingly in force. To be a work means to set up a world. But what is it to be a world?" (672). Woolf answers: to be a world is to reflect and to refashion "the fabric through which the light must shine" (42), to be both a model of and a model for an unwritten global future.

\section{UNIFORMS AND UNIFORMITY}

The narrator of Jacob's Room observes the Cambridge students "pass into service, how airily the gowns blow out as though nothing dense and corporeal were within. What sculptured faces, what certainty, what authority controlled by piety, although great boots march under the gowns" (32). In this regard, Jacob's academic uniform is not so far removed from his military one: in both, he "pass[es] into service" of a patriarchal 
institution; in both, clothing subjects him to a rigid system in which sartorial accessories signify "certainty" and "authority"; in both, he is stripped of individual personality, made identical to any other member of the group and depersonalized; in both, his body is erased, "as though nothing dense and corporeal were within" the garment that, instead of making Jacob appear, makes him disappear.

Military dress was a theme that Woolf was already exploring in 1922 with Jacob's Room, but by the mid-1930s - with fascism on the rise, the Spanish Civil War (in which Woolf lost her beloved nephew Julian) raging, and Europe preparing for another world war - military dress had taken on renewed and urgent political meaning. In Three Guineas (1938), Woolf makes explicit the connection between male, anti-fashion uniformity and the sinister politics of militaristic mandate, showing definitively that "the connection between dress and war is not far to seek" (26). Because "your finest clothes are those that you wear as soldiers," military uniforms seduce young men with "the red and gold, the brass and feathers" (26-7) that cover over institutionalized brutality with ornament. As Woolf reveals, male academic spectacle and male military spectacle perform the same fascist hierarchies. If military uniforms - whether the "Blueshirt" adopted by the party of British fascists from 1927, the "Blackshirts" worn by the Union of Fascists in 1932, or the "Redcoat" of the British army — encourage war, academic regalia "encourag[es] a disposition toward war" (26), an "emotion ... of the utmost violence" that inflict "flesh wounds," (212) just as surely war does.

Responding to imagined letters, Woolf initially conceived of Three Guineas as a discursive response to questions like "Shd. women smoke. Short skirts. War—\&c" (Diary IV: 361) that link fashionability to the violence of fascism and war, the exclusion 
of women from the public sphere, and the systemic institutionalization of dominance and submission that shapes them both. Although critics have, since the moment of its publication, misunderstood Woolf's radical socialist feminism and been quick to lodge against Three Guineas the accusation of elitism, claiming that Woolf pays too little attention to differences in race, class, and nation in her brand of feminism, Woolf herself never claims to speak for all women everywhere in Three Guineas. In fact, she articulates her position in materially specific terms from the very first: as a woman with an independent income, she acknowledges that her response may not be the same as that of someone in a different class, racial, national, or gender position.

The three essays in Three Guineas set about revealing what "connection is there between the sartorial splendours of educated men and the photograph of houses and dead bodies" (26), and Woolf's reading notes evince her close attention to a wide range of ceremonial dress during the course of Three Guineas's composition. The famous photographs Woolf included in Three Guineas show English professional and military men in all their "sartorial splendour," including an academic procession at Cambridge and an Admiral covered in medals where "every button, rosette and stripe seems to have some symbolical meaning" (24) designed to "emphasize their superiority over other people, either in birth or intellect, by dressing differently" (27). Further, Barbara Green's archival research shows that Woolf's scrapbooks from the period include countless newspaper cuttings on the topics of official orders to regulate dress for royal funerals and coronations, reports of committees commissioned to fashion "smarter walking-out 
uniforms" for the military, and even the initiation of a project for the redesign of postal workers' uniforms. $^{13}$

As Green (among others) has charted, Woolf's argument about men's military uniforms revises J.C. Flugel's theory of the "great masculine renunciation" (113) of fashion. Flugel, whose The Psychology of Clothes was published by Woolf's own Hogarth Press in 1930, argued that bourgeois masculinity had, by and large, no stake in fashion, and that uniforms were a rare exception borne out of male narcissism. Woolf agrees that men derive narcissistic pleasure from clothes, but she reads this as the rule and not the exception. The ridiculousness of these frills lies for Woolf in their pointless precision and utter illegibility: "no single pair of eyes can observe all these distinctions, let alone account for them accurately" (24). Each accessory meticulously marks its wearer's social position within a hierarchical system. The very patriarchal values that permeate England's cultural institutions from the university to the military are crystallized in those masculine uniforms, which are archaic, static, and unchangingwhich is to say, antithetical to the dynamic modernity of fashion.

Academic uniforms, like the ones displayed in the photograph of a Cambridge procession included in Three Guineas, serve an "advertisement function" like "tickets in a grocer's shop":

instead of saying 'This is margarine; this pure butter; this the finest butter in the market,' it says, 'This is a clever man- he is a Master of Arts; this man is a very clever man- he is a Doctor of Letters; this is a most clever man-he is a Member of the Order of Merit.... We can say that for educated men to emphasize their

\footnotetext{
${ }^{13}$ See especially pages $146-9$ in Green.
} 
superiority over other people, either in birth or intellect, by dressing differently ... rouse[s] competition and jealousy_emotions which ... encourag[e] a disposition toward war. If we can then express the opinion that such distinctions make those who possess them ridiculous and learning contemptible, ... we can refuse all such distinctions and all such uniforms for ourselves. (26-7)

In advertising the intellectual achievements of its wearer, academic regalia casts people as commodities by displaying their value to the gross national product. Where academic uniforms turn people into groceries, military uniforms turn them into instruments of war. Uniforms, in this way, erase the very real materiality of the bodies that wear them "as though nothing dense and corporeal were within ... although great boots"- - like Jacob Flanders's - "march under the gowns" (Jacob 32) of academia and militarism alike. Further, and even more pernicious, uniforms set up hierarchies that categorize and rank the value of individual human beings as if they were goods, turning people into Heideggerian things to be listed like the objects in Jacob's room. Such hierarchical inventorying of human beings, Woolf shows, breed antagonism, resentment, hostility, and violence, thus "encouraging a disposition toward war."

For this reason, Woolf's plan for an "experimental college" rejects "all such distinctions and all such uniforms" and centers on reclaiming fashion as an important political, aesthetic, and philosophical lens through which to teach disparate victims of British imperialism about the anti-fashion structures that oppress them: 
the arts that can be taught cheaply and practised by poor people ... the art of understanding other people's lives and minds, and the little arts of talk, of dress.... The aim of the new college, the cheap college, should be not to segregate and specialise, but to combine. It should explore the ways in which mind and body can be made to co-operate; discover what new combinations make good wholes in human life. (43)

Woolf argues that to recover the bodies and the boots beneath the uniforms, students must be taught to empathically project themselves into someone else's - indeed, perhaps even Jacob Flanders's — shoes. The project is to be achieved through language and fashion, "the little arts of talk, of dress," which stand in such stark contrast to the indecipherable code of uniforms. Uniforms depersonalize, "segregate and specialize" individuals; they camouflage social solidarity, democratic community, the material bases of modern life, and the cosmopolitan "art of understanding other people's lives." In rejecting the sinister social logic of the uniform, Woolf's affordable, accessible university teaches the building of connection and "combination" as process that, like fashion, is simultaneously individual ("mind and body") and transindividual ("good wholes in human life"). Students at Woolf's "experimental college" will take up the same questions that her own work does, exploring how fashion and language, working together, can forge "new combinations" both within and between individual human beings.

Because self-fashioning is on the other end of the political spectrum from the social logic of uniforms, Woolf hesitates over donating her guinea to "women whose professions require that they should have presentable day and evening dresses" (179) in 
Three Guineas's second epistle. Patriarchal institutions, including the professions and the university, cooperate with militaristic fascism, and Woolf refuses to perpetuate them. She worries that “if we help an educated man's daughter to go to Cambridge are we not forcing her to think not about education but about war?" (152). Thus Woolf's guinea is contingent: if its effect would be to deck women out in the same judge's wigs, academic robes, and military uniforms that underwrite the systemic practices "of dominating other people, ... of ruling, of killing, of acquiring land and capital" (34), then she will not donate to the cause of dressing women for the professions. But on the condition that professional women dedicate their lives toward working to "abolish the inhumanity, the beastliness, the horror, the folly of war" (151), Woolf agrees to contribute her guinea. She supports the endeavor of dressing women for the professions insofar as those women, dressed as they will be in "presentable day and evening dresses" but never in uniform, might refashion the very institutions they enter dressed as such.

By “dispens[ing] with personal distinctions_-medals, ribbons, badges, hoods, gowns — not from any dislike of personal adornment, but because of the obvious effect of such distinctions to constrict, to stereotype and to destroy" (134-5), women can ally themselves with "any other human being, whether man or woman, white or black" (164), "of whatever sex, class, or colour" (205), who have also been subjected to systemic imperialism. For Three Guineas, there is no one kind of difference; to oppugn one form of oppression is to oppugn them all. In this way, those who struggle against tyranny, domination, and dispossession in all their myriad forms become a "Society of Outsiders" that interrupts the familiar dominant structures with the poetics of collectively selffashioned community. Though founded upon what might be shared in common, the 
Society never meets, never collects dues, and is "without office, meetings, leaders, or any hierarchy" (135). And yet, Woolf insists, the Society is anything but invisible. As she shows with an example, it makes recourse to fashion as a mode of appearing. Woolf points to the Mayoress of Woolwich, a Society member "would not even do as much as to darn a sock to help in a war" (137). Woolf commends her "courageous and effective experiment in the prevention of war by not knitting socks" (137) because her experiment is simultaneously aesthetic and political: allowing the hole in the sock to remain as it is exposes the snags, loose threads, and tears in the social fabric. In this regard, Mayoress Mrs. Rance is an extension, in extremis, of Mrs. Brown, who "had mended both glovesindeed, the thumb of the left-hand glove had been replaced" ("Mr. Bennett" 328). In allowing her patchwork to remain visible, Mrs. Brown refuses to be integrated seamlessly into the reductive caricatures of the realist novel just as Mrs. Rance refuses to assist in tidy stitching-up of supposedly benevolent militarism.

\section{DRESSING THE Wound}

Three Guineas generated a huge and varied response from its readers, as evinced in Anna Snaith's and Brenda Silver's meticulous readings of eighty-two letters from correspondents. Further, it was - and continues to be - met with charges of ivory tower elitism (see, among others, Leavis, Cunningham, Carey, and Jonathan Rose; Melba Cuddy-Keane's Virginia Woolf, the Intellectual, and the Public Sphere an important corrective to these readings of Woolf.) Among Three Guineas's interlocutors was a Yorkshire textile worker and unsuccessful Labour candidate for the local council named Agnes Smith, with whom Woolf continued to correspond until her death in 1941. Though 
an admirer of Three Guineas, Smith critiqued Woolf for not having acknowledged that "the problems with which you deal are those of the working woman also" (qtd. in Silver, “Three Guineas," 268), and proposed to write a political pamphlet similar to Three Guineas that would explore its questions in the framework of exploited female labor in the textile industry. Woolf heartily encouraged Smith's project, and offered to publish Smith's work through her own Hogarth Press - a promise that she no doubt would have kept had she not died before she could print Smith's A Worker's View of the Textile Industry. $^{14}$

Smith's particular “Worker's View” has been discussed by Froula (275), Briggs (334), and Jonathan Rose (401), but the fact that her employment was in the wool "Textile Industry" is crucial, especially insofar as Woolf characterized her own work the "lapsing into that stream which people call, so oddly, consciousness, and gathering wool" (“Middlebrow” 202). Wool-gathering was a process of picking up stray bits of sheep's wool caught on bushes that, as early as the sixteenth century, came to be a metaphor for imaginatively letting one's mind wander, and Woolf makes the metaphor material. In producing textiles as in producing texts, one must engage in the intellectual labor of weaving a social fabric from organic matter.

In fact, wool would become the key term through which Woolf articulated her life's work only months before she ended it:

And so I go on to suppose that the shock-receiving capacity is what makes me a writer. I hazard the explanation that a shock is at once I my case followed by the

\footnotetext{
14 The study was eventually published in 1944 by Hillcroft Studies.
} 
desire to explain it. I feel that I have received a blow; but it is not, as I thought as a child, simply a blow from an enemy hidden behind the cotton wool of daily life; it is or will become a revelation of some order; it is a token of some real thing behind appearances; and I make it real by putting it into words. It is only by putting it into words that I make it whole; this wholeness means that it has lost its power to hurt me.... From this I reach what I might call a philosophy; at any rate, it is a constant idea of mine; that behind the cotton wool is a pattern; that we- - I mean all human beings_-are connected with this; that the whole world is a work of art; that we are parts of the work of art.... I prove this, now, by spending the morning writing. (Moments 72-3)

That Woolf makes recourse to "cotton wool" is no coincidence: invented by Dr. Joseph Sampson Gamgee of Queen's Hospital in Birmingham in the late 1880s, cotton wool is an absorbent surgical gauze that was and is still used to dress the war wounds of soldiers. The "cotton wool of daily life" protects against the shock of acute consciousness, which hits Woolf like a "blow." Characterized by the extraordinary violence of "a peculiar horror and a physical collapse" (72), such "moments of being," as Woolf calls them, tear through the cotton wool bandage and inflict psychic wounds upon their perceiver.

Woolf dresses those wounds of consciousness not with scraps of cotton wool, but rather with writing, because in "lapsing into that stream which people call, so oddly, consciousness, and gathering wool," she collects "the cotton wool of daily life" that is the raw material of the world. Woolf creates out of whole cloth, but "it is only by putting it into words that I make it whole." She shows how "the whole world is a work of art" to 
which "we-I mean all human beings - are connected" by stitching literature into a social fabric as she stitches individuals to each other. In Maurice Merleau-Ponty’s ontology as in Woolf"s "moments of being," "the whole fabric of the sensible world comes, and with it, come the others who are caught in the fabric" (330). If "behind the cotton wool is a pattern," that pattern is "whole fabric of the sensible world," the whole cloth from which the scraps of cotton wool are plucked. That social fabric is what Merleau-Ponty calls the "real thing behind appearances," "a fabric of invisible being" (394) whose appearance in Woolf's consciousness allows subjects to appear and co-appear in her texts. Cotton wool can cover a wound, prevent infection, lessen festering, minimize scars. But writing the wound "means that it has lost its power to hurt."

For Woolf, "the whole world is a work of art... I prove this, now, by spending the morning writing." In this regard, writing is inseparable from worldedness: aesthetics and politics are inextricably interwoven, because "we-I mean all human beings — are connected with this; that the whole world is a work of art; that we are parts of the work of art" that is itself a world in which clothing is not so much a matter of self-fashioning as it is of world-fashioning. Woolf's whole cloth is a material interface between modern subjects and the social world, a global "frock consciousness" in which the materiality of dress refashions the materiality of Woolf's writing, which — its experimental fabrication, in its hopeful futurity, and its interconnected globality — strives for nothing less than refashioning modernity. If cotton wool dresses a wound in the flesh, Woolf dresses a wound in the flesh of the world. 


\section{Chapter Four}

\section{The Empire's New Clothes: Global Branding and Zadie Smith's On Beauty}

The publication of White Teeth in 2000 turned Zadie Smith, almost overnight, into the first global literary celebrity of the twenty-first century. Translated into more than twenty languages and lauded in a dazzlingly diverse array of publications from highbrow intellectual forums like The Guardian and The New Yorker to popular British tabloids and even the Polish edition of Cosmopolitan, Smith is, as an Observer headline hailed, “young, black, British—and the first publishing sensation of the millennium" (Merritt n.pag.). The hype has not waned in the fourteen years since White Teeth first garnered such praise; reviewers and literary critics alike have continued to celebrate Smith's recurrent themes of multiculturalism, immigrant identity, and race and class conflict in The Autograph Man (2002), On Beauty (2005), and most recently, NW (2012), calling her “the Bard of Willesden" (Itakura 27) and "the Tiger Woods of literature" (Procter 111). Although praise for Smith's work abounds, her novels have also been called pat, accused of presenting a too easily consumable "fairy-tale" (Childs 209) of "Happy Multicultural Land" (Smith, White 384) that, as Graham Huggan has pointed out, “capitalize[s] on perceived marginality while helping to turn marginality itself into a valuable cultural commodity" (viii). That Smith's work has been met with such critical acclaim and mass popularity may well be due, at least in part, to what Huggan calls the "global commodification of difference" (vii): wry parodies of national cultures, vibrant celebrations of cultural hybridity, and the sort of aesthetic complexity and formal 
experiment that cosmopolitan audiences are both so accustomed to and so hungry for. On the one hand, this speaks to what Paul Gilroy has called the "corporate multiculturalism" of the global literary market, in which only the most "user-friendly, house-trained, and marketable reading" (Against 252, 242) achieves such international success. On the other hand, it downplays the extent to which, as Loren Glass has shown, "celebrity makes authorship a corporate affair" (672). The "cover girl of the 'Multicultural Novel"” (Thomas n.pag.), Smith is a global celebrity author who is featured as frequently in Vogue as she is in journals of literary criticism.

Smith's chic, cosmopolitan look contributes significantly to her international visibility as a poster child for the global Anglophone novel in the twenty-first century; not only her writing, but so too her image has become a focal point for the marketing, promotion, and management of her brand. Reviewers regularly point out that Smith is “a stylist's dream" in her signature "oriental turban" (Jakubiak 211), branding her look "the Zadie persona: dramatic vintage dresses, flowers in her hair, colourful headwraps, glossed lips" (Viner n.pag.). Discussions about Smith's stylish image have gone hand in hand with discussions about her writing: as a Guardian article puts it,

We'd like to tell you about her prose, which inspires many clichés of the 'sparklingly vivid' variety. But we can't — at least not without mentioning the enchanting vintage silk frocks that Smith habitually combines brilliantly with Louboutin clutch bags and platform shoes ... which Smith works with an insouciant panache worthy of Sarah Jessica Parker, or Chloe Sevigny, or yes, dammit! Kate Moss. (Vernon n.pag.) 
Smith's fashionable prose is as "sparklingly vivid" as her fashionable image, and her name is linked to such global brands as designer Christian Louboutin or supermodel Kate Moss because Smith too is a global brand whose fashion sense is inseparable from her literary sensibility.

Yet Smith herself has been ambivalent and inconsistent on the subject of dress. In one interview she'll claim that "fashion is far from my mind, to be honest" (McBee n.pag.), but in the next she'll state, "we are all very different people. We dress differently, we think differently, we have different politics" (Watchell 127), lending to styles of dress the same gravity as individual psychology or political conviction — which, in another interview, she equates with one another: "I think what interested me is when you ask yourself what makes a person innately conservative or innately liberal, it's really interesting. It's more than the political argument, it's a personality trait, one way or another" (McBee n.pag.). When asked, "if, for you, there's a connection between fashion and identity as a person who seems to care about her style?" Smith explained that she has "tried to write about it a little bit... There's a lot of pleasure in looking at beautiful things and considering beautiful things, and clothing is part of that" (McBee n.pag.). But what part is it, exactly? Her third novel, On Beauty - the very title of which leaves no doubt as to its primary theme of "looking at beautiful things and considering beautiful things"often seems to beg the question, lingering as it does over sartorial details like Kiki Belsey's "flame-coloured headwrap" (98), Claire Malcolm's "Salome dress-red, sequinned" (56), the Nigerian dandyism of Erskine Jegede, who is perennially clad in "a 
three-piece suit of the yellowest of yellows" (19), or the fact that Howard Belsey "ha[s] only one suit" (336).

On Beauty is especially infatuated with the ways in which the Belsey children are fashioned by practices of global branding, and as Smith explains in an interview about On Beauty,

The Belsey children don't struggle to find an identity because they're mixed race, they struggle because they are 'of Modernity,' and the product of a twentieth century that invented and patented this claptrap called 'finding an identity'... The search for an identity is one of the most wholesale phony ideas we've ever been sold. In the twenty-first century it's almost entirely subsumed in its purest form of 'brand identity[.]' (Anonymous, “A conversation” n.pag., emphasis added)

Here, she makes explicit that Jerome, Zora, and Levi's subjective experiences cannot be reduced to familiar categories of identity politics like race, class, gender, sexuality, or nationality; rather, their lives are cosmopolitan, shaped by what Arjun Appadurai has called the "irregularly self-conscious, and unevenly experienced ... constitutive feature[s] of modern subjectivity" (Modernity 3) in the global cultural economy. By Smith's account, her characters are "the product of a twentieth century" processes of globalization — commoditized personalities that, in their hybridity, are cosmopolitan. But as Smith underscores, the Belsey children's cosmopolitan brand identities did not spring 
up automatically in the twentieth or twenty-first centuries. ${ }^{1}$ Rather, cosmopolitan identity is "the product of a twentieth century that "invented and patented" it as a brand, fabricated and fashioned it as modern — which is to say that, under conditions of late twentieth and early twenty-first century globalization, identity itself has been branded new on a global scale. Smith shows here that her characters are embedded in the same modes of global branding that have authorized Smith, herself - modes that are a cultural manifestation of the economic base of globalization.

Brands function as a kind of talismanic typecasting; they are universalizing gestures through which labels constitute legibility. This applies, in equal measure, to what Smith calls "brand identities" as it does to clothing affected by logos, even though the value of a "brand identity" is primarily social, whereas the value of branded clothes is primarily economic. The former is hardly limited to individual subjectivity; concepts, too, can be branded, and On Beauty is self-reflexively positioned vis-à-vis some of the most urgent "brand identities" attached to the categorization, canonization, and study of contemporary literature. The latter marks a material way to think globally, insofar as fashion brands transcend both time and space, marking new global territories on the symbolic level; as Maynard explains, "branded garments are lawless, without links to geographical place and local time, and so are truly global” (94). Because, as Lash and Urry have shown, the "ordinary manufacturing industry is becoming more and more like the production of culture" (123), global brands stage tensions between uniformity and

\footnotetext{
${ }^{1}$ Here I follow Paul Jay, who has shown that globalization has a long history spanning "the various epochs of colonization, decolonization, and postcolonialism in all their historical complexity" (51).
} 
originality, between seriality and singularity, between the individual and the group, between global sameness and global difference.

In her meticulous study Dress and Globalisation, Margaret Maynard wonders, "Where can we possibly find common ground between the global branded product and the signaling of personal identity?" (93). In what follows, I trace the ways in which On Beauty asks - and answers - the very same question. The brands attached to the novel's characters, its author, and even to On Beauty itself reveal the messy, multivalent global politics that cannot be separated from aesthetic experience. Global brands build their empires upon this tension. Infused with meaning well beyond the individuals or garments that sport them, brands operate in the global cultural economy not as material goods, but as concepts. Like Naomi Klein, who writes in her hugely influential No Logo that she is "convinced that it is in these logo-forged global links that global citizens will eventually find sustainable solutions" (xx), On Beauty too puts forth that because nothing escapes the cultural logic of the brand under conditions of early twenty-first century global modernity, brands might paradoxically be our best hope for refashioning the world.

In an interview about On Beauty, Smith says of her novel that the "Belsey[s] need to stop worrying about their identity and concern themselves with the people they care about.... It's a tough, unimaginably lonely and complicated way to be in the world. But that's the deal: you have to live; you can't live by slogans, dead ideas, clichés, or national flags" (Anonymous, "A conversation," n.pag.). But in the world of the early twenty-first century, where globalization perpetuates profound inequalities and forecloses possibilities for radical solidarity at every turn, it is precisely "slogans, dead ideas, clichés, or national flags" - better known by their short hand name, global brands - that we all 
have no choice but to live by. The question is not how we can find a way to be in the world despite these brand identities. Rather, it is how we might find a way to be in the world with global branding, and how such brand identities might come — as they do in $O n$ Beauty - to signal disaffection with and resistance to the very global processes that fashioned them in the first place. And so if clothing is, as Smith claims, a part of beauty, then it is the part of On Beauty that grinds its geopolitical teeth.

\section{STREeT COSMOPOLITANiSM}

Of the Belsey children, who are all "“of Modernity,' and the product of a twentieth century that invented and patented ... 'brand identity"' (Anonymous, "A conversation" n.pag.), On Beauty is especially infatuated with the fashion statements made by the teenaged Levi Belsey, who sports a "skullcap, baseball cap, hoodie, duffel hood" (6) and pants "so low they're not even covering your ass" (9). Smith imbues his fashion statements with political significance because when "faced with the smallest slight to his character and, in particular, his clothes, Levi would argue for justice as long as he had breath in his body, even when - especially when-he was in the wrong" (87). Levi equates dress with redress, defending his fashion sense as the grammar of a style of existence, which is, as he explains,

a matter of attitude. He said, “.... That's street. To hustle is to be alive-you dead if you don't know how to hustle. And you ain't a brother if you can't hustle. That's what joins us all together-whether we be on Wall Street or on MTV or sitting on a corner with a dime-bag. It's a beautiful thing, man. We hustling!” .... 
Hustler, Playa, Gangsta, Pimp.... The Street, the global Street, lined with hustling brothers working corners from Roxbury to Casablanca, from South Central to Cape Town. (245-6, italics in original)

In “[ $t]$ his, the most complete version of Levi's personal philosophy that he himself had ever articulated" (245), Levi sounds quite a bit like a theorist of cross-cultural connectedness and transnational affinity, which in political philosophy most often goes under the name "cosmopolitanism." Very much in line with recent articulations of multiple cosmopolitanisms—including "vernacular cosmopolitanism, rooted cosmopolitanism, critical cosmopolitanism, comparative cosmopolitanism, national cosmopolitanism, discrepant cosmopolitanism, [and] situated cosmopolitanism" (Hollinger 228), among others - Levi here fashions what could be called street cosmopolitanism, a "beautiful thing" that "joins us all together" by connecting "Roxbury to Casablanca" and "South Central to Cape Town."

Street cosmopolitanism is much more than a style of dress; rather, a style of dress makes visible a set of practices ("We hustling!") that constitutes a form of life ("To hustle is to be alive") and, indeed, a brand identity ("Hustler, Playa, Gangsta, Pimp"). But Levi's "global Street" cosmopolitanism is nevertheless limited in its capacity to forge global solidarities: "To Levi, black folk were city folk. People from the islands, people from the country, these were all peculiar to him, obstinately historical... He felt the same way about farmers, anybody who wove anything, and his Latin teacher" (81). Street cosmopolitanism cannot account for forms of black life that are not urban, industrial, capitalist, and modern, even as it is thoroughly underwritten by exactly what Levi 
excludes from it: global farmers, who grow the cotton crop that makes his clothes; global textile workers, whose labor produces his garments; and global intellectuals, who reveal (as indeed a Latinist would) the etymological inextricably of "stylus" and "style," "mode" and "modernité," "text" and "textile," and who in so doing uncover and articulate the globalized base of cosmopolitanism's superstructure.

It is especially striking, then, that Levi's very name links him to the multinational corporation Levi Strauss \& Co., a global market leader in the jeans industry frequently cited in fashion studies, marketing analyses, and economic theories of globalization alike as a key example of successful global branding. Founded in 1873, the company experienced tremendous growth in the 1960s and 70s under post-war Fordist forms of production and high demand from a range of cosmopolitan youth subcultures. This countercultural brand image stands in stark contrast to the conditions of its production. As Michiel Scheffer has noted, "the vintage Levi's 501 model became as it were the 'model-T Ford' of apparel. Made with a rotor-spun yarn [and] woven on high-speed looms, [...] jeans became a modern and Fordist product" until the 1970s, when "brand development [had] to be compatible with global branding.... Levi's is an example of a brand with a universal message...[that is] only affordable by tapping into low labor-cost production in developing countries" $(130,132)$.

The "universal message" of Levi's brand jeans, like the universalist claims of Levi's street cosmopolitanism, are dependent upon neocolonial forms of economic exploitation. Over the course of the late 1980s and early 1990s-just when Levi Belsey would have been born-Levi Strauss \& Co. shut down the last of its U.S. factories and increased its global outsourcing through offshore subcontracting agreements. As Naomi 
Klein and Karl Schoenberger (among others) have studied extensively, in 1991 the company was cited for sub-minimum wages and twelve-hours-a-day, seven-days-a-week work shifts; it paid more than nine million dollars in fines, the highest in U.S. labor history at that point. These appalling sweatshop conditions and human rights violations, which garnered tremendous media attention, were accompanied by what was then the largest number of trademark infringement cases in the history of the apparel industry. By 2001, only four years before Smith published On Beauty, Levi Strauss \& Co. had filed nearly one hundred lawsuits against competitors to protect and consolidate its brand identity.

Global outsourcing and global branding are mutually constitutive, and this applies no less to Levi Strauss's jeans than it does to Levi Belsey’s street cosmopolitanism. Of course many other factors including the growth of distribution and retail networks, fixed pricing, and the growth of advertising affect the growth of a brand (and Levi Strauss \& Co. is no exception), but without the concomitant growth of global outsourcing and copyright, patent, and trademark legislation, brand emergence would be unable either to attain such high visibility or attract the attention of international markets. In this way, Levi Belsey conjures what Bruce Robbins calls, "with a certain inevitable discomfort, the sweatshop sublime. The sublime may not seem like the most useful way to pose the question of our responsibilities as citizens faced with the reality of sweatshop labor.... But the pairing of sweatshops and sublimity is also intended to raise issues of politics and aesthetics ... that links the thoughts and feelings of ordinary people to the fate of others in a larger collectivity" ("Sweatshop" 85-6). 
Levi-a suburban teenager who "treasured the urban the same way previous generations worshipped the pastoral" (81)—registers, revises, and ultimately refashions exactly the forms of solidarity that Robbins describes. In an early scene in the novel, he does so through "rais[ing] issues of politics and aesthetics" figured in his style of dress:

"What's the deal with this?" asked Howard, flipping the interrogation round and touching Levi's head. "Is it a political thing?"

Levi rubbed his eyes. He put both his hands behind his back, held hands with himself and stretched downward, expanding his chest hugely. 'Nothin', Dad. It's just what it is," he said gnomically. He bit his thumb.

"So then," said Howard, trying to translate, "it's an aesthetic thing. For looks only."

"I guess," Levi said and shrugged. "Yeah. Just what it is, just a thing that I wear."

.... "They let you wear it at the wotsit, the record shop?"

"Sure, sure. It's not a record shop-I keep telling you—it's a mega-store." (22, italics in original)

Locking hands with himself, bending vertically, and increasing his own size and scope, Levi seems here to embody allegorically the Fordist practice of upstream vertical integration and expansion that had allowed Levi Strauss \& Co. to grow in the 1960s and 70s. Just as Levi's body takes on the structures of global capital, his skull cap figures its social effects. Levi's garment is both "an aesthetic thing" and "a political thing"-an 
individual expression of himself that articulates the economic and political conditions of the global modernity in which he lives, though neither Howard nor his son can make sense of the inseparability of aesthetics and politics in Levi's skull cap. For the elder Belsey the two are mutually exclusive, while the younger construes his fashion sense tautologically: the skull cap "just is what it is," and then "just what it is, just a thing that I wear."

At first blush, Levi's response might seem to be nothing more than the petulant mutterings of a sullen teenager who has not given much thought to the question he has been asked. But Levi's answers are actually much more sophisticated than his father's questions. Levi's tautology mirrors the logic of the brand insofar as brands, like tautological statements, define themselves by repeating themselves. For this reason, Wittgenstein considers tautologies neither meaningful nor nonsensical. Though they may not say anything, tautologies nevertheless "describe the scaffolding of the world" (6.124) — its grammars, structures, forms, and logics_ - just as brands describe the scaffolding of the world economy, in which multinational corporations, signified metonymically by their brand names, erase the exploited human producers of their commodities.

This might seem a case of commodity fetishism, displacing onto objects the meaning, affect, and value that should be attached to human bodies and social relations. But it is actually quite a bit more sinister, because as Klein has so convincingly shown, "successful corporations must primarily produce brands, as opposed to products" (3). This sentiment was echoed by the highest ranking corporate officers at Levi Strauss \& Co. as the corporation moved exclusively to offshore contracting. The president of the North 
American division of Levi's, John Ermatinger, explained “Our strategic plan in North America is to focus intensely on brand," and Joe Middleton, the European president of Levi's, announced “Our brand is our most important asset. It's more valuable than our factories, our buildings, our warehouses and our inventory" (qtd. in Haig 225).

Additionally, Levi's chairman Robert Haas, who has been routinely celebrated for his corporate ethics, justified the company's outsourcing insofar as it allowed Levi's “to inject more quality and distinctiveness into the brand" (Klein 200) rather than its products. If under capitalism the commodity is the only tangible sign of the production process, then under global capitalism the brand erases even the commodity, leaving no product to bear the trace of human production at all. The brand now stands in for the commodity that once stood in for social relations.

It comes as no surprise then that Levi does not, as his father imagines, work for a "record shop" (22) distributing a once-popular, now-dated commodity. Rather, he works for an ultramodern "megastore" (22) that goes unnamed, identified only by "the global brand behind these stores ... tagging the world" (180); any and all commodities are fair game, as "Planes, trains, finance, soft drinks, music, cellphones, vacations, cars, wines, publishing, bridal wear — anything with a surface that would take his simple logo" (180) is branded by Levi's employer. Like a tautology, the megastore's global brand sells itself, and even human bodies are assimilated it: at work, megastore employees must wear "the branded T-shirt, the baseball cap and the cheap, skinny-legged, tapered-ankle, lint-ballattracting black polyester pants" (179) rather than "that uniform—cap, hood, jeans" (268) that Levi tells Howard he is permitted to wear at work, but actually is not. Even though Levi "had never seriously considered what his employer, the impressive global brand, 
really meant by these shared ideas, values, interests and goals of which he and...all the rest supposedly partook" (180, italics in original), he embraces the corporation's ostensibly cosmopolitan, but actually homogenizing, mission statement, intending to "Watch, learn, supplant—Machiavelli style" (180) its brand.

When Levi is asked to work on Christmas day, his "Machiavelli style" conjures for his Marxist father Gramsci's styling of Machiavelli. Howard suggests his son "implement some kind of direct action.... He spoke at length about someone called Gramsci and some people called the Situationists" (181). For Gramsci, the Modern Prince is an expression of the national-popular; as he writes, "if one had to translate the notion 'Prince' as used in Machiavelli's work into modern political language, one would have to make a series of distinctions: the 'Prince' could be a Head of State, or the leader of a government, but it could also be a political leader whose aim is to conquer a State, or to found a new type of State; in this sense, 'Prince' could be translated in modern terms as 'political party'" (252-3). Following his father's advice, Levi tries to gather his coworkers together to organize a collective "protest with action" (186), imagining that the employees of the global brand might come together as a revolutionary party fighting a war of position. Levi is surprised to discover his working-class coworkers do not share his "aim to conquer" the megastore "or to found a new type" of brand identity for it; as it turns out, they are more than happy to work on Christmas Day: "Man, I could do with the extra dollars. I know you know what I'm saying" (184, italics in original), his coworker LaShonda tells him. Levi, of course, has no idea what she's saying; although he has embraced the global brand's "shared ideas, values, interests and goals" (180), Levi has 
nevertheless failed to register differences in "situations, economically. There are so many different ways to need money" (184). ${ }^{2}$

The meeting that Levi organizes, like the street cosmopolitanism that underwrites it, is interrupted by his boss, who puts Levi in his place by quite literally placing him:

“Don't—act—like—a-nigger-with-me-Levi," said Bailey in a whisper, each word with a momentum of its own, like darts he was throwing at a target.... "I know where you're from. Those kids don't know shit, but $I$ know. They nice suburban kids. They think anyone in a pair of baggy jeans is a gangsta. But you can't fool me. I know where you pretend to be from," he said, his anger newly virulent, still holding the door but leaning in towards Levi. "Because that's where I'm from".... This was not the world of the megastore any more, where everyone was family and 'Respect' was one of the five daily 'personal conduct' reminders written on the board in the coffee room. (192, italics in original)

Bailey's rhetorical maneuvers are precise ("like darts he was throwing at a target"). But the place from which he hails, and from which Levi pretends to, is decidedly not. Bailey cannot name "where you're from," "where you pretend to be from," "where I'm from," because that place cannot be located in a particular nation, nor a particular city, nor even

\footnotetext{
${ }^{2}$ As Brennan reminds us, Gramsci himself lodges exactly this complaint against cosmopolitanism (Wars 215). Until conditions for erasing difference equitably and ethically exist, Gramsci argues, cosmopolitanism cannot but be hegemonic. Thus he distinguishes between cosmopolitanism and internationalism, which in its insistence upon national sovereignty, emphasizes solidarity across rather than erasure of differences in polity and culture.
} 
a particular black ghetto. Rather, this place seems to be the same nameless "global Street" that signifies black urban struggle from "Roxbury to Casablanca, from South Central to Cape Town" (245-6) to Levi. Although Bailey may accuse Levi of appropriating the style and posture of black urban poverty, he nevertheless buys into the same universalizing street cosmopolitanism that Levi does — and in so doing, he falls into the same paradoxical exclusivities. Where Levi's street cosmopolitanism excludes "People from the islands, people from the country" (81), Bailey's excludes mixed race, middle-class teenagers. If for Levi, the "Hustler, Playa, Gangsta, Pimp" (245) dons "that uniformcap, hood, jeans" (268), for Bailey not just "anyone in a pair of baggy jeans is a gangsta" (192). And when Levi realizes that "[t]his was not the world of the megastore any more" (192), it is not because Bailey has challenged the "shared ideas, values, interests and goals" of the "impressive global brand" (180) that employs them both, nor because he has challenged the brand identity borne of Levi's street cosmopolitanism, but rather because he has exposed the continuities between the two.

\section{IF THE SHOE FITS}

This exchange with Bailey wakens Levi for the first time to the difficulty of practicing "'Respect"” as "daily "personal conduct"” (192), which will require much more of him than a quick glance at a white board in the megastore's break room. In facing the question of where he is from, Levi does an about face in where he is going - which, it turns out, is "back on the street in his own clothes" (192). But this is no longer the homogenizing "global Street" of Levi's brand of cosmopolitanism, nor the homogenizing uniform of the megastore's global brand. In the wake of his altercation with Bailey, Levi 
finds himself negotiating the tension between acknowledging difference and articulating solidarity as he watches a group of Haitian immigrants lay out their off-brand wares,

revealing CDs, DVDs, posters and, incongruously, handbags.... One of them pressed play on a big boom-box, and summery hip-hop, out of place but welcome on this chill autumn day, blew up into the passing shoppers. Many people tutted; Levi smiled. It was a joint he knew and loved. Slipping effortlessly between the high hat and the drum or whatever machine it is that makes those noises these days, Levi began to nod his head and watch the activity of the men, itself a visual expression of the frantic bass line.... One of the guys swiftly hung the bags off the railings, and these new announcements of colour brought a rush of delight to Levi, so strong because so unexpected, so queerly timed.... Their display was so magnificent no further hustling was required.... An unanchored sentence of Howard's from his morning lecture - now floating free of the tedious original context—meandered into Levi's consciousness. Situationists transform the urban landscape. (193-4, italics in original)

Having been forced by Bailey only pages earlier to consider difference grimly as an unbridgeable divide, Levi here sees an alternative that neither smoothes over the rough edges of alterity nor embraces the radical individualism that would make any collective identity arbitrary and politically useless. His "rush of delight" derives not from a confirmation of continuity and sameness, but from the surprising pleasure of incongruity and difference. Levi is moved by the "summery hip-hop, out of place but welcome on 
this chill autumn day" and by the brightly colored purses in contrast to the cold metal rail upon which they hang, watching the "activity of the men, itself a visual expression of the frantic bass line" (193) of diaspora. These disjunctures - between the origin place of the music and the place in which it is playing, between vibrant and dreary colors, between the aural and the visual components of this moment - figure what Appadurai calls "fundamental disjunctures between economy, culture and politics" (Modernity 6): Levi's "imagination has become an organized field of social practices, a form of work (both in the sense of labor and of culturally organized practice) and a form of negotiation between sites of agency ('individuals') and globally defined fields of possibility” (Modernity 5).

Where Levi had previously understood "hustling" as a universal, connective practice that "joins us all together-whether we be on Wall Street or on MTV or sitting on a corner with a dime-bag” (245), here he experiences just such a simultaneously aesthetic and political force—one "so magnificent no further hustling was required," just as no further street cosmopolitanism is required. This is not to say, however, that no further forms of subversion or creative, cosmopolitan connectivity are required. By way of Howard, Levi associates the street hawkers with the Situationist International (SI) of 1957-72, and this scene might be best understood in the SI's terms as a "situation." In one of the founding documents of the SI, Guy Debord explains that, "Our central idea is the construction of situations, that is to say, the concrete construction of momentary ambiances of life and their transformation into a superior passional quality" ("Report" n.pag.). Situations are ephemeral, but not spontaneous; they are playful, but not silly. What Debord understands as the transformation of "momentary ambiances" into a "superior passional quality" describes precisely how the everyday scene of street hawkers 
laying out their off-brand goods "brought a rush of delight to Levi, so strong because so unexpected."

For Debord, situations and their effects are made possible by two practicesdérive and détournement — that reinvigorate the aesthetic dimension of the public sphere. The "superior passional quality," or "rush of delight," that Levi experiences is brought about in part by his own transient passage on a city street, or what Debord calls a dérive: "In a dérive one or more persons during a certain period drop their usual motives for movement and action, their relations, their work and leisure activities, and let themselves be drawn by the attractions of the terrain and the encounters they find there" (Theory 23). Levi, who finds himself on the street in the first place because he has abandoned his work at the megastore, has actually dropped all activity: "Halfway down Newbury Street he stopped altogether" (192).

Levi's dérive is paired with the Haitians' reordering of the physical space of the street as they "swiftly hung the bags off the railings, $[\ldots]$ immune to the frowns of Bostonian ladies passing with their stupid little dogs" (193-4) who stand in for the bourgeois populace of the city. This might best be understood as what Debord calls a détournement, in which human agents rearrange materials both to show their banality and to challenge the alienation generated by capitalist spectacle through the "reuse of preexisting artistic elements"-_hip hop, handbags_-"in a new ensemble" ("Report" n.pag.). Debord's metaphor of an ensemble links the meticulous construction of an outfit or the meticulous construction of "many harmonized voices" (408) in a song to the meticulous construction of a situation. Further, it is worth noting that détournement is often cited in relation to contemporary cultural resistance movements like culture 
jamming, a good example of which is the plastering of Charles Manson's face over a thirty-nine-foot billboard advertisement for none other than Levi Strauss \& Co.'s; this was intended to show that the jeans were "Assembled by prisoners in China, sold to penal institutions in the Americas" (Klein 281).

As he watches the Haitians, "An unanchored sentence of Howard's from his morning lecture — now floating free of the tedious original context—-meandered into Levi's consciousness. Situationists transform the urban landscape" (194). "[U]nachored," “meandered"- Howard's sentence seems to practice its own dérive, drifting through Levi's mind as he drifts through the city. But the thought is also "now floating free of the tedious original context," appearing different to Levi because of the new ensemble of ideas that accompany it, as if it had been subject to a détournement. If "Situationists transform the urban landscape," then this particular situation transforms Levi's experience of space and place — or what Debord and the SI called a "psychogeography" that "by virtue of the resulting mobile space ... the independence of places will be rediscovered without any new exclusive tie to the soil" (Society 126).

This idea transforms Levi entirely. He befriends and begins working with the Haitians, and takes out books from the library to educate himself about Haitian history and culture. He is "in the square pretty much every weekend with leaflets helping this Haitian support-group campaign" (400), and "fights shoulder to shoulder with us for justice" (404) because he now registers the complicity of cosmopolitanism with globalization. But of course, this revision to his street cosmopolitanism does not exempt Levi from the logic of global branding, as becomes evident when Levi teams up with Chouchou, a Haitian immigrant, to sell knock-off designer handbags: 
"Chouchou."

... “That's your name?" asked Levi, as they crossed the street. "Like a train?"

.... "It's Haitian. C-H-O-U-C-"

"Yeah, yeah-I see.” Levi considered the problem. "Well, I can't call you that, man. How about just Choo — that works, actually. It works. Levi and Choo." .... "I really fucking hate to sell things, you know? .... Louis Vuitton, Gucci, Gucci, Fendi, Fendi, Prada, Prada,” called Choo.... "Originals — eight hundred dollars," he said pointing at a store across the street. "Fakes—-thirty dollars. Cost to produce-five dollars, maybe three. That's economics." ... "Can you believe these stupid bitches be paying thirty dollars for a three-dollar handbag? That shit's unbelievable. That's a hustle."

And here Choo looked down at Levi's sneakers. "How much did you pay for them?"

"A hundred and twenty dollars," said Levi proudly and demonstrated the shock reducers built into their soles by bouncing up and down on his heels.

"Fifteen dollars to make," said Choo, blowing horns of smoke from both of his nostrils. "No more. Fifteen dollars. You're the one being hustled, my friend." 'Now, how would you know that? That ain't true, man. That ain't true at all." 
"I come from the factory where they make your shoes. Where they used to make your shoes. We don't make anything now," said Choo, and then cried "PRADA!" (244-7, italics in original)

Levi appears to be nothing more than Choo's straw man, his posturing played for Choo's politics; he is unable to recognize himself as one of the "stupid bitches" imbricated in the same globalized forms of consumption even as he insists on a cooler nickname for his new friend. But although "Chou" and "Choo" may be homonyms, when Smith shifts the spelling she does much more than up Choo's hipness quotient for the naïve Levi; the shift "works, actually. It works" in every sense, because in dubbing his new friend "Choo," Levi links him to the global luxury shoe and handbag brand Jimmy Choo, whose name could easily be added to a list that includes "Louis Vuitton, Gucci, Gucci, Fendi, Fendi, Prada, Prada.” Like Levi, whose name cannot but conjure Levi Strauss \& Co., his friend and colleague's new nickname cannot but similarly summon forth the history of a global fashion brand.

Jimmy Choo came of age in the increasingly globalized world of the late 1960s and early 70s. He was born in 1952 to a Chinese father who cobbled shoes in Penang, Malaysia, which had just had its free port status abruptly revoked and was suffering an economic crisis as a result. Choo studied under his father until 1973, when he emigrated to North London - the very same area where, two years later, Zadie Smith would be born - to study at Cordwainers College, which specializes in footwear and accessories design and manufacture. Already self-conscious about his position within "a long history of downtrodden foreign students" at Cordwainers, Choo recalls that "People laughed at 
me, and at college one teacher said: 'You can't speak English, speak properly.' So I was quiet" (qtd. in Crowe 15). Although Levi has the decency to keep his assumptions about his immigrant colleague to himself, "an extended piece of grammatically correct English was not what Levi had been expecting" (245) from his Choo, either. After his graduation from Cordwainers, Jimmy Choo set up shop in an abandoned hospital in East London where, equipped with only a sewing machine and worktable, he made one-of-a-kind shoes and handbags that he sold at a stall in the local market that he manned himself. Like Choo, who "really fucking hate $[s]$ to sell things" (245) and whose "English transform[s] at once into something simpler, monosyllabic" (246) when he "releas[es] a pile of colourful handbags on to the sidewalk" (244), Jimmy Choo too "spent most of his waking hours at his workshop at the Hospital" (Crowe 19) rather than his outdoor stall at the market, much more interested in production than in distribution and terribly selfconscious about his command of English.

Further, Jimmy Choo's career took off because of the growth of the same knockoff industry that Choo works in. During the humble early years of Jimmy Choo's career, the supply of sexy high-heeled shoes was almost monopolistically controlled by the already legendary Manolo Blahnik. But if Blahnik had produced only kneehigh boots in gold that season, an editor [of a fashion magazine] was pretty much stuck... Now a new modus operandi emerged: The market editors charged with calling in the items to be used in the shoots could borrow the gold boot from Manolo's showroom in Chelsea, have it delivered to Jimmy's workshop in the East End, and ask him to recreate it in silver. (Crowe 19) 
Building upon this demand, Choo developed a small private clientele, who would ask for "the heel from Calvin, the backside from someone else, the toe thinner" (Crowe 21). His early design philosophy was in essence a kind of détournement, cobbling together, as Debord would have it, "preexisting artistic elements in a new ensemble." But unlike Levi's Choo, who hawks "Fakes—-thirty dollars. Cost to produce—five dollars, maybe three" in sweatshop factories in places like Malaysia and Haiti from which both Choos fled, Jimmy Choo custom made his wares under self-imposed sweatshop conditions. Plugging in "twenty-hour working days" (Crowe 22) at his workshop in the abandoned hospital, he was hesitant when told that "'we could mass-produce some of his styles and sell them,' Aydin recalls. Jimmy didn't jump at the chance. The idea made him nervous" (Crowe 23).

Jimmy Choo resisted this offer because, like Levi's Choo, he "come[s] from the factory where they make your shoes." He had witnessed first-hand the appalling labor conditions in Penang in his youth. But he also had to face the reality that "no matter how many twenty-hour days he worked, no matter how many family members he employed, $[\ldots]$ he would never have the same success as the designers whose shoes were made in factories and not by hand.... [T] he son of a shoemaker from Penang was on his way to becoming a household name" (Crowe 23) akin to those his namesake hollers on Newbury Street. "'We don't make anything now,"” said Choo, and then cried "“PRADA!"” (247); Jimmy Choo does not make anything now either, but Choo has indeed become a global brand name. In 1996, Jimmy Choo sold half of his company to the accessories editor at British Vogue, Tamara Mellon, who became its president and came to control not only 
the marketing, promotion, and factory manufacture of Choo's designs, but even the designs themselves. Mellon and the ever-growing group of her hires pushed Choo further and further out of the business; Choo came to speak more and more publicly about how his name was being exploited without his consent; and finally in 2001, he was bought out of the now multinational corporation that still bears his name. ${ }^{3}$

Like Levi Belsey, Jimmy Choo too was “the one being hustled," because globalization hustles us all. But as Levi comes to realize, it does not hustle everyone equally. An autodidact, Levi checks books out of the library, and

[e]ach time he returned to the Haiti book he felt impassioned; he wanted to stop Haitians on the streets of Wellington and make it better for them somehow. And, conversely, he wanted to stop the American traffic, stand in front of the American cars, and demand that somebody do something about this wretched, blood-stained island a mere hour's boat trip from Florida.... Haitian Aids patients in Guantanamo, drug barons, institutionalized torture, state-sponsored murder, enslavement, CIA interference, American occupation and corruption. It all became a haze of history to him. He retained only the searing, unwelcome

\footnotetext{
3 “Jimmy was granted a seven-year license on his own name in exchange for royalties of one pound per year and a number of conditions: Jimmy was free to continue making shoes for his private clients provided that he branded them Jimmy Choo Couture, that he never operated outside of London, that he made sure his shoes would always cost more than the ready-to-wear collection, and, crucially, that he would never speak to the press about anything without the explicit permission of someone in charge at Jimmy Choo" (Crowe
} 117). 
awareness that somewhere, not far from him, a people were suffering greatly. (355-6, italics in original)

The raw pain that Levi experiences when confronted with Haitian reality is roughly analogous to what Robbins, playing on Gramsci's idea of the national-popular, calls "the international-popular," in which "an imperfect and historically determined version of common sense ... links the thoughts and feelings of ordinary people to the fate of others in a larger collectivity.... It is to be expected that the international-popular will fall well short of any ideal action-oriented solidarity. But it is also to be expected that, under present global conditions, solidarity and even action itself will fall similarly short, will be subject to the same sorts of quasi-sensory, all-too-human interference that we have come to associate with the aesthetic" ("Sweatshop" 86). Levi's proximity to Haitian immigrants, his passion for their music, and his budding friendship with Choo draw him to this particular cause, and although Levi's sense of solidarity may be limited in all the ways that Robbins details, it is nevertheless the novel's most viable, ethical alternative to the street cosmopolitanism that Levi had previously upheld.

Because it is not predicated upon likeness, Levi's connection to Haiti appears arbitrary to his mother. "'Don't you find it a little strange,"” Kiki asks her son Jerome, “"that he's so interested in Haitian things? I mean, we're not Haitian, he's never been to Haiti—six months ago he couldn't have pointed to Haiti on a map. I just think it seems a little random" (400, italics in original). In fact, it is anything but: meticulously constructed, like a situation or indeed, an ensemble, Levi's commitment to the Haitian cause is grounded in his passion for its music, his autodidactic education in its history, 
and perhaps above all, his intimate friendships with its exiles, including especially Choo. His connection to Haiti is forged over and against, rather than in and through, difference. Levi comes to figure, in Paul Gilroy's beautiful phrase, the "invaluable solidarity of the slightly different" (After 88) in a world where solidarity has become suspect. But Kiki lacks her son's sense of psychogeography, believing that Haitians have an "exclusive tie to the soil" (Debord, Society 126). Because Levi himself is not Haitian, because he has not traveled to Haiti, because he has never previously expressed any interest in its culture or its history, Kiki thinks that his "is not the way you go about solving social problems" (429).

On Beauty very nearly follows Kiki's lead in thinking that Choo is just "some brother [who] spun you a load of conspiracy bullshit" and Levi is "an idiot ... want[ing] to be cool, show you the big man around a load of no-good Negroes" (428); it almost appears to share her assumption that because Levi and Choo are so different, the intimacy they share could only be founded upon a perfect storm of juvenile naïveté and gross manipulation; and it very nearly joins her in brushing off Levi's astute observations and strong sense of affinity, dismissing these political stances as so much fleeting teenage angst. But while On Beauty registers Kiki's objections and takes them seriously, the novel is capacious enough to show that Levi's mode of connection, for all its problems and limitations, is nevertheless the most powerful one in the novel—one in which aesthetics and politics are inseparable, and in which acknowledging, sheltering, and honoring difference is valued above and beyond minimizing, assimilating, or glossing over it. To steal a phrase from Robbins writing about what he calls sweatshop sublimity, Levi too "offers grounds for anyone interested in defending the significance to society at 
large of work performed in the domain of the aesthetic - a kind of case that can never rely on the language of the aesthetic alone, that must step outside that language to anchor itself in other interests and concerns" ("Sweatshop" 86).

\section{Postcolonial, Cosmopolitan, Global: Branding ON Beauty}

Similarly, any critical interpretation of On Beauty also "can never rely on the language of the aesthetic alone." Close readings of global branding within the novel must be paired not only with the cultural and economic context of contemporary branding practices, but so too with attention to mass-mediated marketing strategies, the corporate publishing industry, and especially to the seemingly paradoxical nature of academic branding. And because of On Beauty's “predilection for scholarly reference” (Tynan 79) — set on a college campus, its cast of characters is composed largely of humanities faculty and students - it lends itself especially to a discussion of branding and literary study. During an interview conducted while she was drafting On Beauty, Smith states that "Books are not brands" (Anonymous, "An interview," n.pag.). But scholarly discussions about On Beauty have, by and large, centered precisely upon trying to brand it as a postcolonial, a cosmopolitan, or a global novel.

Branding and academia are strange bedfellows. Brands are fundamentally reductive in nature, distilling complex concepts into logos and slogans, while academic discourse celebrates complexity, subtlety, nuance, and ambiguity. But academic disciplines, like brands, are marked by shorthand terms that operate primarily on historical ("medievalist," "Victorianist”), national (“Americanist," "Germanist”), and political ("Marxist," "feminist") axes, which serve to delineate and differentiate fields of 
study; furthermore, as Ania Loomba notes, oftentimes "name-brand critics have become more important than the field itself' (xv). These aspects of academic branding help to consolidate fields of study, making practices and paradigms legible not merely within individual departments, universities, or scholarly associations, but across them-which is to say, on a global scale.

Nowhere is this more the case than in the field of contemporary literature, which — by dint of its contemporaneity — is fundamentally characterized by both elasticity and instability insofar as it is formed alongside the literary production it studies; in turn, contemporary fiction responds to current trends in both the marketplace and the academy. The field's key terms — "postcolonialism," "cosmopolitanism," and "the global"- -are hotly contested and, as Huggan succinctly puts it, because of the "booming alterity industry" (vii) in the literary marketplace, scholars have "capitalised on perceived marginality [latent in these terms] while helping turn marginality itself into a valuable intellectual commodity. Meanwhile, postcolonial [cosmopolitan, and global] writers, and a handful of critics, have accumulated forms of cultural capital that have made them recognised - even celebrity_figures despite their openly oppositional stance" (viii) to the very fields and literary canons they have shaped. ${ }^{4}$ As a result, terms like postcolonial, cosmopolitan, and global "function as a sales-tag" - or a brand — "in the context of today's globalised commodity culture" (ix), which is governed by the cultural logic of the global brand from which nothing is exempt.

\footnotetext{
${ }^{4}$ Studies by Huggan, Damrosch, and Brouillette have explored the ways in which this phenomenon has given rise a set of celebrity "global authors."
} 
On Beauty's dizzying list of intertexts - from the more prominent references to E.M. Forster's Howards End and Elaine Scarry's On Beauty and Being Just through Toni Morrison's The Bluest Eye, Vladimir Nabokov's Lolita, and Zora Neale Hurston's Their Eyes Were Watching God and Tell My Hors $e^{5}$ — has provided a significant jumping off point for these critical conversations. Mason argues that Smith engages in "some truly inspired thieving.... Smith doing Virginia Woolf, E.M. Forster, Nabokov.... [S]he can write herself out of, back into and around" (83) the English literary canon. Smith not only incorporates multiple allusions to many sources but also disperses those references widely across her own text, which lends further credence to the sense that, as Tim Brennan writes, global "authors [like Smith] ... exist not as individuals but as elements in an intertextual coterie that chooses them as much as they choose it" (At Home 203). Most readings of On Beauty have followed this logic, tracing the ways in which its allusions and intertexts form what Dorothy Hale has tellingly called "the novelistic aesthetics of alterity that Smith pursues" (3).

Readings by Matthew Paproth and Laura Moss, among others, cast On Beauty as a postcolonial novel that defamiliarizes canonical source texts to reveal suppressed structures of power in the tradition Jean Rhys's Wide Sargasso Sea or J.M. Coetzee's Foe. But this particular branding of the novel is misleading because On Beauty does not share many of the common features of postcolonial rewritings. First, it does not revive indigenous characters as Rhys does of Brontë's Bertha or Coetzee of Defoe's Friday, nor does not seize upon the immanent markers of imperialism, even when they are available in the source text. (For example, Forster has the Imperial and West African Rubber

\footnotetext{
${ }^{5}$ See, respectively: Hale, Moraru, Batra, Lopez-Ropero, and Anjaria.
} 
Company as the source of the Wilcox family fortune in Howards End; neither the company nor anything analogous to it appear in On Beauty.) Second, and more importantly: unlike Jane Eyre or Robinson Crusoe, Howards End is a profoundly antiimperialist text. Forster forges the intimacy between Margaret Schlegel and Ruth Wilcox through affinity and hospitality, rather than through national or identity-based bonds. Drawing upon Howards End's famous mantra "only connect," Smith focuses on Forsterian connectedness itself. Based in disinterested affective ties, Forster's cosmopolitanism is an apology for the catastrophe of empire just as Smith's is a new cosmopolitanism for a new millennium where there can be no compensation for neoimperial globalization.

Third, On Beauty does not write back to one particular canonical work, but rather corresponds to multiple source texts. It does not critique these texts, but rather draws upon them affectionately and indiscriminately — a kind of dense love letter to English literary history that, as Smith asserts in the acknowledgment pages of On Beauty, is an effort to "repay the debt with hommage" ("Acknowledgments" n.pag.). Finally, unlike postcolonial rewritings, which are often criticized for replicating the structures of colonialism insofar as, it is argued, their meaning and intelligibility depend upon the audience's prior knowledge of the source text, On Beauty uses its source texts as a scaffold. Smith acknowledges of her references to Howards End that "in the end the books only meet properly at two or three points" (Anonymous, "A conversation," n.pag.), and many of the more oblique references to Forster-Kiki's telling Howard that "this isn't 1910" (15), the year of Howards End's publication; Howard's father's friend Carol reading A Room With a View —feel heavy-handed. Further, Smith herself "actually 
think[s] the points in the book where On Beauty meets Howards End are the least interesting bits of the book," likening her use of Forster not to Brontë/Rhys or Defoe/Coetzee, but rather to "Helen Fielding using Pride and Prejudice" in her chick-lit bestseller Bridget Jones 's Diary. In fact, Smith even confesses that "I didn't even re-read Howards End" (Anonymous, “A conversation,” n.pag.) in writing On Beauty.

On Beauty, then, is not to be most fruitfully branded as a postcolonial rewriting of imperial source texts. Moss considers Smith's work as a kind of rebranding of postcolonialism itself, emblematic of "the next phase of postcolonial studies" insofar as Smith shows "a state of everyday cultural and racial hybridity, [... a 'normalization' of hybridity in contemporary postcolonial communities" (12). Yet even broader postcolonial interpretations like Moss's elide the fact that it is actually erroneous to brand Smith a postcolonial novelist in the first place: born in England to a Jamaican mother and a white English father, Smith—who “consider[s her]self very English” (Wolinky n.pag.)— belongs to "a third generation of post-war Black British experience, a generation for which the concepts of 'migrancy' and 'exile' have become too distant to carry their former freight of disabling rootlessness" (Head 107-8). ${ }^{6}$ In fact, during a 2006 book reading of On Beauty at the New York Festival of International Literature, Kurt Andersen asked Smith about her thoughts on being classified as a postcolonial author, and she explained that

\footnotetext{
${ }^{6}$ Smith might be better understood as part of the school of Black British authors, fraught though the term is in its problematic implication that there is a contradiction between blackness and Britishness.
} 
it's a factual description for a great deal of writing. I mean, you're really pushing it with me, I'm born and bred in England and I'm about as post-post-post-colonial as it's possible to be.... I don't mean to sound cynical about it, but part of it is just convenience, and I kind of apologize to the rest of the postcolonial authors because they have a right to be there.... I feel slightly disingenuous to be there.... [My work] doesn't really fit into the whole postcolonial thing[.] (Andersen 19)

"Postcolonial" here becomes a brand-name label not unlike the "Lanvin cocktail dresses, the Citizen of Humanity jeans, or the Celine skirts" that The Guardian highlights, and Smith acknowledges the "convenience" of her inclusion in "the whole postcolonial thing," which is as useful for literary critics trying to contextualize her work as it is for publishers trying to market it.

If Smith is, as she herself puts it, a "post-post-post-colonial” writer, then her work might be better understood as global. As such, interpretations of On Beauty that have focused on the cosmopolitanism of its intertexts come closer to capturing the novel's geocultural position. Focusing on cross-cultural connections, be they between Smith and her myriad source texts or between characters within the novel who come together through shared experiences of beauty, these intertextual reading practices are themselves cosmopolitan in nature, emphasizing relationality and connectivity and celebrating the often surprising and profoundly moving links that can be forged between diverse and seemingly unrelated texts, images, and cultures more broadly. Yet despite similarities in method, these interpretations of the text are often incompatible with one another-and, because of their incommensurability, they reveal the limitations of cosmopolitan reading 
practices. For example, Lourdes Lopez-Ropero suggests that Smith summons forth Forster's commitment to a panoply of othernesses to forge new kinds of human connections both within the novel and between literary texts, while in Ulka Anjaria's analysis, Smith revives Forster's Edwardian drawing rooms only to show how such settings are "unsuited to account for the complex experiences of post-postcolonial family life" (31) in which diverse cultural variety has permeated domestic space. Though LopezRopero and Anjaria share a methodology, that methodology nevertheless produces mutually exclusive interpretations of the novel at hand — and it does so because cosmopolitanism is itself a kind of brand, and is thus subject to the contradictory nature of branding.

Literary and critical "celebrations of cosmopolitan diversity" have, as Robbins has argued, "largely been uninterrupted by the issues of economic equality or geopolitical justice" ("Cosmopolitanism" 51). Critics including Robbins and Brennan have convincingly shown that although cosmopolitanism's colloquial connotations are liberal, characterized by "supple open-mindedness, broad international norms of civic equality, a politics of treaty and understanding," cosmopolitanism as a brand is "a fundamentally ambivalent phenomenon" (Brennan, Wars 205). Socially exclusive and complicit with the assimilation or, worse yet, the erasure of difference, cosmopolitanism—-for all its ostensible liberalism—often functions as “a relay for the center's values, sublimating differences on grounds of understanding by way of a motive to export ideological products made to the measure of the world of saleable things" (Brennan, Wars 206). More urgent, then, is Christian Moraru's argument that On Beauty's “ample use of intertextuality suggests that Smith's reading of Forster ... reworks Howards End's 
cosmopolitan discourse of connectedness into a "neocosmopolitan' vision" ("Forster Connection” 145). What Moraru calls On Beauty's “neocosmopolitanism” actually skirts the hemline of neoliberalism, its human connections thoroughly underwritten by processes of globalization that go just as unacknowledged in scholarly readings of the novel as they do in popular readings of Smith, herself.

I follow Moraru, Brennan, and Robbins in “wonder[ing] whether it isn't time to stop and ask how much of the praise" — of cosmopolitanism as, indeed, of On Beauty's dense intertextuality — “is merited, what work cosmopolitanism is and isn't doing” (Robbins, "Cosmopolitanism" 51) in the novel, and where (or whether) the urgent global "issues of economic equality of geopolitical justice" rise to the surface of the text. Of her most recent novel, $N W$, Smith herself states that,

I kind of wanted to make a book in which you had to think about such things on a very basic level. Not, "How do I feel about 20,000 immigrants coming on one day into my country?" but "How do I feel about a girl at my door?" Fundamentally they're the same questions. (McBee n.pag.)

Much like Brennan and Robbins, I am not convinced that they are. The latter, as Smith goes on to explain, is ultimately one about defining cosmopolitanism: "The idea of what you owe this person who arrives at your door, or what they owe you, and how much they have to be like you in order for you to sympathize with them" (McBee n.pag.). But the former seems to reveal the globalized base of cosmopolitanism's superstructure. As Moraru shows, 
[C]osmopolitanism's professed universalism and internationalism prove lopsided, [...] wedded to the Eurocentric, colonizing, and leveling underbelly of modern rationality.... It appears socially exclusive rather than inclusive. In spite of its declared intentions, cosmopolitanism rarely manages to derail the geocultural processes whose fundamental premises it shares" ("Forster Connection” 138-9).

Smith's cosmopolitan characters can only ask "How do I feel about a girl at my door?" because there are in fact " 20,000 immigrants coming on one day into my country" who create the privileged conditions that make its asking possible in the first place. The cosmopolite can wonder about a girl at a door and frame it as metonymy, taking a question about the threshold of a private home as a part that stands in for the diasporic whole of displaced peoples standing on the thresholds of nations all over the globe. But this equation only works in one direction, which is why Smith's insistence that "Fundamentally they're the same questions" is so troubling. The whole cannot be made to stand for the part: those who have been subjected to "issues of economic equality of geopolitical justice" — which is to say, those "20,000 immigrants" — cannot be made to stand for "this person who arrives at your door, or what they owe you, and how much they have to be like you in order for you to sympathize with them."

To be sure, wrestling with " 20,000 immigrants coming on one day into my country" is profoundly overwhelming. As Robbins writes, "your sudden, heady access to the global scale is not access to a commensurate power of action on the global scale, $[\ldots$ and so] we fail to express those powers in any potentially risky, disobedient action" 
(“Sweatshop” 85). To illustrate this dilemma, Robbins tellingly turns to dress for an example:

while getting dressed, you either do or do not examine the label of your shirt. If you do, you either do or do not realize the conditions of life under which this shirt was, or perhaps was not, produced.... But whether your thoughts linger or not, whether the shirt turns out to have been made in Mexico or Thailand, or the United States, the result is the same as if you had not examined the label[...]: you put on the shirt and forget about it. ("Sweatshop" 85)

It would be far too reductive to say that Smith too "fails to express ... in any potentially risky, disobedient" way the global processes that underwrite her fiction, or that the question of a girl at a doorstep is her own version of "put[ting] on the shirt and forget[ting] about it," because On Beauty actually reveals the ways in which twenty thousand immigrants are not in fact the same as a girl at the door, even while it insists that the two are nevertheless fundamentally inseparable. Smith makes the very brandname of cosmopolitanism analogous to "the label of your shirt." In so doing, she calls attention to the ways in which the cultural logic of global branding has so thoroughly driven, in equal measure, both the fashion industry and the twenty-first century corporate university.

"An OLd Man in a Baseball Cap" 
Central to the corporatization of the university has been a market-driven paradigm through which, as J.M. Coetzee writes, "the neoliberal enemies of the university have succeeded in their aims [... of dismantling] the university built on humanistic grounds"; he wonders, "Is a university without a proper faculty of humanities (or faculty of humanities and social sciences) still a university?” (n.pag.). The same question preoccupies On Beauty, which epitomizes even as it discredits the branding of humanistic critical inquiry. A novel whose title, ${ }^{7}$ setting (a college campus), cast of characters (faculty and students of humanities disciplines), and style (a "predilection for scholarly reference" (Tynan 79)) highlight the global contemporary crisis of the humanities driven by the neoliberal view of higher education, On Beauty reveals that the unfashionability of humanistic critical inquiry is fashioned by global branding.

As critics including Elaine Showalter and Philip Tew have pointed out, the novel is rife with campus politics. Smith includes extended scenes of erudite lectures and lively seminar discussions, vivid portrayals of petty faculty in-fighting (characterized as “complete exposure, a cataclysmic embarrassment— this is one of the purest academic pleasures" (29)), a number of awkward and anxious graduate students who are the best "replicas on campus to normal human beings" (107), and several staged debates on topics

\footnotetext{
${ }^{7}$ It is worth noting that Smith borrows her title from Elaine Scarry's philosophical treatise on aesthetics and ethics, On Beauty and Being Just, which Scarry—who holds an endowed professorship in the English Department at Harvard—published three years before Smith herself took a fellowship at the Radcliffe, during the course of which she and Scarry became friends. Smith began drafting On Beauty while living in Cambridge, and though the novel is set in a fictional town just outside of Boston, the Wellington of $O n$ Beauty contains many obvious parallels to Harvard/Cambridge.
} 
from canonicity to affirmative action, all of which work to satirize the stereotypically self-important conversations about academic life. Yet surprisingly, interpretations of $\mathrm{On}$ Beauty that have focused on its participation in the genre of the campus novel have not come to the defense of what Coetzee calls "the university built on humanistic grounds" (n.pag.). Rather, these readings of On Beauty — penned by the very scholars whose profession the novel caricatures and, at several points, even lambasts - tend to take up positions that reproduce "the tenuous link between the social and the academic that, Smith suggests, characterizes the disciplines" (Batra 1082) of the humanities. Such interpretations tend, to steal a phrase from Eve Sedgwick in her hugely influential "Paranoid Reading and Reparative Reading," to be "sappy, aestheticizing, defensive, anti-intellectual, or reactionary" (35), joining the novel in castigating practices of critical inquiry not only at the fictional Wellington University, but so too at its real-life counterparts.

Howard, On Beauty's protagonist, embodies nearly every unkind stereotype of the humanities professor and is almost supremely unsympathetic. A bad husband, a bad father, a bad teacher, a bad scholar, Howard begins an affair with his undergraduate student — who also happens to be his son's ex-fiancé — on the day of her mother's funeral, tirelessly complains about his untenured status despite not having published any new research in over a decade, and bemoans the disrespect of his family, his colleagues, and his students alike. But despite his profound unlikeability - much of which converges upon his professorial identity-Howard is not mistaken when he "recast[s] Aesthetics as a rarified language of exclusion ... with which we both console ourselves and make ourselves" (155, italics in original). That Howard is an unsavory character does not make 
him any less right about aesthetics: art does not spring up automatically of its own volition, untouched by global structures of power. Aesthetic objects are of the world even as they refashion it, responding and corresponding to lived experience. Showing this is exactly what humanistic critical inquiry_even if not what Howard, On Beauty's ostensible practitioner of it-does best.

Passages like this one-

“It's our shorthand for when we say, like, Professor Simeon's class is 'The tomato's nature versus the tomato's nurture,' and Jane Colman's class is 'To properly understand the tomato you must first uncover the tomato's suppressed Herstory' — she's such a silly bitch that woman — and Professor Gilman's class is 'The tomato is structured like an aubergine,' and Professor Kellas's class is basically 'There is no way of proving the existence of the tomato without reference to the tomato itself' .... Your [Howard's] class is all about never ever saying I like the tomato. That's why so few people take it-I mean, no offence, it's a compliment. They can't handle the rigour of never saying I like the tomato. Because the tomato's not there to be liked.... It's properly intellectual. The tomato is just totally revealed as this phoney construction that can't lead you to some higher truth—nobody's pretending the tomato will save your life. Or make you happy. Or teach you how to live or ennoble you or be a great example of the human spirit. Your tomatoes have got nothing to do with love or truth. (312, italics in original) 
— satirize academic methodologies: an outdated anthropological model, a second-wave feminist critique, a comparative approach, a deconstructionist mode. In so doing, the painstaking interpretative paradigms of the humanities are reduced to "our shorthand," to the status of academic brands. Further, each of these parodied brands of humanistic critical inquiry stand, on some level, in contrast to Howard's embodied parody of the brand of the humanities more broadly, because Howard's own pedagogical and research methodology is the all-pervasive hermeneutics of suspicion. In fact, a hermeneutic of suspicion toward the exigencies of global capitalism and the corporate university it has produced allows for interpretations that might lead to transformation-a "hermeneutic communism," as Gianni Vattimo and Santiago Zabala have recently called it, that could restore Stuart Hall's rallying cry that "the University is a critical institution or it is nothing" (qtd. in Giroux, n.pag.). No wonder, then, that the corporate university does not value Howard's critical interpretations of the texts he studies and teaches: "Howard was nowhere near as successful or as popular or as well paid as his peers in Wellington” (98); his students are "so scared of you they don't say anything" (313); and at fifty-seven years old, with "six years in upstate New York, eleven in London, one in the suburbs of Paris" (17-8) under his belt and "[a]fter ten years of service [at Wellington] they had still opposed Howard's tenure when it was put forward last fall. They would oppose it once more this year." (320).

Because Howard's approach to aesthetic objects centers on asking "What's so beautiful about this tomato?" (312), it might seem to put forth what John Freeman calls a "tacit ban on beauty" (n. pag.). But in fact, what Howard actually puts forth is a tacit ban on what Sedgwick identifies as "sappy, aestheticizing, defensive, anti-intellectual, or 
reactionary" (35) interpretative practices. In its insistence that "the tomato's not there to be liked" (312), Howard's approach refuses to capitulate to what Coetzee calls "the ideological force driving the assault on the independence of universities" (n.pag.), because Howard will not offer an easily digested answer to the question, "What's so beautiful about this tomato?" (312). Rather than the drippy sentimentality of claims that art will "lead you to some higher truth, ... [or] will save your life. Or make you happy. Or teach you how to live or ennoble you or be a great example of the human spirit" (312), what Howard calls for is political vigilance in asking ourselves: under what material historical conditions and ideological formations, and from which subject positions and geocultural locations, do we experience the aesthetic - and how in turn does the aesthetic reveal us to ourselves?

Howard's interpretative method does not evacuate beauty from aesthetic objects any more that it evacuates subjectivity or affect from our response to them. Nevertheless, that which is "properly intellectual" (312) is equated with that which is properly unemotional. This reduces critical inquiry to branding, and offers a false choice: if the only two available options are either to consider "prettiness as the mask that power wears" (155) or to find art "impressive, beautiful, awe-inspiring" (251), who would pick the former? Appreciation, admiration, and pleasure are evacuated from humanities disciplines; humanistic critical inquiry comes to signify a sterile and bloodless response to the aesthetic; and the aesthetic in turn produces neither empathy nor humility nor joy nor knowledge, because Howard's "tomatoes have nothing to do with love or truth" (312). Instead, they have everything to do with the sinister and palpably effective branding of the humanities as a set of skills_- "critical thinking," or as Coetzee calls it, "critical 
literacy"-in the corporate university. "[T]he claim," he writes, "that only the full apparatus of a humanistic education can produce critical literacy seems to me hard to sustain, since it is always open to the objection: if critical literacy is just a skill or set of skills, why not just teach the skill itself" (n.pag.) — the brand instead of the tomato.

As it turns out, Howard's tomato is—rather troublingly—quite far removed from Smith's own. As she tells an interviewer, "I think critical theory, in its obsession with modernity, has become a little tragic, like an old man in a baseball cap" (Gual 38). The baseball cap, like the tomato, proves a fruitful analog to the critical study of (or, as Smith somewhat ungenerously puts it, "the obsession with") modernity. Baseball capstypically customized by logos from sports teams to designers' names to catch-phrases and worn, as Maynard notes, in every part of the globe (112) — signify a wide range of meanings. Alternately associated with athleticism (they are part of the traditional baseball uniform), fandom (the wearer's favorite team or designer made legible), working-class professions (associated often with truckers, "rednecks," and blue collar workers), or racialized ghettoization (worn backwards, they are "linked to homeboy and homegirl culture ... no longer a catchy affectation, but part of the iconography of social crisis, perhaps the first truly global symbol of youth" (Maynard 112)), the baseball cap signals affinity with diverse social and political movements, much like critical theory itself.

Smith's fashion metaphor casts an elderly person in youthful garb as pathetic and desperate, grasping at a style of being in the world to which he has no longer has any claim, access, or understanding. But her "old man in a baseball cap" might just as easily be understood as engaged in a deliberate act of self-fashioning that fights back against the cultural imperatives of aging that tell him he is out of touch with contemporary life, 
unwelcome in youth subcultures of resistance, or-worse yet-utterly irrelevant to both. These are exactly the accusations that the humanities face in the neoliberal view of higher education. The humanities are widely cast in this neoliberal rhetoric as "a little bit tragic" in the same way that Smith seems to regard her "old man in a baseball cap," and the "obsession with modernity" that is branded at best as precious and at worst as silly, is what makes critical theory appear anti-modern in the corporate university. But just like an "old man in a baseball cap," critical inquiry into the social, political, and economic conditions of global modernity reveals the fundamental inseparability of individual selffashioning and global branding.

On Beauty puts Howard “in a baseball cap pointing at Emily Dickinson’s house” (19), such that if critical theory is an "old man in a baseball cap," Howard is critical theory made material and embodied. While Howard understands "Aesthetics as a rarified language of exclusion ... with which we both console ourselves and make ourselves" (155, italics in original), his baseball cap actually reveals the ways in which critical theory refuses to be branded as "rarified" or "exclusi[ve]," much less "a little bit tragic." Rather, the baseball cap_like the critical theory it stands in for-is the very garment of consolation for the conditions of global inequality that that have produced the inescapable cultural logic of the brand, which despite its ubiquity can never foreclose the radical and resistant acts of individual self-fashioning that become thinkable, possible, visible, legible in and through critical inquiry. These global fabrications might do much more than rebrand the humanities and the inhumanities of modernity: they might just refashion the world. 


\section{Works Cited}

Abernathy, Frederick, John Dunlop, Janice Hammond, and David Weil. A Stitch in Time: Lean Retailing and the Transformation of Manufacturing. Lessons from the Apparel and Textile Industries. New York: Oxford University Press, 1999.

Anand, Mulk Raj. Conversations in Bloomsbury. London: Wildwood House, 1981.

------. Mulk Raj Anand: A Reader. An Anthology of Select Writings of Mulk Raj Anand. Ed. with an Introduction by Atma Ram. Delhi: Nagri Printers, 2005.

Adamson, Glenn, Giorgio Riello, and Sarah Teasley, eds. Global Design History. New York: Routledge, 2011.

Anderson, Amanda. The Powers of Distance: Cosmopolitanism and the Cultivation of Detachment. Princeton, NJ: Princeton University Press, 2001.

Andersen, Kurt. "Zadie Smith in Conversation With Kurt Andersen.” Pen World Voices: The New York Festival of International Literature. New York: NYPL, 2006.

Anesko, Michael. "Friction with the Market": Henry James and the Profession of Authorship. New York: Oxford University Press, 1986.

Anjaria, Ulka. "On Beauty and Being Postcolonial: Aesthetics and Form in Zadie Smith." Zadie Smith: Critical Essays. Ed. Tracey L. Walters. New York: Peter Lang, 2008. $31-56$.

Anonymous. “A conversation with Zadie Smith.” Penguin.com. http://www.us.penguingroup.com/static/rguides/us/on_beauty.html. N.d. N. pag. Web. 5 May 2013.

-------. “Cropped Hair.” Household Words (November 1881): 456. 
------. "Four Novels." The Saturday Review 62 (1886): 728.

------. "In the Depths," in Oscar Wilde: Interviews and Recollections, 2 vols. Ed. E.H. Mikhail. New York: Barnes and Noble Books, 1979. 328-9.

------. “An interview with Zadie Smith.” Pbs.org. http://www.pbs.org/wgbh/masterpiece/teeth/ei_smith_int.html. N.d. N.pag. Web. 9 May 2014.

------. Lady's Pictorial. 21 October 1899: n.pag.

------. “Review of The Princess Casamassima.” Graphic 35 (1886): 646.

------. “Review of The Princess Casamassima.” Literary World 18 (1887): 5.

-------. "Review of The Princess Casamassima." Philadelphia Public Ledger, 30 Nov. 1886: 2.

------. "Review of The Princess Casamassima." St. Paul Daily Pioneer Press, 28 Nov. 1886: 12.

-------. “A Slumming Romance.” New York Times, 21 Nov. 1886: 12.

Appadurai, Arjun. Modernity at Large: Cultural Dimensions of Globalization. Minneapolis: University of Minnesota Press, 1996.

------. The Social Life of Things: Commodities in Cultural Perspective. New York: Cambridge University Press, 1988.

Apter, Emily. Feminizing the Fetish: Psychoanalysis and Narrative Obsession in Turnof-the-Century France. Ithaca, NY: Cornell University Press, 1991.

Arendt, Hannah. Lectures on Kant's Political Philosophy, ed. Ronald Beiner. Chicago: University of Chicago Press, 1982.

------. The Life of the Mind, 2 vols., ed. Mary McCarthy. New York: Mariner, 1981. 
Armstrong, Nancy. Fiction in the Age of Photography: The Legacy of British Realism. Cambridge, MA: Harvard University Press, 1999.

Armstrong, Tim. Haunted Hardy: Poetry, History, Memory. New York: Palgrave Macmillan, 2000.

Arrighi, Giovanni. The Long Twentieth Century. London: Verso, 2010.

Ash, Juliet. Dress Behind Bars: Prison Clothing as Criminality. London: I.B. Tauris, 2010.

Banner, Lois W. American Beauty. New York: Knopf, 1983.

Barber, Stephen. “Lip-Reading: Woolf's Secret Encounters.” Novel Gazing: Queer Readings in Fiction, ed. Eve Kofosky Sedgwick. Durham, NC: Duke University Press, 1997. 415-6.

Barnard, Malcolm. Fashion as Communication. London: Routledge, 1996.

Barthes, Roland. The Fashion System, trans. Matthew Ward and Richard Howard. New York: Hill, 1983.

Batra, Kanika. “Kipps, Belsey, and Jegede: Cosmopolitanism, Transnationalism, and Black Studies in Zadie Smith's On Beauty.” Callaloo 33.4 (2010): 1079-92.

Baudelaire, Charles. "The Painter of Modern Life." In The Painter of Modern Life and Other Essays, trans. and ed. Jonathan Mayne. London: Phaidon, 2003. 1-41.

Baudrillard, Jean. For a critique of the political economy of the sign. St. Louis, MO: Telos Press, 1981.

------. "Fashion, or the Enchanting Spectacle of the Code." In Fashion Theory: A Reader, ed. Malcolm Barnard. New York: Routledge, 2007. 462-472.

Beach, Joseph Warren. The Technique of Thomas Hardy. Chicago: University of Chicago 
Press, 1922.

Bell, Millicent. Meaning in Henry James. Cambridge, MA: Harvard University Press, 1991.

Bell, Quentin. On Human Finery. New York: Schocken, 1976.

Virginia Woolf: A Biography, 2 vols. New York: Harcourt Brace Jovanovich, 1972.

Benjamin, Walter. The Arcades Project. Ed. and trans. Rolf Tiedemann. Cambridge, MA: Harvard University Press, 1999.

-------. The Correspondence of Walter Benjamin, 1910-1940. Ed. M.R. and E.M. Jacobson. Chicago: University of Chicago Press, 1994.

-------. “Theses on the Philosophy of History.” Illuminations. Trans. Harry Zohn. London: Pimlico, 1999.

-------. Walter Benjamin: Selected Writings 1938-1940, ed. Michael William Jennings. Cambridge, MA: Harvard University Press, 2003.

Bennett, Arnold. Our Women: Chapters on the Sex Discord. New York: George H. Doran Co., 1920.

Benstock, Shari and Suzanne Ferris, eds. On Fashion. New Brunswick, NJ: Rutgers University Press, 1994.

Berman, Jessica. Modernist Commitments: Ethics, Politics, and Transnational Modernism. New York: Columbia University Press, 2012.

Bernstein, Susan David. Confessional Subjects: Revelations of Gender and Power in Victorian Literature and Culture. Chapel Hill: University of North Carolina Press, 1997. 
Betensky, Carolyn. Feeling for the Poor: Bourgeois Compassion, Social Action, and the Victorian Novel. Charlottesville: University of Virginia Press, 2010.

Bishop, E.L. “The Shaping of Jacob's Room: Woolf's Manuscript Revisions.” Twentieth Century Literature 32 (1986): 115-35.

Black, Naomi. Virginia Woolf As Feminist. Ithaca, NY: Cornell University Press, 2004.

Blair, Sara. Henry James and the Writing of Race and Nation. Cambridge: Cambridge University Press, 1996.

-------. “Local Modernity, Global Modernism: Bloomsbury and the Places of the Literary.” ELH 71.3 (2004): 813-838.

Blanchard, Mary Warner. Oscar Wilde's America: Counterculture in the Gilded Age. New Haven, CT: Yale University Press, 1998.

Bloomer, Amelia. "Female attire.” The Lily, February 1851.

-------. “"Mrs. Kemble and Her New Costume.” The Lily, December 1849.

Bourdieu, Pierre. Distinction: A Social Critique of the Judgment of Taste, trans. Richard Nice. Cambridge, MA: Harvard University Press, 1984.

Bowlby, Rachel. Carried Away: The Invention of Modern Shopping. New York: Columbia University Press, 2001.

------. Just Looking: Consumer Culture in Dreiser, Gissing, and Zola. New York: Methuen, 1985.

Brennan, Timothy. At Home in the World: Cosmopolitanism Now. Cambridge, MA: Harvard University Press, 1997.

------. Wars of Position: The Cultural Politics of Left and Right. New York: Columbia University Press, 2006. 
Breward, Christopher. The hidden consumer: masculinities, fashion, and city life 18601914. New York: St. Martin’s Press, 1999. and Caroline Evans, eds. Fashion and Modernity. New York: Berg, 2005. , Becky Conekin, and Caroline Cox, eds. The Englishness of English Dress. New York: Berg, 2002.

Briggs, Julia. Virginia Woolf: An Inner Life. London: Penguin Group, 2005.

Brooks, Peter. Body Work: Objects of Desire in Modern Narrative. Cambridge, MA: Harvard University Press, 1993.

Brouillette, Sarah. Postcolonial Writers and the Global Literary Marketplace. New York: Palgrave Macmillan, 2007.

Brown, Bill. "A Thing about Things: The Art of Decoration in the Work of Henry James." The Henry James Review 23.3 (2002): 222-232.

Brown, Judith. Glamour in Six Dimensions: Modernism and the Radiance of Form. Ithaca, NY: Cornell University Press, 2009.

------. “Glamour's Silhouette: Fashion, Fashun, and Modernism.” A Handbook of Modernism Studies. Ed. Jean-Michel Rabaté. Malden, MA: Blackwell, 2013. Buckley, Cheryl and Hilary Fawcett. Fashioning the feminine: Representation and Women's Fashion from the Fin de Siècle to the Present. London: I.B. Tauris, 2002.

Butler, Judith. Gender Trouble: Feminism and the Subversion of Identity. New York: Routledge, 1990.

Carey, John. The Intellectuals and the Masses: Pride and Prejudice Among the Literary Intelligensia, 1880-1939. Chicago: Academy Chicago Publishers, 2005. 
Casanova, Pascale. The World Republic of Letters. Trans. M. B. DeBevoise. Cambridge, MA: Harvard University Press, 2007.

Chandler, Charles F. and Arthur H. Elliott, eds. Anthony's Photographic Bulletin, Volume XVII. New York: E. \& H. T. Anthony \& Co. Publishers, 1887.

Christian, Barbara. "Layered Rhythms: Virginia Woolf and Toni Morrison.” Virginia Woolf: Emerging Perspectives, ed. Mark Hussey and Vara Neverow. New York: Pace University Press, 1994. 164-77.

Childs, Peter. Contemporary Novelists: British Fiction since 1970. New York: Palgrave Macmillan, 2005.

Coffin, Judith G. The Politics of Women's Work: The Paris Garment Trades 1750-1915. Princeton, NJ: Princeton University Press, 1996.

Coetzee, J.M. “Universities Head for Extinction.” Mail and Guardian, 1 November 2013. N.pag. Web. 3 November 2013.

Cox, Edward W., ed. Cox's Criminal Cases: Reports of Cases in Criminal Law, Argued and Determined in All the Courts in England and Ireland, 31 vols. London: J. Crockford, Law Times Office, 1843-1941.

Cox, R.G., ed. Thomas Hardy: The Critical Heritage. New York: Routledge, 2005. Craik, Jennifer. The Face of Fashion: Cultural Studies in Fashion. New York: Routledge, 1994.

Crane, Diana. Fashion and Its Social Agendas: Class, Gender, and Identity in Clothing. Chicago: The University of Chicago Press, 2000.

Crowe, Lauren Goldstein and Sagra Maceira de Rose. The Towering World of Jimmy Choo: A Glamorous Story of Power, Profits, and the Pursuit of the Perfect Shoe. 
New York: Bloomsbury USA, 2009.

Cuddy-Keane, Melba. Virginia Woolf, the Intellectual, and the Public Sphere.

Cambridge: Cambridge University Press, 2003.

-------. "World Modelling: Paradigms of Global Consciousness in and Around Virgina

Woolf." Virginia Woolf's Bloomsbury, Volume 2: International Influence and

Politics, ed. Lisa Shahriari and Gina Potts. New York: Palgrave Macmillan, 2010. $158-76$.

Cunningham, Valentine. British Writers of the Thirties. Oxford: Oxford University Press, 1988.

Dalgarno, Emily. Virginia Woolf and the Migrations of Language. Cambridge:

Cambridge University Press, 2012.

Damrosch, David. What Is World Literature? Princeton, NJ: Princeton University Press, 2003.

de Certeau, Michel. The Practice of Everyday Life. Trans. Steven Rendall. Berkeley and Los Angeles: University of California Press, 1984.

Debord, Guy. "Report on the Construction of Situations and on the International Situationist Tendency's Conditions of Organization and Action.” Trans. Ken Knabb. Situationist International Online. http://www.cddc.vt.edu/sionline/si/report.html. N.d. N. pag. 21 May 2013.

------. The Society of the Spectacle. Trans. Donald Nicholson-Smith. New York: Zone Books, 1995.

------. Theory of the Dérive, and Other Situationist Writings on the City. Ed. Libero Andreotti and Xavier Costa. Barcelona: ACTAR: Meseu d'art Contemporani de 
Barcelona, 1996.

De Grazia, Victoria and Ellen Furlough. The Sex of Things: Gender and Consumption in Historical Perspective. Berkeley and Los Angeles: University of California Press, 1996.

Deleuze, Gilles and Felix Guattari. A Thousand Plateaus: Capitalism and Schizophrenia. Minneapolis: University of Minnesota Press, 1987.

Delson, Roberta Marx. "Brazil: the origin of the textile industry." In The Ashgate Companion to the History of Textile Workers, 1650-2000. Ed. Lex Heerma Van Voss, Els Hiemstra-Kuperus, and Elise Van Nederveen Merrkerk. Burlington, VT: Ashgate, 2010.

Dettmar, Kevin, and Stephen Watt, eds. Marketing Modernisms: Self-Promotion, Canonization, Rereading. Ann Arbor: University of Michigan Press, 1996.

DeVine, Christine. Class in Turn-of-the-Century Novels of Gissing, James, Hardy and Wells. Burlington, VT: Ashgate, 2005.

Díaz, Junot. The Brief Wondrous Life of Oscar Wao. New York: Riverhead, 2007.

Dick, Susan. “"What fools we were!': Virginia Woolf’s 'A Society."” Twentieth Century Literature 33 (1987): 51-66.

Dickerson, K.G. Textiles and Apparel in the Global Economy. Upper Saddle River, NJ: Merrill, 1999.

Dollimore, Jonathan. Sexual Dissidence: Augustine to Wilde, Freud to Foucault. Oxford: Oxford University Press, 1991.

Doyle, Laura and Laura Winkiel, eds. Geomodernisms: Race, Modernism, and Modernity. Bloomington: Indiana University Press, 2005. 
Doylen, Michael. “Oscar Wilde's De Profundis: Homosexual Self-Fashioning on the Other Side of Scandal." Victorian Literature and Culture 27.2 (1999): 547-66.

Duffy, Enda. The Speed Handbook: Velocity, Pleasure, Modernism. Durham, NC: Duke University Press, 2009.

and Maurizia Boscagli. "Selling Jewels: Modernist Commodification and Disappearance as Style.” Modernism/modernity 14.2 (2007): 189-207.

Durden, Mark. "Ritual and Deception: Photography and Thomas Hardy." Journal of European Studies 30.1 (2000): 57-69.

Edel, Leon. Henry James: 1882-1895, The Middle Years. Philadelphia: J.B. Lippincott Company, 1962.

Edwards, Brent Hayes. The Practice of Diaspora: Literature, Translation, and the Rise of Black Internationalism. Cambridge, MA: Harvard University Press, 2003.

Eicher, Joanne, ed. The Visible Self: Global Perspectives of Dress, Culture, and Society. New York: Fairchild, 2008.

Eliot, George. Adam Bede. Edited with an Introduction and Notes by Margaret Reynolds. New York: Penguin Books, 2008.

Ellmann, Richard. Oscar Wilde. New York: Knopf, 1988.

Enstice, Andrew. Thomas Hardy: Landscapes of the Mind. London and Basingstoke: Macmillan, 1979.

Entwistle, Joanne. The Fashioned Body: Fashion, Dress, and Modern Social Theory. Malden, MA: Blackwell, 2000.

Etsy, Jed. Unseasonable Youth: Modernism, Colonialism, and the Fiction of Development. New York: Oxford University Press, 2011. 
Evans, Caroline. Fashion at the Edge: Spectacle, Modernity, and Deathliness. New Haven, CT: Yale University Press, 2003.

Felski, Rita. The Gender of Modernity. Cambridge, MA: Harvard University Press, 1995. ------. Uses of Literature. Malden, MA: Wiley-Blackwell, 2008.

Ferrer, Daniel. "Variant and Variation: Toward a Freudo-bathmologico-BahktinoGoodmanian Genetic Model?” Genetic Criticism and the Creative Process: Essays from Music, Literature, and Theater. Ed. William Kinderman and Joseph Jones (Rochester, NY: University of Rochester Press, 2009. 35-50.

Fido, Martin. Oscar Wilde. New York: Viking Press, 1973.

Finkel, Alicia. “A Tale of Lilies, Sunflowers, and Knee-Britches: Oscar Wilde’s Wardrobe for His American Tour.” Dress 15 (1989): 4-15.

Fischer, Mike. "The Jamesian Revolution in The Princess Casamassima." The Henry James Review 9.2 (1988): 87-104.

Flugel, J.C. The Psychology of Clothes. London: Hogarth Press, 1930.

Foucault, Michel. Discipline and Punish: The Birth of the Prison. New York: Vintage, 1995.

Fowles, John and Jo Draper. Thomas Hardy's England. Boston: Little, Brown and Co., 1984.

Freedman, Jonathan. Professions of Taste: Henry James, British Aestheticism, and Commodity Culture. Stanford, CA: Stanford University Press, 1990.

Freeman, John. "Zadie Smith's Satire Mixes Race and Rivalry in a Place Like Harvard," San Francisco Chronicle, September 18, 2005.

Friedman, Susan Stanford. "World Modernisms, World Literature, and Comparativity." 
Oxford Handbook of Global Modernisms. Ed. Mark Wollaeger with Matt Eatough. Oxford: Oxford University Press, 2012.

Froula, Christine. Virginia Woolf and the Bloomsbury Avant-Garde: War, Civilization, Modernity. New York: Columbia University Press, 2005.

Gagnier, Regenia. The Insatiability of Human Wants: Economics and Aesthetics in Market Society. Chicago: the University of Chicago Press, 1999.

Garrity, Jane. "Selling Culture to the 'Civilized': Bloomsbury, British Vogue, and the Marketing of National Identity." Modernism/modernity 6.2 (1999): 29-58.

------. "Virginia Woolf, Intellectual Harlotry and 1920s British Vogue." Virginia Woolf in the age of Mechanical Reproduction, ed. Pamela L. Caughie. New York: Garland, 2000. 185-218.

Gatrell, Simon. "Wessex." In The Cambridge Companion to Thomas Hardy, ed. Dale Kramer. New York: Cambridge University Press, 1999.

Ghosh, G.K. and Shukla Ghosh, Indian Textiles: Past and Present. New Delhi: S.B. Nangia for APH Publishing Corporation, 1995.

Gibson, James, ed. Thomas Hardy: Interviews and Recollections New York: St. Martin's Press, 1999.

Gikandi, Simon. "Preface: Modernism in the World." Modernism/modernity 13.3 (2006): 419-424.

Gilroy, Paul. After Empire: Melancholia or Convivial Culture? Oxford: Routledge, 2004.

-------. Against Race: Imagining Political Culture Beyond the Color Line. Cambridge, MA: Belknap Press of Harvard University Press, 2002.

Giroux, Henry. "Public Intellectuals Against the Neoliberal University." Truthout, 29 
October 2013. http://truth-out.org/opinion/item/19654-public-intellectualsagainst-the-neoliberal-university. Web. 7 May 2014.

Glass, Loren. “Trademark Twain.” American Literary History 13.4 (2001): 671-693. Goldman, Jonathan. Modernism is the Literature of Celebrity. Austin: University of Texas Press, 2011.

Gordon, S.S. Turn of the Century Fashion Patterns and Tailoring Techniques. New York: Jno. J. Mitchell Co., 1901.

Goldman, Jane. The Feminist Aesthetics of Virginia Woolf: Modernism, PostImpressionism and the Politics of the Visual. Cambridge: Cambridge University Press, 1998.

Goodlad, Lauren. “Cosmopolitanism's Actually Existing Beyond; Toward a Victorian Geopolitical Aesthetic." Victorian Literature and Culture 38 (2010): 399-411.

------. Victorian Literature and the Victorian State: Character and Governance in a Liberal Society. Baltimore, MD: Johns Hopkins University Press, 2003.

Graham, Wendy. Henry James's Thwarted Love. Stanford, CA: Stanford University Press, 1999.

Gramsci, Antonio. Selections from the Prison Notebooks. Ed. Quintin Hoare and Geoffrey Nowell-Smith. New York: International Publishers, 1971.

Green, Barbara. Spectacular Confessions: Autobiography, Performative Activism, and the Site of Suffrage 1905-1938. New York: St. Martin's, 1997.

Guiget, Jean. Virginia Woolf and Her Works, trans. Jean Stewart. New York: Harcourt, 1976.

Guillory, John. "The Ethics of Reading," in The Turn to Ethics. Ed. Marjorie Garber. 
New York: Routledge, 2000. 29-46.

Haig, Matt. Brand Failures: The Truth About the 100 Biggest Branding Mistakes of All Time. $2^{\text {nd }}$ ed. London: Kogan, 2011.

Hale, Dorothy. "On Beauty as Beautiful?: The Problem of Novelistic Aesthetics by Way of Zadie Smith.” Contemporary Literature 53.4 (2012): 814-844.

Hamilton, C. J. "Life Behind the Counter," The Young Woman (1893): 128-30.

Hardy, Thomas. "Candour in English Fiction.” New Review 1 (1890): 6-21.

------. “The Dorsetshire Labourer" (1883). In Thomas Hardy's Personal Writings: Prefaces, Literary Opinions, Reminiscences, edited by Harold Orel, 168-91. Lawrence: Kansas University Press, 1966.

------. "Preface to the 1895 edition of Far From the Madding Crowd." London: Osgood, McIlvaine, 1895.

------. Tess of the D'Urbervilles, edited with Notes by Tim Dolin, with an Introduction by Margaret R. Higonnet. New York: Penguin, 2003.

------ and Florence Emily Hardy. Thomas Hardy. London: Wordsworth Editions Limited, 2007.

Harrison, W. Jerome. A History of Photography Written as a Practical Guide and An Introduction to its Latest Developments. New York: Scovill Manufacturing Co., 1887.

Harris, Frank. Oscar Wilde. East Lansing: Michigan State University Press, 1959.

Hasam, Noorul. Thomas Hardy: The Sociological Imagination. London and Basingstoke: Macmillan, 1982.

Hayot, Eric. “On Literary Worlds.” Modern Language Quarterly 72.2 (2011): 129-161. 
------. On Literary Worlds. Oxford: Oxford University Press, 2012.

Head, Dominic. “Zadie Smith's White Teeth: Multiculturalism for the New Millenium.” Contemporary British Fiction. Ed. Richard Lane, Rod Mengham, and Philip Tew. Cambridge: Polity, 2003. 106-19.

Hebdige, Dick. Subculture: The Meaning of Style. New York: Routledge, 1979.

Hegel, G.W.F. Aesthetics: Lectures on Fine Art. Trans. T.M. Knox. Oxford: Claredon, 1975.

Heidegger, Martin. "The Origin of the Work of Art." Philosophies of Art and Beauty. Ed. A. Hofstadter and R. Kuhns. Chicago: University of Chicago Press, 1990. 651703.

Hobsbawn, Eric. Industry and Empire: The Birth of the Industrial Revolution. London: The Penguin Group, 1999.

Hollander, Anne. Sex and Suits. New York: Knopf, 1994.

Hollinger, David. “The New Cosmopolitanism.” Conceiving Cosmopolitanism: Theory, Context, and Practice. Ed. Steven Vertovec and Robin Cohen. New York: Oxford University Press, 2002.

Hughes, Clair. Henry James and the Art of Dress. New York: Palgrave Macmillan, 2001. Huggan, Graham. The Postcolonial Exotic: Marketing the Margins. New York: Routledge, 2001.

Hungerford, Edward. “Is ‘A Society’ A Shorty Story?” Virginia Woolf Miscellany 21 (1983): 3-4.

Huyssen, Andreas. After the Great Divide: Modernism, Mass Culture, Postmodernism. Bloomington: Indiana University Press, 1986. 
Hyde, H. Montgomery. Oscar Wilde: The Aftermath. New York: Farrar, Strauss \& Company, 1963.

Itakura, Gen'ichiro. “On Beauty and Doing Justice to Art: Aesthetics and Ethics in Zadie Smith's On Beauty." ariel: a review of international literature 41.1 (2011): 27-44.

Jackson, Arlene. "Photography as Style and Metaphor in the Art of Thomas Hardy." Thomas Hardy Annual 2 (1984): 91-109.

Jacobson, Marcia. Henry James and the Mass Market. University, AL: University of Alabama Press, 1983.

Jaffe, Aaron. Modernism and the Culture of Celebrity. Cambridge: Cambridge University Press, 2005.

Jakubiak, Katarzyna. “Simulated Optimism.” Zadie Smith: Critical Essays. Ed. Tracey L. Walters. New York: Peter Lang, 2008. 201-218.

James, Henry. “The Art of Fiction.” In The Art of Criticism: Henry James on the Theory and Practice of Fiction, ed. Susan Griffin and William Veeder. Chicago: University of Chicago Press, 1986. 165-83.

------. The Complete Notebooks of Henry James, ed. Leon Edel and Lyall H. Powers. Oxford: Oxford University Press, 1987.

------. The Letters of Henry James, ed. Leon Edel., 4 vols. London: Bodley Head, 197480.

------. Literary Criticism: French Writers, Other European Writers, etc. New York: Library of America, 1984.

------. “A New England Winter” (1884). In Complete Stories, 1884-1891, ed. Edward Said. New York: Literary Classics of the United States, 1999. 
-------. The Portrait of a Lady, ed. by Robert D. Bamberg. New York: W.W. Norton \& Company, 1995.

------. The Princess Casamassima, ed. Derek Brewer. New York: Penguin Books, 1987.

------. Roderick Hudson, ed. Geoffrey Moore. New York: Penguin Books, 1986.

-------. A Small Boy and Others. Chappaqua, NY: Turtle Point Press, 2001.

Jay, Paul. Global Matters: The Transnational Turn in Literary Studies. Ithaca, NY: Cornell University Press, 2010.

Johnston, Georgia. "Virginia Woolf's Talk on the Dreadnought Hoax." Woolf Studies Annual 15 (2009): 1-45.

Joplin, Patricia. “The Authority of Illusion: Feminism and Fascism in Virginia Woolf's Between the Acts." South Central Review 6 (1989): 88-104.

Kant, Immanuel. "Idea for a Universal History with a Cosmopolitan Purpose." Political Writings, ed. Hans Reiss and trans. H.B. Nisbet. New York: Cambridge University Press, 1991.

Kaplan, Joel and Sheila Stowell. Theater and Fashion: Oscar Wilde to the Suffragettes. New York: Cambridge University Press, 1995.

Kennard, Jean. "Power and Sexual Ambiguity: The Dreadnought Hoax, The Voyage Out, Mrs Dalloway, and Orlando.” Journal of Modern Literature 20.2 (1996): 149-64.

Klein, Naomi. No Logo: Taking Aim at the Brand Bullies. New York: Picador USA, 1999. König, Rene. The Restless Image: A Sociology of Fashion. Sydney, Australia: Allen \& Unwin, 1973.

Koppen, Randi. Virginia Woolf, Fashion, and Literary Modernity. Edinburgh: Edinburgh University Press, 2009. 
Kortsch, Christine Bayles. Dress in Late Victorian Women's Fiction: Literacy, Textiles, and Activism. Burlington, VT: Ashgate, 2009.

Kunin, Aaron. "Decoration, Modernism, Cruelty.” Modernism/modernity 17.1 (2010): $87-107$.

Ladsun, James. "Howard’s Folly.” The Guardian, 10 September 2006.

Laird, J.T. The Shaping of 'Tess of the D'Urbervilles. ' Oxford: Clarendon Press, 1975. Langland, Elizabeth. Nobody's Angels: Middle-Class Women and Domestic Ideology in Victorian Culture. Ithaca, NY: Cornell University Press, 1995.

Lash, S. and Urry, J. Economies of Signs and Space. London: Sage, 1994.

Leavis, Q.D. “Caterpillars of the Commonwealth Unite!,” Scrutiny 7.2 (1938): 203-14.

Lecercle, Jean-Jacques. The Violence of Language. London: Routledge, 1990.

Lee, Hermione. Virginia Woolf. New York: Knopf, 1997.

Lehmann, Ulrich. Tigersprung: Fashion in Modernity. Boston: Massachusetts Institute of Technology University Press, 2000.

Levinas, Emmanuel. Totality and Infinity: An Essay on Exteriority. Trans. Alphonso Lingis. Pittsburgh, PA: Duquesne University Press, 1969.

Lewis, Lloyd and Henry Justin Smith. Oscar Wilde Discovers America. New York: Benjamin Blom, 1936, reprinted 1967.

Litvak, Joseph. Caught in the Act: Theatricality in the Nineteenth-Century English Novel. Berkley and Los Angeles: University of California Press, 1992.

Lodge, David. "Thomas Hardy as a Cinematic Novelist." In Thomas Hardy After Fifty Years, ed. Lance St. John Butler, 78-89. London and Basingstoke: Macmillan, 1977. 
Logan, Annie Robertson. “Recent Novels.” Nation 44 (1887): 123-124.

Loomba, Ania. Colonialism/Postcolonialism. London: Routledge, 1998.

Lopez-Ropero, Lourdes. “Homage and Revision: Zadie Smith's Use of E.M. Forster in On Beauty." Commonwealth Essays and Studies 32.2 (2010): 7-19.

Luckhurst, Nicola. Bloomsbury in Vogue. London: Cecil Woolf, 1998.

Mahaffey, Vicki. States of Desire: Wilde, Yeats, Joyce and the Irish Experiment. Oxford: Oxford University Press, 1998.

Majumdar, Robin and Allen McLaurin, eds. Virginia Woolf: The Critical Heritage. London: Routledge and Kegan Paul, 1975.

Mallet, Phillip. Thomas Hardy: Texts and Contexts. New York: Palgrave Macmillan, 2002.

Mao, Douglas. Solid Objects: Modernism and the Test of Production. Princeton, NJ: Princeton University Press, 1998.

------ and Rebecca Walkowitz. "The New Modernist Studies." PMLA 123.3 (2008): 73748.

Marcus, Jane. "Britannia Rules The Waves." Decolonizing Tradition: New Views of Twentieth-Century Literature," ed. Karen Lawrence. Urbana: University of Illinois Press, 1992. 136-62.

------. Hearts of Darkness: White Women Write Race. New Brunswick, NJ: Rutgers University Press, 2004.

Marcus, Sharon. "Reflections on Victorian Fashion Plates." differences: A Journal of Feminist Cultural Studies 14.3 (2003): 4-33. 
Marx, John. Geopolitics and the Anglophone Novel, 1890-2011. Cambridge: Cambridge University Press, 2012.

Mason, Wyatt. “White Knees: Zadie Smith’s Novel Problem.” Harper's Magazine (October 2005): 83-8.

Mauss, Marcel. The Gift: The Form and Reason for Exchange in Archaic Societies, trans. W. D. Halls. New York: Norton, 1990.

May, Trevor. Victorian and Edwardian Prisons. Buckinghamshire, UK: Shire Publications Ltd., 2006.

Mayhew, Henry and John Binney, The Criminal Prisons of London. London: Griffin, Bohn, \& Co., 1971/1867.

Maynard, Margaret. Dress and Globalisation. Manchester: Manchester University Press, 2004.

McBee, Thomas Page. “The Rumpus Interview with Zadie Smith.” Rumpus 1 January 2013, N. pag. Web. 5 May 2013.

McNeil, Peter, Vicki Karaminas, and Catherine Cole, Fashion and Fiction: Text and Clothing in Literature, Film, and Television. New York: Berg, 2009.

Meissner, Collin. "The Princess Casamassima: A Dirty Intellectual Fog." The Henry James Review 19.1 (1998): 53-71.

Melchiori, Barbara. Terrorism in the Late Victorian Novel. London: Croom Helm, 1985. Merleau-Ponty, Maurice. The Merleau-Ponty Reader. Ed. Leonard Lawlor and Ted Toadvine. Evanston, IL: Northwestern University Press, 2007.

Merritt, Stephanie. "She's Young, Black, British—and the First Publishing Sensation of the New Millennium.” Observer 16 January 2000. N. pag. Web. 1 May 2013. 
Michie, Elsie. 'Dressing Up: Hardy's Tess of the D'Urbervilles and Oliphant's Phoebe Junior." Victorian Literature and Culture 30.1 (2002): 205-323.

Miller, Daniel. Blue Jeans: The Art of the Ordinary. Los Angeles and Berkeley: University of California Press, 2012.

Miller, Elizabeth Carolyn. Framed: The New Woman Criminal in British Culture at the Fin de Siecle. Ann Arbor: University of Michigan Press, 2008.

------. "The Inward Revolution: Sexual Terrorism in The Princess Casamassima." The Henry James Review 24.2 (2003): 146-167.

Miller, J. Hillis. Thomas Hardy: Distance and Desire. Cambridge, MA: Harvard University Press, 1970.

Miller, Monica. Slaves to Fashion: Black Dandyism and the Styling of Black Diasporic Identity. Durham, NC: Duke University Press, 2009.

Millgate, Michael, ed. The Life and Work of Thomas Hardy. London: Macmillan, 1984.

------. Thomas Hardy: A Biography. Oxford: Oxford University Press, 1982.

-------, ed., Thomas Hardy: Selected Letters. Oxford: Claredon Press, 1990.

The Modern Girl Around the World Research Group (Alys Eve Weinbaum, Lynn M. Thomas, Priti Ramamurthy, Uta G. Poiger, Madeleine Yue Don, and Tani E. Barlow), eds. The Modern Girl Around the World: Consumption, Modernity, and Globalization. Durham, NC: Duke University Press, 2008.

Moraru, Christian. Cosmodernism. Ann Arbor: University of Michigan Press, 2011.

------. “The Forster Connection or, Cosmopolitanism Redux: Zadie Smith's On Beauty, Howards End, and the Schlegels." Comparatist: Journal of the Southern Moretti, Franco. Modern Epic. New York: Verso, 1996. Morris, Barbara. Victorian Embroidery: An Authoritative Guide. Mineola, NY: Dover 
Publications, 2003.

Morris, Virginia. Double Jeopardy: Women Who Kill in Victorian Fiction. Lexington: University of Kentucky Press, 1990.

Moss, Laura. "The Politics of Everyday Hybridity: Zadie Smith's White Teeth." Wasafiri 39 (2003): 11-17.

Mullin, Katherine. "The Shop-Girl Revolutionary in Henry James's The Princess Casamassima." Nineteenth-Century Literature 63.2 (2008): 197-222.

Mullenix, Elizabeth Reitz. "So Unfemininely Masculine: Discourse, True/False Womanhood, and the American Career of Fanny Kemble." Theatre Survey 40.2 (1999): 27-42.

Nava, Mica. “Modernity’s Disavowal: Women, the City, and the Department Store.” In Modern Times: Reflections on a Century of Modernity, ed. Mica Nava and Alan O’Shea. London: Routledge, 1996. 38-76.

Nemesvari, Richard. "Hardy and His Readers." In Palgrave Advances in Thomas Hardy Studies, ed. Phillip Mallet. New York: Palgrave Macmillan, 2004.

Niemeyer, Paul J. Seeing Hardy: Film and Television Adaptations of the Fiction of Thomas Hardy. Jefferson, NC: McFarland \& Company, 2003.

Nies, Frederick and John Kimmey. "David Copperfield and The Princess Casamassima." The Henry James Review 10.3 (1989): 179-184.

Niessen, Sandra, Ann Marie Leshkowich, and Carla Jones, eds. Re-Orienting Fashion: The Globalization of Asian Dress. New York: Berg, 2003.

North, Michael. Camera Works: Photography and the Twentieth-Century Word. New York: Oxford University Press, 2005. 
North, Susan. "From Neoclassicism to the Industrial Revolution: 1790-1860." The Fashion Reader: Second Edition. Ed. Linda Welters and Abby Lillethun. New York: Berg, 2011.

Ofek, Galia. Representations of Hair in Victorian Literature and Culture. Farnham, UK: Ashgate Publishing Ltd., 2009.

Kevin Ohi, "Erotic Bafflement and the Lesson of Oscar Wilde," Genre: Forms of Discourse and Culture XXXV (2002): 309-330.

Oltean, Roxana. “A ‘unnatural alliance': Realism and Revolution in Henry James's The Princess Casamassima," The Henry James Review 30.2 (2009): 144-161.

Orel, Harold, ed. Thomas Hardy's Personal Writings: Prefaces, Literary Opinions, Reminiscences. Lawrence: University of Kansas Press, 1966.

Palumbo-Liu, David, Bruce Robbins, and Nirvana Tanoukhi. Immanuel Wallerstein and the Problem of the World: System, Scale, Culture. Durham, NC: Duke University Press, 2011.

Paproth, Matthew. "The Flipping Coin: The Modernist and Postmodernist Zadie Smith." Zadie Smith: Critical Essays. Ed. Tracey L. Walters. New York: Peter Lang, 2008. 9-31.

Parsons, Deborah L. Streetwalking the Metropolis: Women, the City, and Modernity. New York: Oxford University Press, 2000.

Paulicelli, Eugenia and Hazel Clark, eds. The Fabric of Cultures: Fashion, identity, and globalization. New York: Routledge, 2009.

Peiss, Kathy. Hope in a Jar: The Making of America's Beauty Culture. New York: Metropolitan Books, 1998. 
Peppis, Paul. Literature, Politics, and the English Avant-Garde: Nation and Empire, 1901-1918. Cambridge: Cambridge University Press, 2000.

Phillips, Kathy. Virginia Woolf Against Empire. Knoxville: University of Tennessee Press, 1994.

Piketty, Thomas. Capital in the Twenty-First Century. Trans. Arthur Goldhammer. Cambridge, MA: The Belknap Press of Harvard University Press, 2014.

Potter, Jane. Boys in Khaki, Girls in Print: Women's Literary Responses to the Great War, 1914-1918. Oxford: Claredon, 2005.

Plowman, Thomas F. "The Aesthetes - The Story of a Nineteenth-Century Cult." The Pall Mall Magazine 5 (1895): 27-44.

Procter, James. "New Ethnicities, the Novel, and the Burdens of Representation." $A$ Concise Companion to Contemporary British Fiction. Ed. James English. Malden, MA: Blackwell, 2006. 101-120.

Puckett, Kent. Bad Form: Social Mistakes and the Nineteenth-Century Novel. New York: Oxford University Press, 2008.

Purdy, Richard Little. Thomas Hardy: A Bibliographical Study. Oxford: Clarendon Press, 1954.

------- and Michael Millgate, eds. Collected Letters of Thomas Hardy, Vol. 1: 1840-1892. New York: Oxford University Press, 1978.

Putzel, Steven. "Virginia Woolf and 'British Orientalism.'” Virginia Woolf Out of Bounds: Selected Papers from the Tenth Annual Conference on Virginia Woolf, ed. Jessica Berman and Jane Goldman. New York: Pace University Press, 2001. 105-13. 
Ramazani, Jahan. A Transnational Poetics. Chicago: University of Chicago Press, 2009. Ray, Martin, ed. Thomas Hardy Remembered. Burlington, VT: Ashgate, 2007.

Rawlings, Peter. "Henry James and the Art of Dress (review)." The Henry James Review 24.1 (2003): 89-91.

Reed, Christopher. Bloomsbury Rooms: Modernism, Subculture, Domesticity. New Haven, CT: Yale University Press, 2004.

Robbins, Bruce. "Blaming the System," in Immanuel Wallerstein and the Problem of the World: System, Scale, Culture, ed. David Palumbo-Liu, Bruce Robbins, and Nirvana Tanoukhi (Durham, NC: Duke University Press, 2011. 41-66.

------. “Cosmopolitanism: New and Newer.” boundary 234.3 (2007): 47-60.

-------. “The Sweatshop Sublime.” PMLA 117.1 (2002): 84-97.

Rose, Jonathan. The Intellectual Life of the British Working Classes. New Haven, CT: Yale University Press, 2003.

Rose, Louis. "Freud and Fetishism: Previously Unpublished Minutes of the Vienna Psychoanalytic Society." Psychoanalytic Quarterly 57. 2 (1988): 31-52.

Rose, Phyllis. Woman of Letters: A Life of Virginia Woolf. Oxford: Oxford University Press, 1978.

Rosenman, Ellen Bayuk. "More Stories About Clothing and Furniture: Realism and Bad Commodities." In Functions of Victorian Culture at the Present Time, ed. Christine Krueger, 47-63. Columbus: The Ohio State University Press, 2002. Rosner, Victoria. Modernism and the Architecture of Private Life. New York: Columbia University Press, 2005.

Rowe, John Carlos. The Theoretical Dimensions of Henry James. Madison: University of 
Wisconsin Press, 1984.

Ruddick, Sara. "Private Brother, Public World.” New Feminist Essays on Virginia Woolf, ed. Jane Marcus. Lincoln: University of Nebraska Press, 1981. 185-215.

Said, Edward. Culture and Imperialism. New York: Vintage, 1994.

------. Orientalism. New York: Vintage, 1979.

Saint-Amour, Paul. The Copywrights: Intellectual Property and the Literary Imagination. Ithaca, NY: Cornell University Press, 2003.

Sanders, Lise Shapiro. Consuming Fantasies: Labor, Leisure, and the London Shopgirl. Columbus: The Ohio State University Press, 2006.

Sassen, Saskia. “The Global Street.” Globalizations 8.5 (October 2011): 565-71.

Savoy, Eric. "The Jamesian Thing." The Henry James Review 22.3 (2001): 268-277.

Scanlan, Margaret. "Terrorism and the Realistic Novel: Henry James and The Princess Casamassima." Texas Studies in Literature and Language 34.3 (1992): 380-42.

Scarry, Elaine. On Beauty and Being Just. Princeton, NJ: Princeton University Press, 2001.

Schaffer, Talia. "Fashioning Aestheticism by Aestheticising Fashion: Wilde, Beerbohm, and the Male Aesthetes' Sartorial Coeds." Victorian Literature and Culture 28 (2000): 39-54.

Scheffer, Michiel. "Fashion design and technologies in a global context." The Fabric of Cultures: Fashion, identity, and globalization. Ed. Eugenia Paulicelli and Hazel Clark. New York: Routledge, 2009. 128-144.

Schoenberger, Karl. Levi's Children: Coming to Terms with Human Rights in the Global Marketplace. New York: Atlantic Monthly Press, 2000. 
Sedgwick, Eve Kosofsky. "Paranoid Reading and Reparative Reading: or, You're So Paranoid, You Probably Think This Introduction is About You." Novel Gazing: Queer Readings in Fiction. Ed. Eve Kosofsky Sedgwick. Durham, NC: Duke University Press, 1997.

Shannon, Brent. The Cut of His Coat: Men, Dress, and Consumer Culture in Britain, 1860-1914. Columbus: The Ohio University Press, 2006.

Sheehan, Lily. "Dressmaking at the Omega Workshops: Experiments in Art and Fashion." Beyond Bloomsbury: Designs of the Omega Workshops, 1913-1919, ed. Alexandra Gerstein. London: Courtauld Institute and the Fontanka Press, 2009. $50-59$.

Silver, Brenda. "Three Guineas Before and After: Further Answers to Correspondents." Virginia Woolf: A Feminist Slant. Ed. Jane Marcus. Lincoln: University of Nebraska Press, 1983. 254-76.

------. Virginia Woolf Icon. Chicago: University of Chicago Press, 1999.

Simmel, Georg. "The Philosophy of Fashion” (1899). Simmel on Culture. Eds. David Frisby and Mike Featherstone. London: Sage, 1997. 187-206.

Simons, Mark. “Hardy’s Stereographic Technique.” Thomas Hardy Journal 13.3 (1997): 86-93.

Sinfield, Alan. The Wilde Century: Effeminacy, Oscar Wilde and the Queer Moment. New York: Columbia University Press, 1994.

Siskind, Mariano. "The Globalization of the Novel and the Novelization of the Global. A Critique of World Literature.” Comparative Literature 62.4 (2010): 336-61. Shires, Linda. "The Radical Aesthetic of Tess of the D'Urbervilles." In The Cambridge 
Companion to Thomas Hardy, ed. Dale Kramer, 145-63. Cambridge: Cambridge University Press, 1999.

Showalter, Elaine. Faculty Towers: The Academic Novel and Its Discontents.

Philadelphia: University of Pennsylvania Press, 2009.

Smith, Zadie. On Beauty. New York: Penguin, 2005.

-------. White Teeth. New York: Random House, 2000.

Snaith, Anna. "The Hogarth Press and the Networks of Anti-Colonialism." Leonard and Virginia Woolf, the Hogarth Press and the Networks of Modernism. Ed. Helen Southworth. Edinburgh: Edinburgh University Press, 2010. 103-127.

-------. Virginia Woolf: Public and Private Negotiations (New York: Bedford St. Martin's, 2000).

------. “Wide Circles: The Three Guineas Letters," Woolf Studies Annual 6 (2000): 1-10, 11-168.

Spencer, Herbert. Principles of Sociology, 3 vols. London: Williams \& Norgate, 1885-96.

Stansky, Peter. On or About December 1910: Early Bloomsbury and Its Intimate World. Cambridge, MA: Harvard University Press, 1996.

Steele, Valerie. Fashion and Eroticism: ideals of feminine beauty from the Victorian Era to the Jazz Age. New York: Oxford University Press, 1985.

Stephen, Adrian. The 'Dreadnought' Hoax. London: Hogarth Press, 1936.

Stevens, Hugh. Henry James and Sexuality. Cambridge: Cambridge University Press, 1998.

Stuart, Christopher. “'Bloom[ing] on a Dog's Allowance': Hyacinth Robinson and the Redemption of the Working Class in Henry James' The Princess Casamassima." 
American Literary Realism 36.1 (2003): 22-39.

Tarlo, Emma. Clothing Matters: Dress and Identity in India. Chicago: University of Chicago Press, 1996.

------. Visibly Muslim: Fashion, Politics, Faith. New York: Berg, 2010.

Taylor, Dennis. Hardy's Literary Language and Victorian Philology. Oxford: Claredon Press, 1993.

Tew, Philip. "Zadie Smith's On Beauty: Art and Transatlantic Antagonisms in the AngloAmerican Academy.” Symbiosis 15.2 (2011): 219-36.

Tilley, W. H. The Background of the Princess Casamassima. Gainesville: University of Florida Press, 1960.

Trilling, Lionel. The Liberal Imagination: Essays on Literature and Society. New York: Harcourt, 1979.

Turner, Paul. The life of Thomas Hardy: a critical biography. Malden, MA: Blackwell, 2001

Tynan, Maeve. "Only Connect: Intertextuality and Identity in Zadie Smith's On Beauty." Zadie Smith: Critical Essays. Ed. Tracey L. Walters. New York: Peter Lang, 2008. 73-90.

Vattimo, Gianni and Santiago Zabala. Hermeneutic Communism: From Heidegger to Marx. New York: Columbia University Press, 2011.

Vernon, Polly. "The best-dressed brains list 2006." Guardian 9 September 2006. N. pag. Web. 3 May 2013.

Viner, Katharine. "Big Read: In conversation with Zadie Smith.” Vogue India 19 November 2012. N. pag. Web. 1 May 2013. 
Walkowitz, Judith. City of Dreadful Delight: Narratives of Sexual Danger in Late-

Victorian London. Chicago: University of Chicago Press, 1992.

------. Prostitution and Victorian Society: Women, Class and the State. Cambridge:

Cambridge University Press, 1980.

Walkowitz, Rebecca. Cosmopolitan Style: Modernism Beyond the Nation. New York:

Columbia University Press, 2006.

Wallerstein, Immanuel. The Modern World-System III: The Second Era of Great Expansion of the Capitalist World-Economy, 1730s-1840s. Berkeley and Los Angeles: The Regents of the University of California Press, 2011, 27.

------. World Systems Analysis: An Introduction. Durham, NC: Duke University Press, 2005.

Wicke, Jennifer. Advertising Fictions: Literature, Advertisement, and Social Reading. New York: Columbia University Press, 1988.

------. "Coterie Consumption: Bloomsbury, Keynes, and Modernism as Marketing." Marketing Modernisms: Self-Promotion, Canonization, Rereading, ed. Kevin Dettmar and Stephen Watt. Ann Arbor: University of Michigan Press, 1996. 10932.

------. “Frock Consciousness: Virginia Woolf’s Dialectical Materialism," in Virginia Woolf Out of Bounds: Selected Papers from the Tenth Annual Conference on Virginia Woolf, eds. Jessica Berman and Jane Goldman, 221-9. New York: Pace University Press, 2001.

------. “Mrs. Dalloway Goes to Market: Woolf, Keynes, and Modern Markets.” NOVEL: A Forum on Fiction 28.1 (1994): 5-23. 
-------. "The Same and the Different: Standards and Standardization in Thomas Hardy's Tess of the d'Urberveilles." In Tess of the D'Urbervilles: Case Studies in Contemporary Criticism, ed. John Paul Riquelme. Boston and New York:

Bedford/St. Martin's, 1998. 571-89.

Widdowson, Peter. Hardy in History: A Study in Literary Sociology. London: Routledge, 1989.

Wilde, Oscar. "The Ballad of Reading Gaol," in in The Complete Works of Oscar Wilde. London: Harper-Collins, 2003. 883-900.

------. De Profundis, The Ballad of Reading Gaol, and Other Writings. London: Wordsworth Classics, 1999.

-------. Complete Letters of Oscar Wilde. Ed. Merlin Holland and Rupert Hart-Davis. New York: Henry Holt and Company, 2000.

------. "The Decay of Lying," in The Complete Works of Oscar Wilde. London: Harper-Collins, 2003. 1071-1093.

-------. “Literary and Other Notes.” The Woman's World 2 (December 1887): 81-5.

-------. "Phrases and Philosophies for the Use of the Young." The Artist as Critic. Ed. Richard Ellmann. Chicago: University of Chicago Press, 1968. 433-34.

-------. The Picture of Dorian Gray, ed. Donald L. Lawler. New York: W.W. Norton \& Company, 1988.

------. "The Soul of Man Under Socialism," in The Complete Works of Oscar Wilde. London: Harper-Collins, 2003. 1174-97.

Williams, Raymond. The Country and the City. London: Chatto and Windus, 1973. ------. Marxism and Literature. Oxford: Oxford University Press, 1977. 
Wilson, Elizabeth. Adorned in Dreams: Fashion and Modernity, rev. ed. New Brunswick, NJ: Rutgers University Press, 2003.

Wittgenstein, Ludwig. Tractatus Logico-Philosophicus. Trans. C.K. Ogden. London: Routledge and Kegan Paul, 1922.

Woodcock, George. "Henry James and the Conspirators.” Sewanee Review 60 (1952): 219-29.

Wolff, Janet. "The Invisible Flâneuse: Women and the Literature of Modernity." In The Problems of Modernity: Adorno and Benjamin, ed. Andrew Benjamin. London: Routledge, 1989. 141-56.

Wolinky, Richard. "Cover to Cover with Richard Wolinky: Interview with Zadie Smith, author of White Teeth and On Beauty." KPFA Radio 30 November 2006. N.pag. (http://www.kpfa.org/archive/id/23983)

Wollaeger, Mark. Modernism, Media, and Propoganda. Princeton, NJ: Princeton University Press, 2006.

Woolf, Leonard. "Foreword.” A Haunted House and Other Short Stories. London: Hogarth Press, 1973.

Woolf, Virginia. The Diary of Virginia Woolf, 5 vols. Ed. Andrew McNeillie and Anne O. Bell. London: Harcourt, 1982

-------. “Dreadnought Hoax Talk (1940).” The Platform of Time: Memoirs of Family and Friends, expanded ed., ed. S.P. Rosenbaum. London: Hesperus, 2008. 182-201.

------. "How It Strikes a Contemporary." The Essays of Virginia Woolf. Ed. Andrew McNeillie. San Diego: Harcourt, 1988. 39-47.

------. "Interview (1910)." The Platform of Time: Memoirs of Family and Friends, 
expanded ed., ed. S.P. Rosenbaum. London: Hesperus, 2008. 201-5.

-------. Jacob's Room. San Diego, CA: Harcourt, 1950.

------. The Letters of Virginia Woolf, 6 vols., ed. Nigel Nicolson and Joanne Trautmann. London: The Hogarth Press, 1975-80.

------. "Middlebrow," in Collected Essays, vol. 2., ed. Leonard Woolf. London: Hogarth, 1966-7.

------. Moments of Being. Ed. Jeanne Schulkind. London: Harcourt, 1985.

------. “Mr. Bennett and Mrs. Brown,” in Collected Essays, vol. 3, ed. Leonard Woolf. London: Hogarth Press, 1966. 319-37.

------. Mrs. Dalloway. Annotated with an introduction by Bonnie Kime Scott. Orlando, FL: Harcourt, 2005

------. "Professions for Women." The Virginia Woolf Reader, ed. Mitchell Leaska. London: Harcourt, 1984. 284-9.

------. Roger Fry: A Biography. New York: Mariner, 1976.

------. “A Society.” Monday or Tuesday: Eight Stories. New York: Dover, 1997. 3-16.

-------. Three Guineas. Ed. Mark Hussey, with an introduction by Jane Marcus. Orlando, FL: Harcourt Inc., 2006.

------. To The Lighthouse. Ed. Mark Hussey. Orlando, FL: Harcourt, 2005.

------. The Waves. Orlando, FL: Harcourt, 1959.

Worth, Rachel. "Rural Laboring Dress, 1850-1900: Some Problems of Representation." Fashion Theory 3.3 (1999): 323-342.

-------. “Thomas Hardy and Rural Dress.” Costume: Journal of the Costume Society 29 (1995): 55-67. 
Wright, T.R., ed. Thomas Hardy on Screen. Cambridge: Cambridge University Press, 2005

Wussow, Helen, ed. Virginia Woolf's The Hours: The British Museum Manuscript of Mrs. Dalloway. New York, Pace University Press, 1996.

Yafa, Stephen. Cotton: The Biography of a Revolutionary Fiber. New York: Penguin Books, 2005.

Zedner, Lucia. Women, Crime, and Custody in Victorian England. Oxford: Claredon, 1991. 